\title{
CHARACTERIZATION OF A HYBRID SEQUENCING BATCH REACTOR SYSTEM FOR TREATMENT OF WASTEWATER USING SUSPENDED MICROBIAL AGGREGATES AND BIOFILMS
}

by

Romeo Gabriel Dumitrache, BSc. Applied Chemistry and Biology

Ryerson University, Toronto, Canada, 2006

\author{
A thesis \\ presented to Ryerson University \\ In partial fulfillment of the \\ requirements for the degree of \\ Master \\ in the Program of \\ Molecular Science
}

Toronto, Ontario, Canada, 2008

CRomeo Gabriel Dumitrache, 2008 
I hereby declare that I am the sole author of this thesis.

I authorize Ryerson University to lend this thesis to other institutions or individuals for the purpose of scholarly research.

I further authorize Ryerson University to reproduce this thesis by photocopying or by other means, in total or in part, at the request of other institutions or individuals for the purpose of scholarly research. 


\section{CHARACTERIZATION OF A HYBRID SEQUENCING BATCH REACTOR SYSTEM FOR TREATMENT OF WASTEWATER USING SUSPENDED MICROBIAL}

\section{AGGREGATES AND BIOFILMS}

Master of Science, 2009

Romeo Gabriel Dumitrache

Molecular Science, Ryerson University

\section{Abstract}

A moving bed biofilm reactor was studied for its capability of carbon oxidation and nitrification. The hybrid system made use of suspended biomass in the forms of microbial aggregates and attached biomass in the form of biofilms on suspended carriers. The carriers used for biofilm support were made of polyethylene and have a wagon wheel shape. The carrier fill ratio, which is defined as the volume ratio of carrier to the whole reactor was a key characteristic parameter of the reactor. The experimental runs used different carrier filling ratios from 25 to $50 \%$ to determine the optimal operating value for this type of hybrid reactor. Also the nutrient conditions were modified to test the capacity of the system to adapt to various changes in phosphorus loading in the influent wastewater. The results showed that for an influent chemical oxygen demand (COD) of $600 \mathrm{mg} / \mathrm{L}$, ammonia of about $24 \mathrm{mg} / \mathrm{L}$ and hydraulic reaction time of 6 hours there was no difference in the performance of the system under the different carrier filling ratios. 


\section{Acknowledgements}

I would like to express my gratitude to my supervisors Dr. Gideon Wolfaardt and Dr. Steven Liss for their extended support, patience and guidance throughout my research studies. A special thanks for supporting me financially to complete my master's thesis project. I would especially like to extend my thanks to Dr. Wolfaardt for his continuous involvement in my research. Also, the opportunity to carry forth this project with the Ontario Ministry of the Environment and the industrial company Hydroxyl Systems Inc. is much appreciated.

I am grateful to Dr. Martina Hausner and Dr. Andrew Laursen for their helpful advice and technical support. Their guidance and expertise helped carry forth my research in making this degree possible. Thanks also go to all the staff and faculty at Ryerson University.

I would like to send my sincere gratitude to my laboratory group for their friendship and creating a welcoming environment within the laboratory. A special thanks for their undivided assistance in passing down their lab techniques and knowledge for this topic.

Finally, I would like to express my gratefulness to my family whose unconditional love and support throughout my personal and professional development has allowed me to reach this important goal. 


\section{Table of contents}

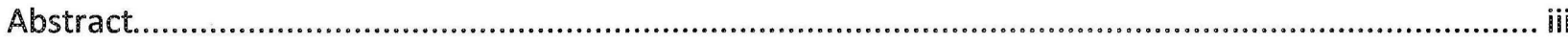

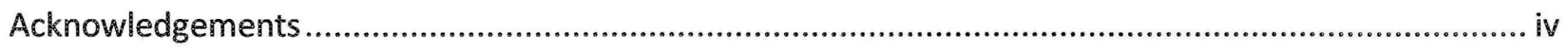

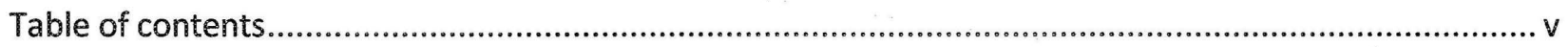

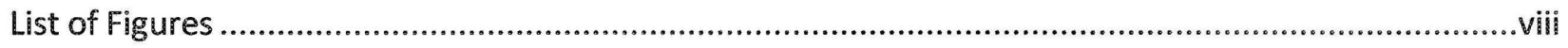

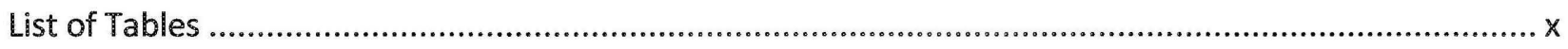

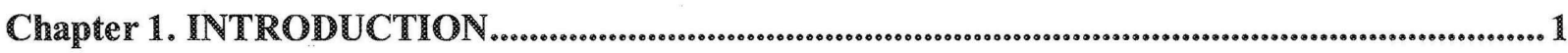

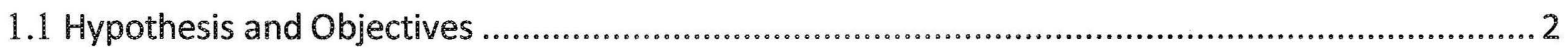

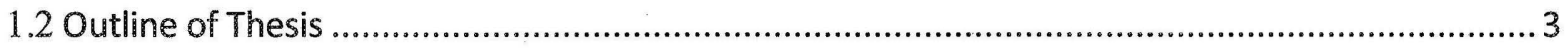

Chapter 2. LITERATURE REVIEW .......................................................................................... 4

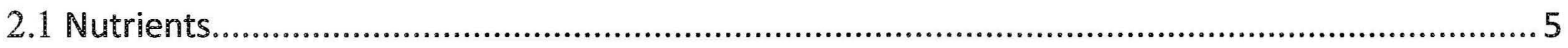

2.2 Classical Wastewater Treatment and the Activated Sludge Process....................................... 8

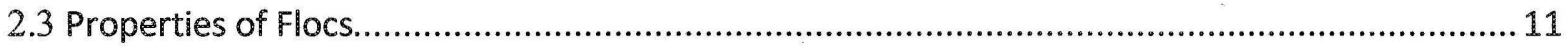

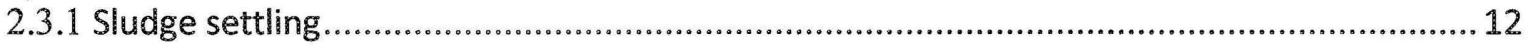

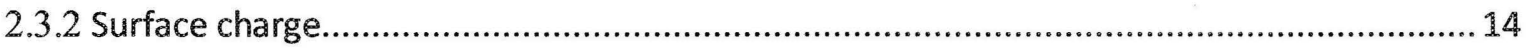

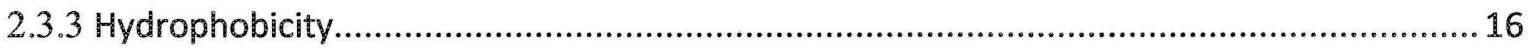

2.4 Hybrid Moving Bed Biofilm Reactors ................................................................. 17

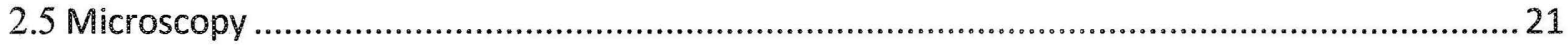

Chapter 3. MATERIALS $\mathrm{AND} \mathrm{METHODS.............................................................................} \mathrm{25}$

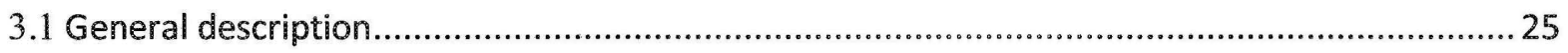

3.2 Experimental setup of the hybrid sequencing batch reactors.........................................26

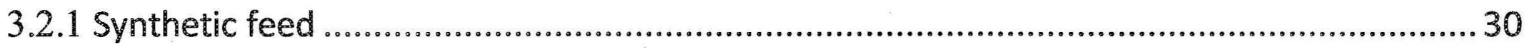

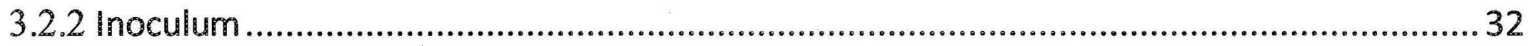

3.2.3 Cyclic Operation of the Hybrid Sequencing Batch Reactors .........................................32

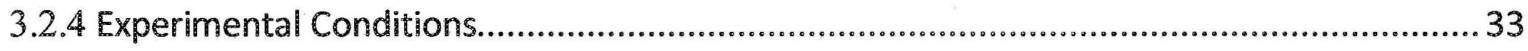

3.3 Experimental setup to measure carbon dioxide.......................................................... 35 
3.3.1 Experimental conditions:

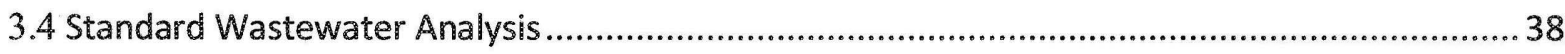

3.4.1 Mixed Liquor Suspended Solids .................................................................... 38

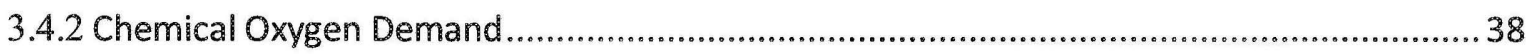

3.4.3 Surface Charge Measurements of the Microbial Flocs............................................... 39

3.4.4 Relative Hydrophobicity Determination....................................................... 40

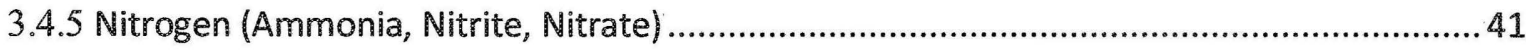

3.4.6 Settled Sludge Volume and Sludge Volume Index .............................................43

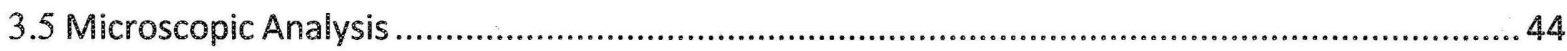

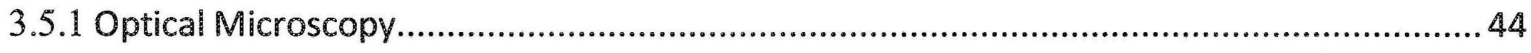

3.5.2 Confocal Laser Scanning Microscopy ........................................................... 44

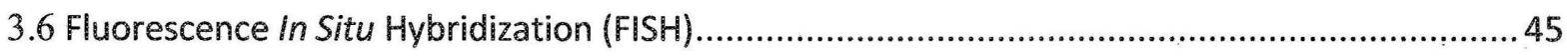

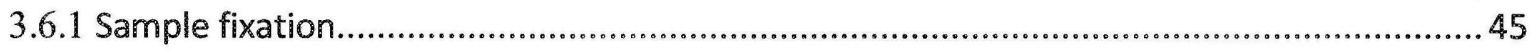

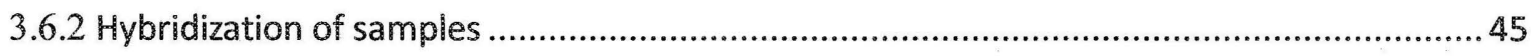

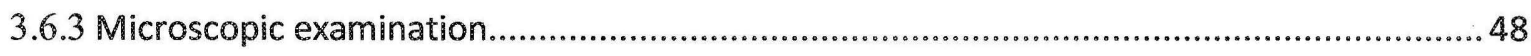

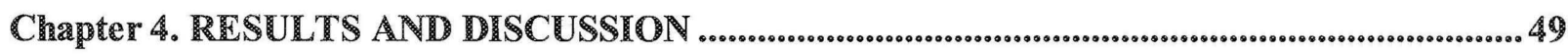

4.1 Sequencing Batch Reactors System Performance .................................................... 50

4.1.1 Chemical Oxygen Demand (COD) Removal Efficiency..........................................5 50

4.1.2 Mixed Liquor Suspended Solids (MLSS) and Attached Biomass in the Reactors .............. 53

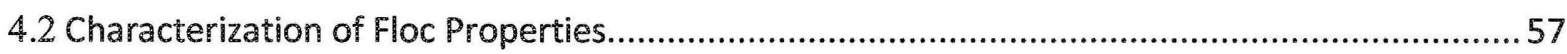

$4.3 \mathrm{CO}_{2}$ profile of the biomass from the SBR system..................................................6.

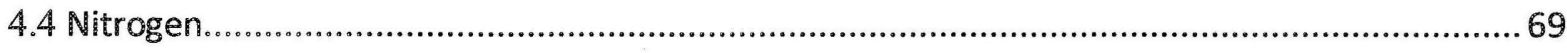

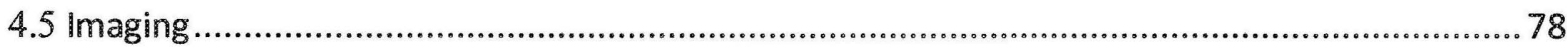

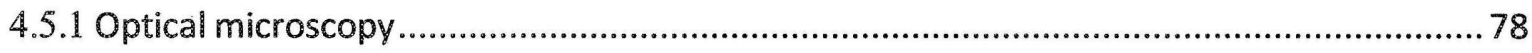

4.5 .2 Images of biofilms on carrier material .......................................................... 80

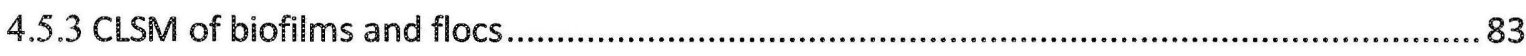


4.5.4 F.I.S.H. imaging of nitrifying bacteria

Chapter 5. General Conclusions

References

.95 


\section{List of Figures}

Figure 3.1 Image of the SBR laboratory setup. .27

Figure 3.2 Schematic diagram of the SBR laboratory setup 27

Figure 3.3 Diagram of the laboratory sequencing batch reactor. 29

Figure 3.4 Picture of the $\mathrm{CO}_{2}$ reactors with separated suspended and attached biomass treating synthetic wastewater. .35

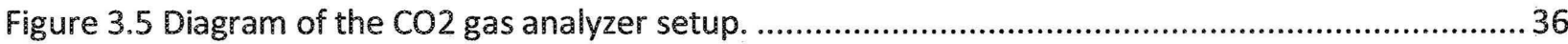

Figure 4.1 Percentage COD removal in the sequencing batch reactors from RUN 1..........................5 51

Figure 4.2 Percentage COD removal in the sequencing batch reactors from RUN 2 .........................552

Figure 4.3 Percentage COD removal in the sequencing batch reactors from RUN $3 \ldots \ldots . . . \ldots \ldots \ldots \ldots \ldots \ldots . . . . . .52$

Figure 4.4 Mixed liquor suspended solids profile from the sequencing batch reactor setup in RUN 1.....55 Figure 4.5 Mixed liquor suspended solids profile from the sequencing batch reactor setup in RUN $2 \ldots 55$ Figure 4.6 Mixed liquor suspended solids profile from the sequencing batch reactor setup in RUN 3.... 56 Figure 4.7 The contribution of the suspended phase (Flocs) and attached phase (Biofilms) to the total biomass (in $\mathrm{g} / \mathrm{L}$ ) present in the hybrid sequencing batch reactors at the end of RUN 1. 56

Figure 4.8 The contribution of the suspended phase (Flocs) and attached phase (Biofilms) to the total biomass (in $\mathrm{g} / \mathrm{L}$ ) present in the hybrid sequencing batch reactors at the end of RUN 3.

Figure 4.9 Surface charge of the suspended biomass in the sequencing batch reactors during RUN 1...59 Figure 4.10 Surface charge of the suspended biomass in the sequencing batch reactors during RUN 2. .60 Figure 4.11 Surface charge of the suspended biomass in the sequencing batch reactors during RUN $3 . .60$ Figure 4.12 Relative hydrophobicity of the suspended biomass in the SBRs during RUN 1 62

Figure 4.13 Relative hydrophobicity of the suspended biomass in the SBRs during RUN $2 \ldots \ldots \ldots \ldots \ldots \ldots . . . .62$

Figure 4.14 Relative hydrophobicity of the suspended biomass in the SBRs during RUN 3.................63

Figure 4.15 Sludge volume index of the sludge from the sequencing batch reactors in RUN 3 ..... .64

Figure $4.16 \mathrm{CO}_{2}$ profile of biofilm on carriers from SBR1 during RUN 3 67

Figure $4.17 \mathrm{CO}_{2}$ profile of flocs from SBR1 during RUN 3. 67

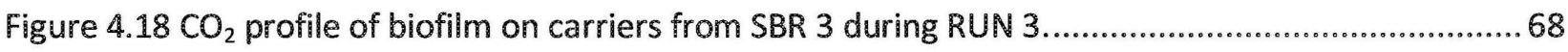

Figure $4.19 \mathrm{CO}_{2}$ profile of flocs from SBR 3 during RUN 3.

Figure 4.20 Average percent removal of ammonia from the sequencing batch reactors from RUN 2 measured from samples collected 1 hour into the reaction cycle....... 
Figure 4.21 Ammonia removal over a full cycle (6 hours) in the sequencing batch reactors from RUN 3.71 Figure 4.22 Comparison of ammonia removal by the suspended phase (flocs) and the attached phase (biofilms) from SBR 1 during a reaction phase in RUN 2.

Figure 4.23 Nitrite and Nitrate concentrations of samples from SBR 1 (COD:N:P=100:5:1) and SBR 3 (COD:N:P=100:5:0.33) in Run 3 .

Figure 4.24 Nitrite and Nitrate concentrations from biofilm and floc samples collected from SBR 1 (COD:N:P = 100:5:1) during Run 3 .

Figure 4.25 Nitrite and Nitrate concentrations from biofilm and floc samples collected from SBR 3 (COD:N:P = 100:5:0.33) during Run 3.

Figure 4.26 Wet mounts of microbial flocs observed by phase contrast microscopy in SBR 1 operating under standard nutrient load (COD:N:P = 100:5:1).

Figure 4.27 Wet mounts of microbial flocs observed by phase contrast microscopy in SBR 3 operating under P-limited conditions (COD:N:P = 100:5:0.33).

Figure 4.28 Average floc size from experimental Run 3 with samples taken from P-normal (SBR 1) and Plimited (SBR 3) conditions.

Figure 4.29 Image of biofilm growing on carrier material. A, B - biofilms on Activecell450TM; C, D biofilms on Activecell550TM

Figure 4.30 Diagram of biofilm growing in the grooves on the outer surface of the carrier material.

Figure 4.31 Confocal laser scanning micrographs of biofilm growing on the inside surface of one of the channels from the Activecell $450^{\mathrm{TM}}$ carriers.

Figure 4.32 CLSM micrograph of biofilm growing in a groove on the outside surface of the Activecell450 ${ }^{\mathrm{TM}}$ carrier showing a top view of a three dimensional projection. .86

Figure 4.33 CLSM micrograph of biofilm growing in the groove on the outside surface of the Activecell $550^{\mathrm{TM}}$ carrier showing a top view of a three dimensional projection.

Figure 4.34 CLSM micrograph of floc structure showing TRITC-conjugated Concanavelin A, lectin with affinity for sugar moieties ( $\alpha$-glucose and $\alpha$-mannose) binding EPS of suspended biomass.. 88

Figure 4.35 CLSM micrograph of ammonia-oxidizing bacteria from biofilms (Sample 1) and flocs (Sample 2).

Figure 4.36 CLSM micrograph of ammonia-oxidizing bacteria from biofilms (Sample 1) and flocs (Sample 2). 


\section{List of Tables}

Table 2.1 List of stain stocks and working concentrations used for visualization of flocs and biofilms in confocal laser scanning microscopy. .24

Table 3.1 Composition of the standard synthetic wastewater feed (COD 600 mg/L, COD:N:P = 100:5:1) 31

Table 3.2 The hybrid SBR cycles for the experimental run .33

Table 3.3 Summary of the experimental conditions in each experimental run. .34

Table 3.4 Summary of the carrier material load in each experimental run. 34

Table 3.5 The dilution of working solution for the hybridization probes. 46

Table 3.6 Hybridization buffer (total volume $1.5 \mathrm{~mL}$ ) 47

Table 3.7 Washing buffer (total volume $50 \mathrm{~mL}$ ). 48

Table 4.1 Average surface charge measurements at the beginning and the end of each experimental run. 


\section{Chapter 1. INTRODUCTION}

The most widely used wastewater treatment technology today is the activated sludge (AS) process which has a high degree of treatment efficiency. In this system, floc particles are responsible for the processing of waste in the secondary treatment process of wastewater. Flocs are viewed as individual microecosystems that interact with the environment and the energy, the nutrients and chemicals required for biological growth and their morphological development (Droppo et al., 1997).

Biofilms have also been used in the treatment of waste and wastewater for a long time (Lazarova \& Manem, 2000) but there was relatively limited application of this technology until the development of new biofilm support media and reactor configurations. Traditional wastewater treatment plants that employ the activated sludge processes are space demanding due to their requirement to accommodate the bioreactors and the sedimentation tanks (Wilderer et al., 2000). The advantages of attached growth in comparison with the classical suspended growth wastewater treatment would be: less energy for operation, less equipment maintenance and simpler operation, compactness due to availability of the biofilm support media with high specific surface area, presence of aerobic and anoxic biomass in the same system and the lower sensitivity and better recovery from shock loading or toxic discharge (Rodgers and Zhan, 2003).

Biofilm processes involved in wastewater treatment can involve fixed-medium systems in which the media for biofilm attachment and growth is static and the moving- 
medium systems in which the support material for biofilm attachment and growth is moving throughout the system by means of hydraulic, mechanical or air forces (Rodgers and Zhan, 2003). Recent developments in biofilm technologies in wastewater treatment include the fluidized-bed and the moving bed reactor (Munch et al., 2000; Rodgers and Zhan, 2004; Plattes et al., 2006).

\subsection{Hypothesis and Objectives}

The hypothesis to be tested in this research was that the efficiency of moving bed biofilm hybrid reactors can be maintained over a broad range of carrier fill ratios (broad range of surface area for microbial attachment on the solid support material), and therefore overall microbial activity in full-scale operations will not be influenced by normal fluctuation in carrier load..

Studying the function and structure of microbial films that are associated with hybrid moving bed biofilm reactors will allow us to gain further information in the following fields:

- The factors and operating conditions of microbial films in wastewater treatment systems (hybrid moving bed biofilm systems) that influence the interrelations between ecology, physiology and physicochemical properties of these systems. In this study the interest was focused on the nitrification capacity of autotrophic organisms. 
- Whether nitrification occurs simultaneously throughout the hybrid fixed film systems.

- The mass transfer of soluble components to, from and within the biofilm to facilitate better modeling of these systems.

- The relative percentage of free floating microorganisms compared to the total attached biomass, and how much of the wastewater treatment capacity of the hybrid reactors is attributed to the metabolic activity of the free floating cells in relation to the attached biomass.

\subsection{Outline of Thesis}

The next section of this report is a review of relevant literature to this study. The information contained in Chapter 2 provides information related to the activated sludge process, moving bed biofilm reactors, nutrient requirements and P-limitations, nitrification and denitrification processes in wastewater environments and physicochemical properties of microbial aggregates. Additionally, the chapter will present microscopic and molecular techniques with emphasis on confocal laser microscopy, fluorescence in situ hybridization and glycoconjugate analysis.

Chapter 3 details the experimental conditions, equipment setup, chemicals used and the microscopic techniques used. Chapter 4 presents and summarizes the results obtained in the study and compares them to previous studies. Chapter 5 contains the conclusions and recommendations given at the end of this thesis. 


\section{Chapter 2. LITERATURE REVIEW}

A hybrid biological reactor was created by mixing both suspended biomass and attached biomass in the same unit. This was achieved by introducing solid support material for attachment of biomass. It is widely accepted now that combining the activated sludge process with biofilm reactors can increase the operating efficiency of wastewater treatment. In addition, there are also several improvements that can benefit this association such as improved sludge settling properties (Wanner et al., 1988). The efficiency of the activated sludge process is dependent on sufficient growth of microbial populations, in particular the flocculating bacteria which have the ability to aggregate and form flocs, thereby allowing for the separation of sludge from treated water. Size and density are some of the most important properties of flocs in sedimentation processes where the rate of floc settling can affect the wastewater treatment operation (Glasgow and Hsu, 1984). The performance of biological wastewater treatment systems can be improved by increasing and maintaining a high concentration of biomass because the wastewater treatment capacity is directly dependent on the total biomass of the reactor. Although the activated sludge process has been used in treating wastewater for a long time now but there have not been so many attempts to increase the concentration of biomass in the aeration tanks due to limitations in sedimentation efficiency in the secondary clarifiers (Hamoda and Bary, 1987). 


\subsection{Nutrients}

Nutrients are by definition the essential chemicals that organisms require to live and grow and they are the substances used in the metabolism which must be taken in from the environment. All living systems require nutrients and proper environmental conditions for growth. Nutrients can be classified into three general categories such as macronutrients ( $\mathrm{C}, \mathrm{N}, \mathrm{O}, \mathrm{H}, \mathrm{P}, \mathrm{S})$, essential cations as micronutrients ( $\mathrm{Fe}, \mathrm{Na}, \mathrm{Ca}, \mathrm{K}$, $\mathrm{Mg}$ ) and trace elements ( $\mathrm{Zn}, \mathrm{Cu}, \mathrm{Mn}, \mathrm{Mo}, \mathrm{Co}$, etc). A typical nutrient source would consist of water, a carbon and energy source (eg. glucose) and sources of inorganic salts, oxygen, hydrogen and various metal ions and can also contain certain growth factors such as vitamins, amino acids, etc. These nutrients need to be supplied in the appropriate amounts in order for the microorganisms to synthesize new biomass and carry out specific enzymatic reactions. The understanding of nutrient requirements of microorganisms involved in wastewater treatment has important implications for the operation and performance of these systems (Grau, 1991).

The composition of wastewater varies based on the sources but the main components are proteins ( 40 to 60 percent), carbohydrates (25-50 percent), fats and oils (10 percent), and a large variety of trace organic compounds that can include pesticides, phenols, surfactants and other pollutants (Metcalf and Eddy, 1991). The greater fraction of the organic matter found in domestic wastewater can be easily biodegraded and it consists of carbohydrates, amino acids, proteins and peptides, fatty acids and volatile acids (Bitton, 2005). There is also a wide range of inorganic components present in wastewater; some of these are sodium, calcium, magnesium, 
chlorine, sulphates, phosphates, nitrates, ammonia and traces of heavy metals (Scragg, 2004).

Besides carbon, nitrogen $(N)$ and phosphorus $(P)$ are essential components of the wastewater because they are the major elements controlling the metabolism and growth of microorganisms. The oxygen uptake by the microorganisms when they metabolize the organic fraction of the wastewater is known as oxygen demand and is usually expressed as biological oxygen demand (BOD) in $\mathrm{mg} / \mathrm{L}$. The process of determining $\mathrm{BOD}$ is achieved by incubating a mixture of microorganisms with a waste sample for 5 days at $25^{\circ} \mathrm{C}$. Because the method is time consuming and does not always properly represent the natural conditions in the reactor another test is used as indicator of the level of organic material in the waste. Chemical oxygen demand (COD) measures all the oxidizable material in the wastewater. The oxygen demand of the sewage in this case is determined using an oxidizing agent. The dichromate ion $\left(\mathrm{Cr}_{2} \mathrm{O}_{7}^{2-}\right)$ is the specific oxidant used according to Standard Methods (Section 5220D, APHA 1998). During the oxidation process the organic carbon is completely transformed into $\mathrm{CO}_{2}, \mathrm{H}_{2} \mathrm{O}$ and ammonia (Bitton, 2005). If the $\mathrm{COD}$ values are higher than that of the BOD value, the sample might contain significant amounts of organic components that are not so easily biodegraded. In untreated domestic wastewater the COD values usually are present in the range of 250 to $1000 \mathrm{mg} / \mathrm{L}$ (Metcalf and Eddy, 1991).

Since there is not a constant availability of the essential nutrients for sustained microbial growth, in municipal and industrial wastewater systems limiting nutrients such as $\mathrm{N}$ and $\mathrm{P}$ sometimes have to be added in order to achieve satisfactory organic matter 
removal efficiency. Lack or limited amounts of the essential nutrients, $N$ and $P$, can lead to changes in the microbial community with a decrease in the biological activity (Saunamaki, 1997). Nitrogen is an essential nutrient required by the microorganisms, but the addition of excess nitrogen in wastewater treatment plants can lead to undesirable effects. This results in elevated concentrations of $N$ and $P$ in the effluent wastewater and leads to the eutrophication of the receiving bodies of water (Grau, 1991). Addition of nutrients to help the biological treatment of wastewater has to be closely monitored in order to provide the microbial community with optimal nutrient levels while still ensuring no excessive discharge of residual nutrients.

In pulp and paper industries the wastewater generated is usually deficient in nitrogen and phosphorus. Therefore limiting nutrients are added in order to provide the microorganisms with a BOD:N:P ratio of 100:5:1 (Saunamaki, 1994). This ratio is generally regarded as a minimum requirement of nutrient availability for proper carbon removal in activated sludge processes (Bitton, 2005). This ratio might vary under different operating conditions and types of wastewater treated. In the test conducted on the pulp and paper wastewaters by Saunamaki (1994) it was found that a ratio of BOD:P of 100: 0.4 was optimal in achieving good treatment results. Any further additions of phosphorus past this level proved to achieve no further improvements in the treatment of the wastewater.

A study on the effect of nutrients on the physicochemical properties of activated sludge flocs in sequencing batch reactors conducted by Lee (1997) showed that there was no improvement of treatment efficiency at high phosphorus loadings of the system and also a lower than traditional BOD:N:P ratio of 100:5:1 for phosphorus did not affect 
the reactor performance. It was found that under limited $P$ conditions however, the composition of the extracellular polymeric substances in the microbial aggregates changed. There was an increase in the concentration of carbohydrates, proteins and deoxyribonucleic acids (DNA) fractions of the EPS. This increase in DNA concentration results in an accumulation of $P$ within the microbial aggregate structure and suggests a possible mechanism of recycling of $P$ within the system during periods of nutrient deficiency.

\subsection{Classical Wastewater Treatment and the Activated Sludge Process}

The methods used in the treating of wastewater involve the use of biological, chemical and physical processes (Metcalf and Eddy, 1991). There are several objectives for wastewater treatment that are based on the removal of major contaminants found in wastewater. Thus the goals of wastewater treatment are: the reduction of organic content of wastewater (Barker and Dold, 1995; Lessard et al., 2007; Hasar et al., 2008), removal or reduction of trace organics that resist biodegradation and may be toxic or carcinogenic (Alexander, 1985; Gulyas, 1997), removal of toxic metals (Kumar and Dara, 1982; Chuichulcherm, 2004), removal or reduction of nutrients $(N, P)$ to reduce the contamination of receiving waters (Raymond et al., 2004), and the removal or inactivation of pathogens and parasites (Chabaud et al., 2006; Reinoso et al., 2008). 
The first step in raw wastewater treatment involves the physical removal of materials that might interfere with the proper operation of the system. The raw wastewater is passed through a set of bar screens and grits when it first enters the treatment process. The pretreated raw wastewater then enters the primary clarifier which is the second step in the treatment process that removes suspended solids or insoluble matter via screening or settling tanks. The primary effluent then enters the secondary treatment to remove the remaining soluble organic matter and fine particles from the wastewater and limit the contamination of receiving waster. The secondary treatment involves both biological and chemical processes. The biological processes are of a particular importance due to the ability of microorganisms to reduce organic matter to inert solids and gasses through metabolic processes. Tertiary treatment focuses on removal of pathogens from the treated effluent. This is mainly achieved by adding chlorine or by exposing it to ultraviolet light.

Activated sludge is one of the most common biological secondary treatments used in wastewater treatment. The effluent from the primary treatment is pumped into an aeration tank and mixed with the bacteria rich slurry that is called activated sludge. Air is usually pumped in the tank from the bottom to provide aeration and mixing which promotes bacterial growth and the subsequent decomposition of the organic matter. The mixed liquor then travels to the secondary settling tank where the treated water is separated from the suspended biomass by sedimentation. The water is removed from the top and the sludge is removed from the bottom (Bitton, 2005). Part of the sludge is recycled to the aeration tanks and the rest is continually removed from the system. 
The activated sludge flocs contain mostly bacterial cells as well as other microorganisms and organic and inorganic particles that can vary in size from under 1 $\mu \mathrm{m}$ to over $1000 \mu \mathrm{m}$ (Parker et al., 1971). Some early studies on floc microbial composition showed that viable cells only account for fewer than 20 percent of the total cells (Weddle and Jenkins, 1971). However, more recent research involving fluorescently labeled oligonucleotides and flow cytometry have estimated that the active fraction of bacteria present in activated sludge aggregates is much greater than (Wagner et al.,1993; Ziglio et al., 2002). The gram negative bacteria are the predominant microorganisms in activated sludge. Other microorganisms such as gram positive bacteria and eukaryotes (protozoa, rotifers and nematodes) are present in the microbial floc.

During floc formation filamentous microorganisms form a backbone to which flocformers attach firmly (Raszka et al., 2006). The floc-formers represented by different chemoorganotrophic bacteria groups and species are able to convert the organic substrates in the wastewater to extracellular material that forms the matrix of extracellular polymeric substances (EPS).

The other major component of the microbial flocs in activated sludge seems to be the extracellular polymeric substances (Liss et al., 1996; Jorand et al., 1998). The extracellular polymeric substance are considered to be responsible for the structural and functional integrity of the biofilms and flocs. In activated sludge systems they are of vital importance for the physico-chemical properties of the activated sludge. 
Despite the wide application of the activated sludge process, there are several problems associated with it. Floc sedimentation occurs because the higher density of microbial aggregates causes them to settle due to gravity. Flocculation of microorganisms is generally a response to low nutrient conditions in the environment. The close proximity to other microorganisms provides a more efficient utilization of food due to the fact that the products released by one group of organisms can serve as nutrient source for another group (McLoughlin, 1994). This in turns shows the direct relationship between food and microorganisms levels (F/M ratio). Good settling occurs when this ratio is low, meaning low carbon and limited energy sources coupled with low rate of microbial specific growth rate (Bitton, 2005). There are other factors that may affect the settling properties of microbial flocs, such as foaming (in the presence of certain microorganisms), physical parameters (temperature, $\mathrm{pH}$ ), very low availability or absence of nutrients (N, P, micronutrients) and the presence of toxic particles (heavy metals, etc) that can cause deflocculation (Bitton, 2005).

\subsection{Properties of Flocs}

Surface properties are important for the activated sludge flocs and also for the attached biomass in the biofilm reactors. Surface charge and hydrophobicity of the cell surface play an important role in aggregation of microorganisms. They also play an important role in cell to surface interactions and determine the attachment of cells to surfaces. Microbial flocs and biofilms are hydrated environments that posses an overall negative charge at neutral $\mathrm{pH}$ and also possess numerous hydrophobic areas on their 
surface (Urbain et al., 1993). Hydrophilic molecules are polar molecules while hydrophobic molecules are non-polar. The fact that non-polar molecules less readily mix in water should help in the aggregation of hydrophobic cells in sludge flocs (Jin et al., 2003). The hydrophilic interactions and the hydrogen bonds between cells and surfaces are the mechanisms for binding biopolymers in water and thus promote flocculation in activated sludge processes (Jin et al., 2003).

\subsubsection{Sludge settling}

In the secondary treatment of wastewater the mixed liquor is transferred from the aeration tank to the settling tank in the classical activated sludge process. In the hybrid system operated in a sequencing batch mode the sludge is separated from the treated effluent in the same reaction tank. In the activated sludge process a portion of the sludge is returned to the aeration tank and the rest is disposed mainly by anaerobic digestion for further treatment. As previously mentioned the aggregation of cells is generally a response to low nutrient conditions (McLoughlin, 1994), thus sludge settling depends on the food to microorganisms (F/M) ratio and on the sludge age. A low F/M ratio and a longer residence time of the sludge in the reactor would improve sludge settleability.

The settled volume of sludge from a biological suspension is used as a monitoring parameter of wastewater treatment processes. In activated sludge plants the 30 minutes settle sludge volume has been usually used to determine the returned- 
sludge flow rate and when to waste the sludge. The sludge volume index was defined as the volume in milliliters occupied by $1 \mathrm{~g}$ of a suspension after 30 minutes of settling (Bitton, 2005).

Independent of the experimental conditions there is a positive linear relationship between sludge volume index (SVI) and the total amount of extracellular polymeric substances in the sludge flocs (Urbain et al., 1993). Several studies that were performed in order to characterize the effect of EPS constituents on sludge settleability have shown that a higher SVI can be correlated to large amounts of total EPS (protein, carbohydrate, DNA) (Liao et al., 2001). The same study also found that there was a significant correlation between the total amount of EPS, including protein, and the SVI, but no correlation was found between carbohydrate and the SVI. A higher carbohydrate level compared to a lower protein level at low sludge retention times (of 4 to 9 days) suggested that maybe not all the carbon sources available for growth were utilized, the excess being stored by conversion into polymers in the EPS. Another study by Shin et al. (2001) found that the increase of carbohydrate levels in the EPS while maintaining a constant protein level inhibited floc formation and thus resulted in poor settling properties for sludge samples from sequencing batch reactors. The study concluded that the ratio between EPS components (carbohydrates and proteins) and not the total amount of EPS was responsible for the variation in sludge settling properties.

There are many factors that affect sludge settling and two main types of settling problems were identified by Jin et al. (2003): the bulking of sludge due to proliferation of filamentous bacteria and poor flocculation properties that lead to the formation of small and light flocs. Bulking of sludge due to filamentous bacteria represents a complex 
issue in activated sludge processes due to the diversity of species and the factors that influence their overgrowth (Urbain et al.,1993; Mino, 1995). But the filamentous organisms are not the only ones responsible for sludge bulking. Through overproduction of EPS a condition known as nonfilamentous bulking is observed. This involves loose flocs that do not settle well and is associated with poor sludge settleability and a high sludge volume index in relation to the total amount of EPS (Liao et al., 2001).

\subsubsection{Surface charge}

The usual $\mathrm{pH}$ range for bioreactors operating with suspended as well as attached biomass is around $\mathrm{pH} 7$ and at this value the bacteria as well as the support materials display an overall negative surface charge (Wuertz et al., 2003). The role of surface charge of floc particles has been investigated in relation to its role in the stability of flocs and its influence on the settleability properties (Liao et al., 2001).

Gram negative bacteria which are present in high numbers in wastewater treatment systems have their cell wall structure different from the Gram positive bacteria. They present a thin peptidoglycan layer surrounded by the dense periplasm of the periplasmic space and the outer membrane that sits on top of this with its lipid bilayer displaying mostly lipopolysaccharides (LPS) on the outer surface. Besides LPS also present on the outer membrane are membrane proteins and phospholipids and lipoproteins which offer additional rigidity. Based on this the physicochemical characteristics of Gram negative bacteria can be attributed to the LPS on the outer 
membrane. The Gram positive bacteria lack the outer membrane and the presence of LPS on the outside surface and their surface charge is dictated by the peptidoglycan layer, teichuronic acids and proteins. The anionic surface of the Gram positive bacteria is thus able to attract metal ions from the environment and cover most of its surface in minerals (Beveridge et al. 1997).

The difference in cell wall structure of various bacterial species is not the only factor accounting for the net surface charge of microbial flocs. There are other structures and components to take into account when determining the physicochemical properties of flocs. For example the interactions between bacteria and other microorganisms with the inorganic particles in the environment and the extracellular polymeric substances they produce are determining the overall surface charge of flocs. According to Morgan et al. (1990) the surface of floc particles from activated sludge processes is usually negatively charged with values between $-10 \mathrm{mV}$ to $-20 \mathrm{mV}$. The study found that higher total EPS values could be correlated to more negative overall charge of the particles and that the ratio between EPS (especially the protein/total carbohydrates) components was more important in determining the surface charge than just the total EPS values. Liao et al. (2001) found that the surface charge and hydrophobicity of flocs was influenced by variations in protein, total carbohydrate and DNA levels of the EPS. The total carbohydrate levels had a negative impact on the surface charge and hydrophobicity while the protein content had a weak influence on the surface charge of flocs. But in that study it was found that the total levels of EPS were not influencing the hydrophobicity of surface charge. 
There seems to be a correlation between surface charge and hydrophobicity of microbial flocs and this relationship is explained by the fact that the surface charge is related to the ionizable groups present on the sludge surfaces. The increase in the EPS interactions with the water molecules, which is attributed more to the carbohydrate fraction of the EPS than to the protein fraction, shows that the more charged the sludge particles are the lower is the hydrophobicity (Liao et al., 2001).

\subsubsection{Hydrophobicity}

In aquatic environments the microbial flocs, which are highly hydrated structures, consist of microbial cells and a polymeric matrix surrounding them. The bacterial cells in the aquatic environment present hydrophilic properties on their surface due to the presence of side chains of amino acids, polysaccharides and the long-chains carbon groups in lipids (Urbain et al., 1993). The hydrophobic interactions exhibited by these structures play an important role in bioflocculation and biofilm formation (Urbain et al., 1993, Liao et al., 2001). The hydrophobic structures expressed on the outside of the bacterial cells are incapable to interact electrostatically with the water molecules in the aquatic environment and cannot form hydrogen bonds with them. Instead the bacterial cells are associating with each other, forming aggregates.

The hydrophobicity of microbial flocs was measured before through various techniques. One widely used technique is the microbial adhesion to hydrocarbons (MATH) method, described by Rosenberg et al. (1980). The method is based on the 
partitioning of cells having hydrophobic surface characteristics at the interface of biphasic hydrocarbon-aqueous system after a brief mixing period. The simplicity of the method makes it a good choice for a fast quantitative assay for measuring cell surface hydrophobicity. The one major problem encountered when processing sludge samples with this method would be the fact that microbial cells tend to aggregate and this method was initially developed for dispersed cultures. Sonication can be used to overcome this problem (Rosenberg et al., 1980).

\subsection{Hybrid Moving Bed Biofilm Reactors}

The use of biofilms in wastewater treatment has been used as early as 1880 when the first trickling filters wastewater treatment process was developed (Lazarova and Manem, 2000). In fixed-film biological processes the microorganisms are attached to a solid substratum where they develop into communities and can reach relatively high concentrations. According to Rittmann et al. (1988) the fixed-biofilm processes have a few advantages over the classical activated sludge processes: they allow the development of microorganisms with low specific growth rate by providing a longer residence time in the system; they are less influenced by variable or intermittent loadings; they are suitable for smaller reactor size and smaller operating costs.

The use of the biofilm process by suspended carrier takes the advantage of activated sludge process and conventional fixed film systems, such as trickling filters and submerged aerated filters. This process is carried forth without the disadvantages 
often found separately within each process. (Rusten et al., 1994). The process includes the biofilm carrier element which is made of polyethylene and other materials with a density slightly less than that of water allowing the elements to be kept in suspension (Dalentoft and Thulin, 1997).

The microorganisms load onto the carrier by several processes. These processes are performed to optimize bacterial growth. Surface conditioning is the first step in biofilm formation where a surface conditioning layer is created by initially adsorbing to the surface a layer made of proteins, glycol-proteins, humic-like substances, and other dissolved or colloidal organic matter (Bitton, 2005). A film forms on the modified substrate acting as a source of nutrients for bacteria especially in oligotrophic environments such as drinking water or groundwater. In order for microorganisms to adhere to surfaces the process is favoured when the Gibbs free energy is negative. Moreover, the Derjaguin Landau, Verwey and Overbeek (DLVO) theory suggests that adhesion is balanced between Van der Waals forces and repulsive or attractive forces due to electrical charges present on the surfaces of microbes and substrates (Bitton, 2005). Hydrophobic interactions are also involved in microbial adhesion to surfaces.

Adhesion of the microbial cells and anchoring to the substrate surface is accomplished by using extracellular polymeric substances (EPS). The EPS consists of polysaccharides such as mannans, glucans, and uronic acids, proteins, nucleic acids, and lipids which support the biofilm structure and give it hydrophilic and hydrophobic properties. Furthermore, attachment organelles including flagella, pili (fimbriae), stalks, or holdfasts are possible (Bitton, 2005). 
The solid support material in the reactor is constructed to give a large protected surface for microbial growth. The carriers are ideally shaped in such a way to protect the biofilm from abrasion (Hem, 1991). To improve growth the filling of the carrier element may be varied to allow flexibility in the specific biofilm area (Dalentoft and Thulin, 1997). However, normally the reactors are filled up to $67 \%$ of their volume with carrier substrate which are kept in suspension by mixing and aeration. The agitation is arranged to constantly move the carriers over the surface of the wastewater. Aeration process using coarse bubble aeration results in better efficiency compared to that of fine bubble diffusers.

Using a suspended carrier process has several advantages when compared to the conventional activated sludge process. The continuous circulation of the carriers in the reactor allows for a good mixing process and since the active biomass grows on the surface of the carriers, this process is insensitive to load variations and other disturbances (Hem et al., 1994). These reactors are able to operate at very high loads and organic loads of $25 \mathrm{~kg} C O D / \mathrm{m}^{3} \mathrm{~d}$ up to $60 \mathrm{~kg}$ have been applied (Broch-Due et al., 1994). Another benefit of using moving bed reactors is since all the suspended biomass is caused by the excess sludge production, recycling of the biomass to the reactor is not required. As a result, chemical precipitation can be applied to the sludge separation without lowering the sludge age (Dalentoft and Thulin, 1997). Moreover, the process is tolerant to fibers in the incoming wastewater.

There are factors that must be taken into account when selecting a process technology for optimal wastewater treatment. These factors are independent of wastewater characteristics which include, investment cost, operating costs, sludge 
production, space available, effluent demands to be met, and whether or not there is an existing treatment plant that may be used (Dalentoft and Thulin, 1997). Some limitations have to be considered when applying this technology. With a high load the suspended carrier process treatment efficiency is decreased partly due to the excess sludge in the effluent as it is difficult to separate (Dalentoft and Thulin, 1997). On the other hand, it allows for use in different applications, such as single or multi stage reactor configuration or in combination with other process technologies. An interesting attribute of using hybrid reactors with suspended carriers is that it is possible to operate at high temperatures up to $50^{\circ} \mathrm{C}$ compared to that applicable to the conventional activated sludge process (Strehler and Welander, 1994).

The use of substrate elements in series with an activated sludge process provides an efficient process for wastewater treatment. Initially, the stability provided by the carrier process used at the same time with the subsequent activated sludge stage lowers the sludge production and flocculates the sludge (Dalentoft and Thulin, 1997). This facilitates the separation in the final clarifier. The compactness and flexibility of this type of reactors makes it ideal for upgrading of existing plants (Dalentoft and Thulin, 1997).

Moving bed reactors have been used for many study purposes. Among the North sea countries an agreement has been reached to reduce the discharge of nutrient into the North sea by $50 \%$ (Hem et al., 1994). In order to achieve this wastewater treatment plants are required to remove nitrogen which could be achieved by using submerged biological filters (Odegaard et al., 1991 and 1995). Though, one disadvantage for some of these reactors is the possibility of clogging on biofilm media. In order to improve this 
shortcoming, development has progressed in using biofilter media with high specific surface. To fulfill the biofilm process demands, the moving bed reactor was brought forth.

There has been a wide application of moving bed biofilm reactors with nitrification and denitrification processes. A study of nitrification has shown that with ammonia and alkalinity present in excess, the oxygen concentration is rate limiting (Hem et al., 1994). The nitrification rate is close to a first order function of the oxygen concentration. In the case where the organic load is low, and the alkalinity is in excess, either ammonia or oxygen is the rate limiting. A high heterotrophic growth suppresses the nitrification rate (Hem et al., 1994). These are not the only aspects influencing the reaction rate, another feature is the history of the biofilm. If it is acclimatized to a high ammonia load, the half order reaction rate is higher than when the biofilm is acclimatized to a low load (Hem et al., 1994).

\subsection{Microscopy}

Since the introduction of confocal laser scanning microscopy (CLSM) significant discoveries have been made with respect to biotechnology. Along with the advancements in the development of higher speed computers for image analysis the CLSM has become a powerful tool for investigating microbial biofilms (Costerton et al., 1995). It allows for the in situ study of fully hydrated biofilms without the destructive effects of the fixation or embedding techniques. CLSM allows for the acquisition of 
detailed information about a thin optical section while eliminating out of focus information from above and below the plane of focus (Caldwell et al.,1992). Since this technique allows for the samples to be scanned at various depths, the information provided can be compiled and a three dimensional image of the structure can be generated. CLSM allows for the scanning of thin sections of biofilms up to tens of microns and this allows for measuring the thickness of those biofilms but one major disadvantage of these technique is that its limitation of depth penetration (Stewart et al., 1995). This means that due to scattering and adsorption of the excitation and emission wavelengths the loss of signal limits the penetration distance through the sample.

CLSM analysis of microbial films can be performed by using a wide range of specific fluorescent probes and nonspecific fluorescent compounds. The technique can be used to determine the biofilm's auto fluorescence, cell distribution, EPS distribution, viability, cell density and activity, and many others (Lawrence and Neu ,1999). Wolfaardt et al. (1998) used lectins conjugated to FITC or TRITC to study the chemical nature and spatial arrangements of exopolymers in a degradative biofilm community. The study demonstrated a high degree of horizontal and vertical heterogeneity in the distribution of glycoconjugates throughout the biofilms. Neu and Lawrence (1997) used lectins to study the dominance of certain bacteria and their major extracellular polymeric secretions. This study identified that biofilms are highly heterogeneous with a complex chemical composition.

A number of fluorescent probes are suited for the in situ analysis and determination of biofilm population architecture. Fluorescently conjugated $16 \mathrm{~S}$ rRNA oligonucleotide DNA probes are used in the fluorescence in situ hybridization method. 
This method is effective in detecting specific bacterial cells and analyzing the spatial organization of a complex bacterial community due to the probe's high specificity. The rRNA molecule is an ideal target because it is present in all microorganisms and the identification of natural populations is based on the phylogenetic classification of the 16 SRNA sequences. Also, the fact that in metabolically active cells there is a high copy number of these sequences greatly increases the detection sensitivity and allows for the detection of even single cells using the CLSM (Aoi, 2002).

Some of the specific fluorescent probes that were previously used for the study of flocs and biofilms in wastewater treatment systems and that were also used in study can be seen in Table 2.1. 
Table 2.1 List of stain stocks and working concentrations used for visualization of flocs and biofilms in confocal laser scanning microscopy.

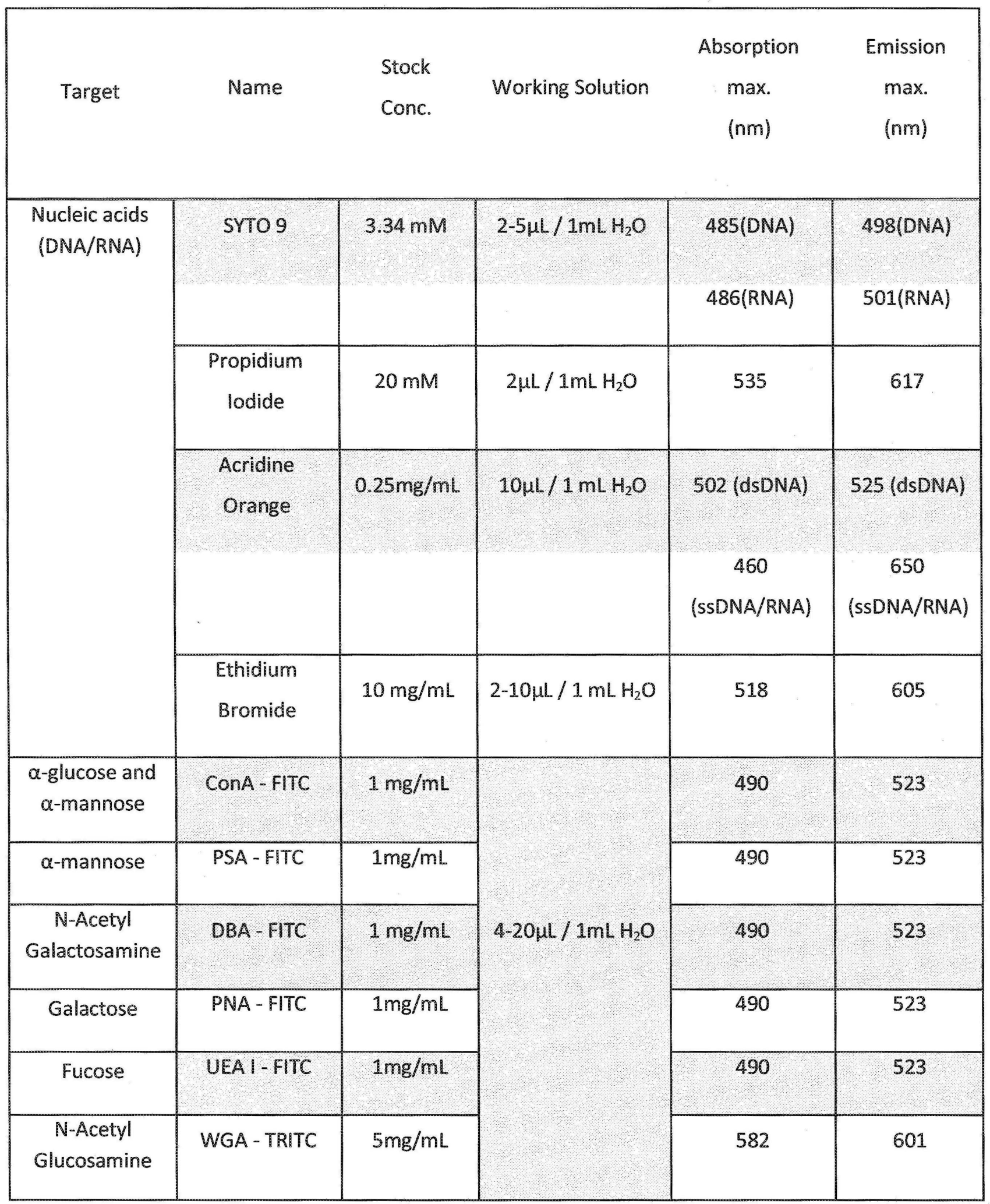




\section{Chapter 3. MATERIALS AND METHODS}

\subsection{General description}

To study the efficiency of wastewater treatment in a system containing flocs and biofilm attached to suspended carrier material, a laboratory scale hybrid sequencing batch reactor (HSBR) setup was used. Similar systems were used in wastewater treatment research and had been found to be adequate setups in the study of the removal efficiency of chemical oxygen demand and nitrogen ( $\mathrm{Li}$ and Zhang, 2002; Bernardes and Klapwijk, 1996). There are several advantages offered by the use of a HSBR that include a smaller reactor volume compared to a conventional reactor, minimal feed requirements, good foaming control. This type of system also eliminates the requirements of a separate settling tank as a clarifier because in the hybrid system the sedimentation and reaction occur sequentially in the same reactor vessel. A glucose and sodium acetate based synthetic wastewater feed was used instead of using industrial or municipal wastewater so that the concentrations of the nutrient components could be easily manipulated without daily fluctuations.

There were a total of three experimental runs for the hybrid reactors in this study. For each of the three experimental periods, inoculums were obtained from the Toronto municipal wastewater treatment plant (Ashbridges Bay Wastewater Treatment Plant ON, Canada). The inoculums was introduced in the hybrid reactors fed with a synthetic wastewater feed containing a desired COD:N:P ratio. Nutrient levels were adjusted in the reactors during the experimental runs by altering the COD:N:P ratio. The surface 
area for attachment of biomass varied in each reactor by changing the type and amount of suspended carrier material used.

For the analysis of carbon dioxide profile over time a different experimental setup was used. The setup consisted of $0.5 \mathrm{~L}$ reactors operated in batch mode that was connected to the $\mathrm{CO}_{2}$ gas analyzer. The reactors were operated under similar conditions to the hybrid sequencing batch reactors with regards to the synthetic wastewater feed for the duration of one reaction stage and data regarding the metabolic activity of the biomass was collected.

\subsection{Experimental setup of the hybrid sequencing batch reactors}

The hybrid sequencing batch reactors setup consisted of a refrigerated feed

storage and three parallel sequencing batch reactors. Figures 3.1 and 3.2 show the experimental setup of the SBR system. 


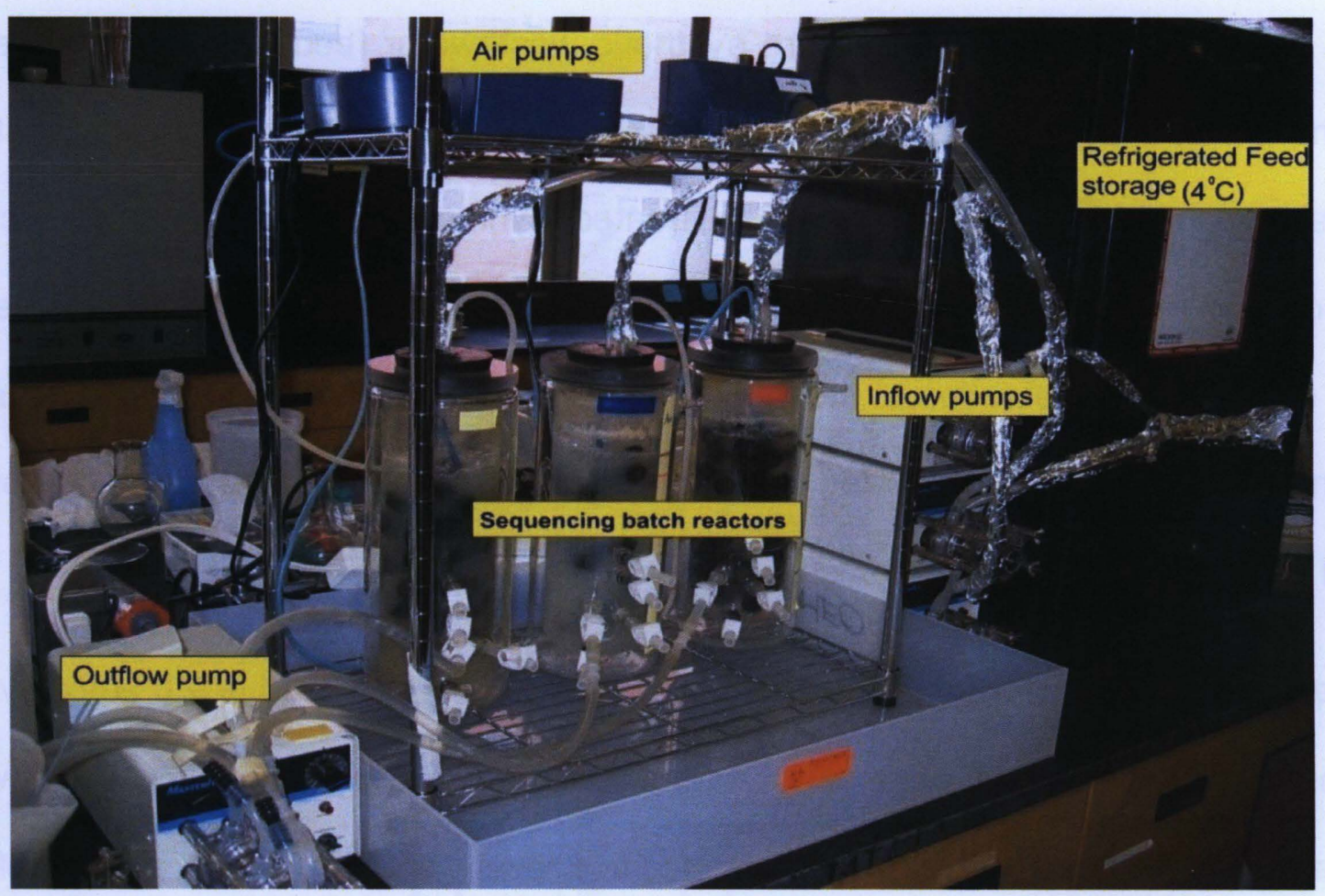

Figure 3.1 Image of the SBR laboratory setup.

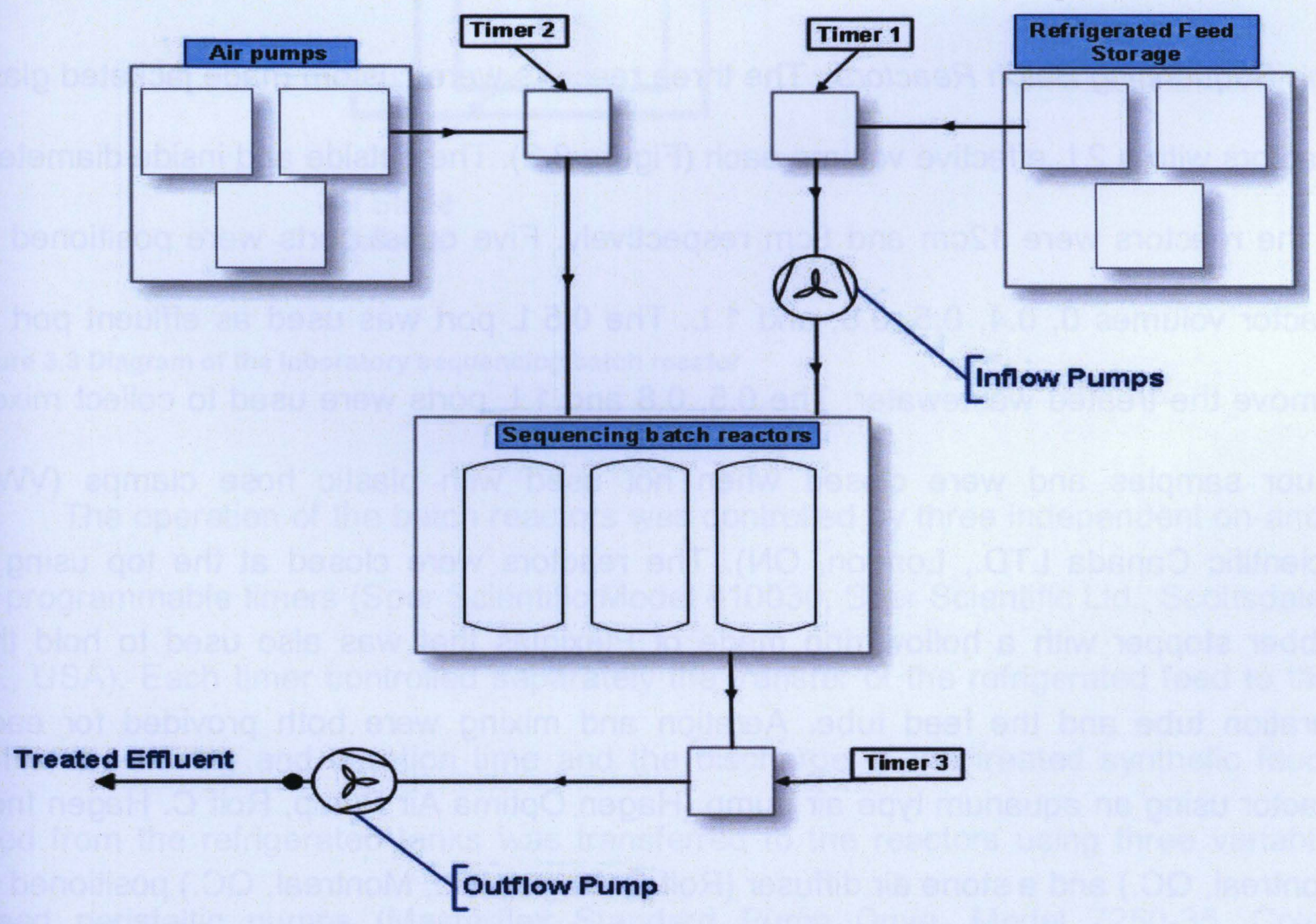

Figure 3.2 Schematic diagram of the SBR laboratory setup 
Feed tanks were used to store synthetic wastewater feed that was transferred into the batch reactors with the aid of three peristaltic pumps and another outflow peristaltic pump that was removing the treated synthetic feed out of the reactors. Aeration and mixing was maintained to ensure aerobic operating conditions inside the batch reactors. The operation of the inflow and outflow pumps as well as the air pumps was managed with the use of three individual timers. A more detailed description of the hybrid sequencing batch reactors is as follows:

The refrigerated feed storage: The synthetic wastewater was stored in $9 \mathrm{~L}$ autoclavable rectangular polypropylene carboys (Nalgene Company, Rochester, NY) which were maintained at $4^{\circ} \mathrm{C}$ in a bar sized refrigerator to prevent premature degradation of the nutrients.

The Sequencing Batch Reactors: The three reactors were custom made jacketed glass reactors with a $2 \mathrm{~L}$ effective volume each (Figure 3.3). The outside and inside diameters of the reactors were $12 \mathrm{~cm}$ and $8 \mathrm{~cm}$ respectively. Five outlet ports were positioned at reactor volumes $0,0.4,0.5,0.8$, and $1 \mathrm{~L}$. The $0.5 \mathrm{~L}$ port was used as effluent port to remove the treated wastewater. The $0.5,0.8$ and $1 \mathrm{~L}$ ports were used to collect mixed liquor samples and were closed when not used with plastic hose clamps (VWR Scientific Canada LTD., London, ON). The reactors were closed at the top using a rubber stopper with a hollow ring made of Plexiglas that was also used to hold the aeration tube and the feed tube. Aeration and mixing were both provided for each reactor using an aquarium type air pump (Hagen Optima Air Pump, Rolf C. Hagen Inc., Montreal, QC.) and a stone air diffuser (Rolf C. Hagen Inc., Montreal, QC.) positioned at the bottom of the reactor. The reactors were operated at room temperature. 


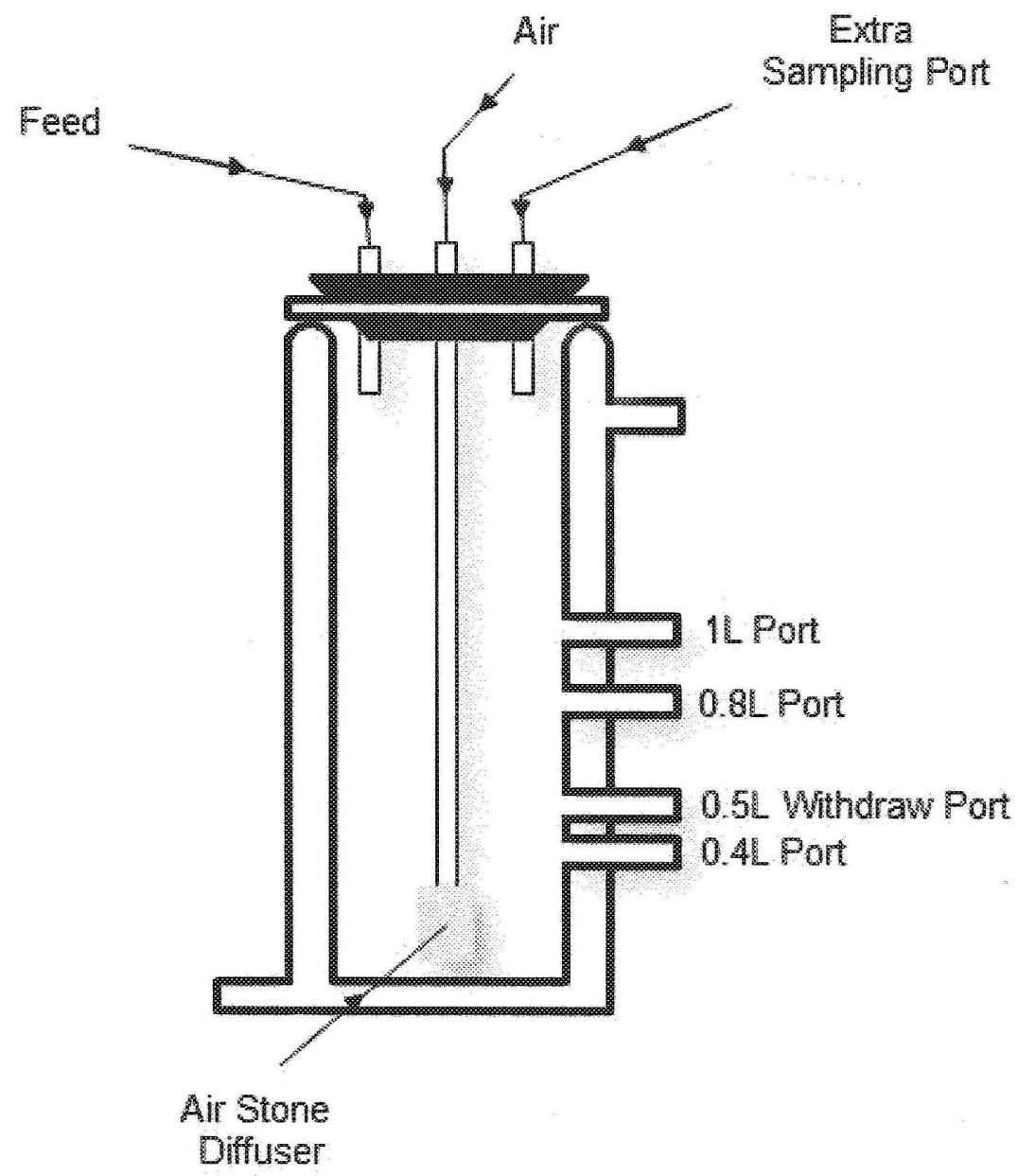

Figure 3.3 Diagram of the laboratory sequencing batch reactor

The operation of the batch reactors was controlled by three independent on-andoff programmable timers (Sper Scientific Model 810030, Sper Scientific Ltd., Scottsdale, AZ., USA). Each timer controlled separately the transfer of the refrigerated feed to the SBRs, the mixing and aeration time and the discharge of the treated synthetic feed. Feed from the refrigerated tanks was transferred to the reactors using three variable speed peristaltic pumps (Masterflex Standard Pump Drive, Model 7250-35, Cole- 
Parmer Instrument Co., Niles, III., USA) with pump heads (Masterflex L/S Size 18, ColeParmer Instrument Co., Niles, III., USA) and the same type of pump with three pump heads was used to remove the treated effluent. The peristaltic pumps were operated at speeds of approximately $12 \mathrm{Lh}^{-1}$.

To prevent phototrophic growth a metal frame was built around the reactors and the whole setup was covered with black cloth material. The metal case also provided support for the tubing and served as protection in case of accidental tipping of the reactors.

The solid support material: Out of the $2 \mathrm{~L}$ effective volume of the sequencing batch reactors between 25 and $50 \%$ of the volume was filled with free floating biofilm carriers (ActiveCell450 ${ }^{\mathrm{TM}}$ and ActiveCell550 ${ }^{\mathrm{TM}}$ ) provided by Hydroxyl Systems Inc., Victoria, BC, Canada. These were made of polyethylene pieces that have a wagon wheel shape with an outer diameter of 20 and $26 \mathrm{~mm}$ respectively and length of $150 \mathrm{~mm}$. The effective surface area of the ActiveCell450 ${ }^{\mathrm{TM}}$ and ActiveCell550 ${ }^{\mathrm{TM}}$ biofilm carriers was $450 \mathrm{~m}^{2} / \mathrm{m}^{3}$ and $550 \mathrm{~m}^{2} / \mathrm{m}^{3}$ respectively.

\subsubsection{Synthetic feed}

The composition of the synthetic wastewater feed is presented in Table 3.1. This feed was used throughout all the runs of the sequencing batch reactors with the exception of the last one in which the concentration of some components was modified in order to test the effect of low phosphorous conditions on the hybrid system. The standard feed contained a COD of $600 \mathrm{mg} / \mathrm{L}$ and a COD:N:P ratio of 100:5:1. Stock 
solutions of glucose, sodium acetate, $\mathrm{KH}_{2} \mathrm{SO}_{4},\left(\mathrm{NH}_{4}\right)_{2} \mathrm{SO}_{4}$ and inorganic salts were prepared separately and kept at $4^{\circ} \mathrm{C}$ before use. From the stock solution the synthetic feed was prepared fresh every day and was kept at 4 OC in the refrigerated feed storage. All chemicals used were of analytical grade. All dilutions were performed using deionized distilled water (Milli-Q Water Systems, Millipore Corporation, MA).

Table 3.1 Composition of the standard synthetic wastewater feed (COD $\sim 600 \mathrm{mg} / \mathrm{L}, \mathrm{COD}: \mathrm{N}: \mathrm{P}=100: 55.1)$

\begin{tabular}{|c|c|c|c|c|}
\hline Nutrients & Compounds & Constituents & Concentration $(\mathrm{mg} / \mathrm{L})$ & Sources \\
\hline \multirow[t]{2}{*}{ C-source } & Glucose & COD & $250(100.0 \mathrm{mg} \mathrm{C})$ & Sigma Chemical, Canada \\
\hline & Sodium acetate & COD & $283.5(83.0 \mathrm{mg} \mathrm{C})$ & Sigma Chemical, Canada \\
\hline \multirow[t]{2}{*}{ P-source } & $\mathrm{KH}_{2} \mathrm{PO}_{4}$ & $P$ & $8.78(2.0 \mathrm{mg} P)$ & Sigma Chemical, Canada \\
\hline & $\mathrm{K}_{2} \mathrm{HPO}_{4}$ & $\mathrm{P}$ & $11.24(2.0 \mathrm{mg} \mathrm{P})$ & Sigma Chemical, Canada \\
\hline N-source & $\left(\mathrm{NH}_{4}\right)_{2} \mathrm{SO}_{4}$ & $\mathrm{NH}_{4}-\mathrm{N}$ & $89.33(19.0 \mathrm{mg} \mathrm{N})$ & Fisher Scientific, Canada \\
\hline \multirow[t]{9}{*}{ Others } & $\mathrm{MgSO}_{4} \cdot 7 \mathrm{H}_{2} \mathrm{O}$ & $\mathrm{Mg}$ & $5.07(0.5 \mathrm{mg} \mathrm{Mg})$ & VWR Scientific, Canada \\
\hline & $\mathrm{CaCl}_{2} \cdot 2 \mathrm{H}_{2} \mathrm{O}$ & $\mathrm{Ca}$ & $2.0(0.5 \mathrm{mg} \mathrm{Ca})$ & VWR Scientific, Canada \\
\hline & $\mathrm{Na}_{2} \mathrm{MoO}_{4} \cdot 2 \mathrm{H}_{2} \mathrm{O}$ & Mo & 0.01 (0.004 mg Mo) & VWR Scientific, Canada \\
\hline & $\mathrm{Fe}(I I I) \cdot E D T A$ & $\mathrm{Fe}$ & $3.0(0.5 \mathrm{mg} \mathrm{Fe})$ & VWR Scientific, Canada \\
\hline & $\mathrm{MnCl}_{2} \cdot 4 \mathrm{H}_{2} \mathrm{O}$ & Mn & $0.36(0.1 \mathrm{mg} \mathrm{Mn})$ & Fisher Scientific, Canada \\
\hline & $\mathrm{FeSO}_{4} \cdot 7 \mathrm{H}_{2} \mathrm{O}$ & $\mathrm{Fe}$ & $0.50(0.1 \mathrm{mg} \mathrm{Fe})$ & Fisher Scientific, Canada \\
\hline & $\mathrm{CuSO}_{4} \cdot 5 \mathrm{H}_{2} \mathrm{O}$ & $\mathrm{Cu}$ & $0.39(0.1 \mathrm{mg} \mathrm{Cu})$ & Sigma Chemical, Canada \\
\hline & $\mathrm{ZnSO}_{4} \cdot 7 \mathrm{H}_{2} \mathrm{O}$ & $\mathrm{Zn}$ & $0.44(0.1 \mathrm{mg} \mathrm{Zn})$ & VWR Scientific, Canada \\
\hline & $\mathrm{CoCl}_{2} \cdot 6 \mathrm{H}_{2} \mathrm{O}$ & Co & $0.41(0.1 \mathrm{mg} \mathrm{Co})$ & Fisher Scientific, Canada \\
\hline
\end{tabular}




\section{2 .2 Inoculum}

The inoculum used in this study was a mixed liquor sample obtained from the Toronto Main Treatment Plant (Ashbridges Bay Wastewater Treatment Plant, ON, Canada). The inoculum was collected, transported to the laboratory and added to the reactors in less than 2 hours from sampling. The reactors were inoculated only once at the beginning of experimental Run 1 and for the Runs 2 and 3 the inoculation was performed several times during the experimental period.

\subsubsection{Cyclic Operation of the Hybrid Sequencing Batch Reactors}

The hybrid reactors operated in a fill and draw cyclic mode with 6 hours per cycle, thus 4 cycles per day basis (see Table 3.2). In each cycle there were four discrete stages: fill, aeration (reaction), sedimentation and withdrawal. In the fill mode the synthetic feed was pumped from the feed storage unit to the reactors. When the reactor volume reached $2.0 \mathrm{~L}$ level, the aeration started mixing the contents. At the end of the reaction stage, the air pumps were turned off and the mixed liquor with the carriers were allowed to settle down (sedimentation). A volume of $1.5 \mathrm{~L}$ of the treated effluent, which represents $75 \%$ of the total operating volume, was withdrawn from the reactors during withdrawal stage. The length of each operating mode in each cycle is shown in Table 3.2. 
Table 3.2 The hybrid SBR cycles for the experimental run

\begin{tabular}{|l|l|}
\hline Cyclic Operation of HSBR & Duration \\
\hline Length of cycle, $n$ (hours) & 6 \\
\hline Number of cycles per day, $N$ & 4 \\
\hline Length of stages: & \\
\hline Fill & $7 \mathrm{~min}$ \\
\cline { 2 - 2 } $\begin{array}{l}\text { Reaction } \\
\text { Settle }\end{array}$ & 5 hours $15 \mathrm{~min}$ \\
\cline { 2 - 2 } Withdrawal & $30 \mathrm{~min}$ \\
\cline { 2 - 2 } & $8 \mathrm{~min}$ \\
\hline
\end{tabular}

\subsubsection{Experimental Conditions}

Stable operating conditions were determined for the hybrid sequencing batch reactors by monitoring the mixed liquor suspended solids (MLSS), and chemical oxygen demand (COD) removal. Only when the data for these parameters reached relatively constant levels the reactors were considered to have reached stable operating conditions. During the same time the biofilm formation on the carrier material was investigated. During the first two experimental runs the COD:N:P ratios and the carrier material load were the same for all reactors. During the last experimental run the COD:N:P ratios were modified for $P$-normal and $P$-limited conditions were $P$ was supplied at only one third of the level. A summary of the COD:N:P ratios of each reactor in each of the three runs are shown in Table 3.3. The carrier material load in each reactor during each of the experimental runs is shown in Table3.4. The reactors were maintained at room temperature throughout all the runs and the $\mathrm{pH}$ of the reactors was found to be in the range of 7 to 8 . A summary of the experimental conditions in each of the three runs is shown in Table 3.3 
Table 3.3 Summary of the experimental conditions in each experimental run

\begin{tabular}{|llll|}
\hline & Run 1 & Run 2 & Run 3 \\
pH & $7-8$ & $7-8$ & $7-8$ \\
Feed COD $(\mathrm{mg} / \mathrm{L})$ & 600 & 600 & 600 \\
\hline COD:N:P ratios & & & \\
SBR1 & $100: 5: 1$ & $100: 5: 1$ & $100: 5: 1$ \\
SBR2 & $100: 5: 1$ & $100: 5: 1$ & $100: 5: 1$ \\
SBR3 & $100: 5: 1$ & $100: 5: 1$ & $100: 5: 0.33$ \\
\hline
\end{tabular}

Table 3.4 Summary of the carrier material load in each experimental run

\begin{tabular}{|c|c|c|c|c|}
\hline & & Run 1 & Run 2 & Run 3 \\
\hline \multirow{4}{*}{ SBR1 } & Fill Ratio $(\%)$ & 50 & 50 & 41 \\
\hline & Number of carriers & 80 Activecell $450^{\text {TM }}$ & 80 Activecell $450^{\mathrm{TM}}$ & $\begin{array}{l}40 \text { Activecell } 450^{\mathrm{TM}} \\
20 \text { Activecell } 550^{\mathrm{TM}}\end{array}$ \\
\hline & $\begin{array}{l}\text { Specific surface area } \\
\left(\mathrm{m}^{2} / \mathrm{m}^{3} / \text { reactor }\right)\end{array}$ & 225 & 225 & 204.2 \\
\hline & Support surface area $\left(\mathrm{m}^{2}\right)$ & 0.45 & 0.45 & 0.408 \\
\hline \multirow{4}{*}{ SBR2 } & Fill Ratio $(\%)$ & 50 & 25 & 41 \\
\hline & Number of carriers & 60 Activecell $550^{\text {TM }}$ & 40 Activecell $450^{\mathrm{TM}}$ & $\begin{array}{l}40 \text { Activecell } 450^{T M} \\
20 \text { Activecell550 }\end{array}$ \\
\hline & $\begin{array}{l}\text { Specific surface area } \\
\left(\mathrm{m}^{2} / \mathrm{m}^{3} / \text { reactor }\right)\end{array}$ & 275 & 112.5 & 204.2 \\
\hline & Support surface area $\left(\mathrm{m}^{2}\right)$ & 0.55 & 0.225 & 0.408 \\
\hline \multirow{4}{*}{ SBR3 } & Fill Ratio (\%) & 25 & 50 & 41 \\
\hline & Number of carriers & 40 Activecell $450^{\text {TM }}$ & 60 Activecell $550^{T M}$ & $\begin{array}{l}40 \text { Activecell } 450^{T M} \\
20 \text { Activecell } 550^{\mathrm{TM}}\end{array}$ \\
\hline & $\begin{array}{l}\text { Specific surface area } \\
\left(\mathrm{m}^{2} / \mathrm{m}^{3} / \text { reactor }\right)\end{array}$ & 112.5 & 275 & 204.2 \\
\hline & Support surface area $\left(\mathrm{m}^{2}\right)$ & 0.225 & 0.55 & 0.408 \\
\hline
\end{tabular}




\subsection{Experimental setup to measure carbon dioxide}

The experimental setup of the carbon dioxide reactors consisted of a $0.5 \mathrm{~L}$ reactor operated in batch mode and a $\mathrm{CO}_{2}$ gas analyzer connected to the air outflow of the reactor to measure carbon dioxide production (see Figure 3.5).

The $\mathrm{CO}_{2}$ reactors: The reactors consisted of a $0.5 \mathrm{~L}$ flasks closed with a two-hole black rubber stoppers (VWR Scientific Canada LTD., London, ON). The two openings were used for the gas inflow and outflow ports. The inflow port provided aeration and mixing via an air stone diffuser (Rolf C. Hagen Inc., Montreal, QC.) situated at the bottom of the reactor (see Figure 3.4). The reactors were operated at room temperature and were covered with tin foil to minimize exposure to light.

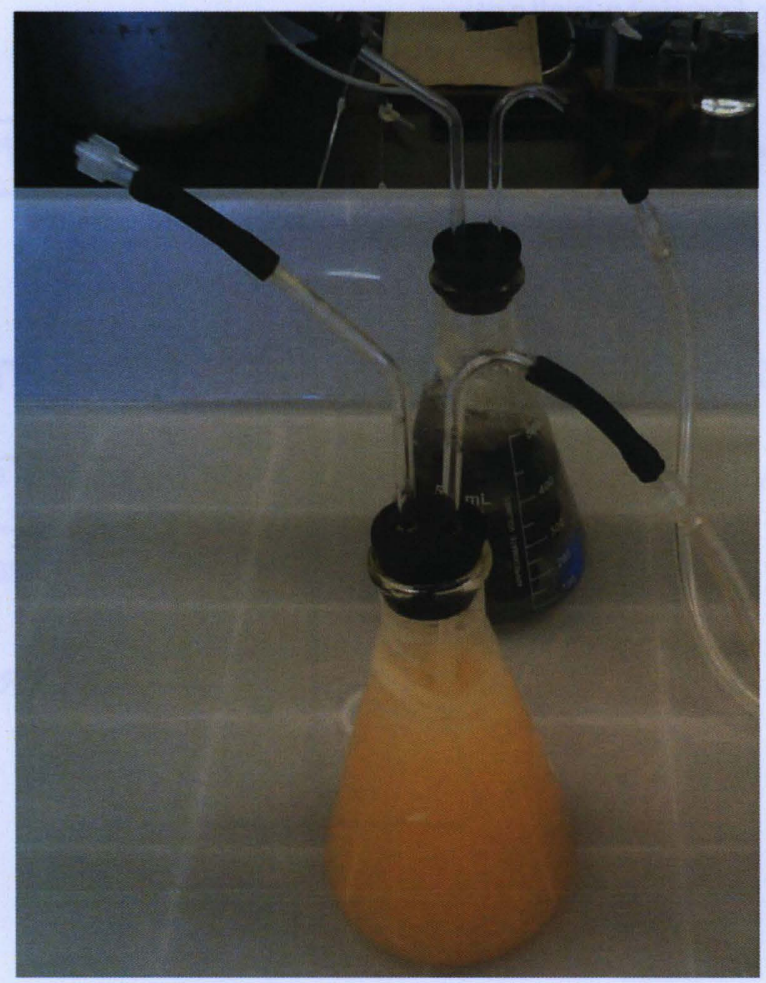

Figure 3.4 Picture of the $\mathrm{CO}_{2}$ reactors with separated suspended and attached biomass treating synthetic wastewater. 
Inflow gas line: The inflow gas line was connected to the laboratory bench air line and was fitted with a pressure valve release system consisting of a 4-way polycarbonate stopcock (model RK-30600-04, Cole-Parmer Instrument Co., Niles, III., USA).

Outflow gas line: The outflow line connected the reactors to the $\mathrm{CO}_{2}$ gas analyzer. The connection was made via a gas flow regulator (Trojan Technologies Inc. SN\#156929, Cole-Parmer Instrument Co., Niles, III., USA) that controlled the constant gas flow of $1 \mathrm{~L}$ per minute going through the $\mathrm{CO}_{2}$ gas analyzer.

$\mathrm{CO}_{2}$ analyzer. The level of carbon dioxide gas was monitored continuously in the reactors over the period of a full reaction cycle ( 5 hours) with a $\mathrm{CO}_{2}$ gas analyzer ( $\mathrm{LI}$ $820 \mathrm{CO}_{2}$ Gas Analyzer, LI-COR Biosciences, Lincoln, NE, USA). The $\mathrm{CO}_{2}$ analyzer was connected to a computer for data collection.

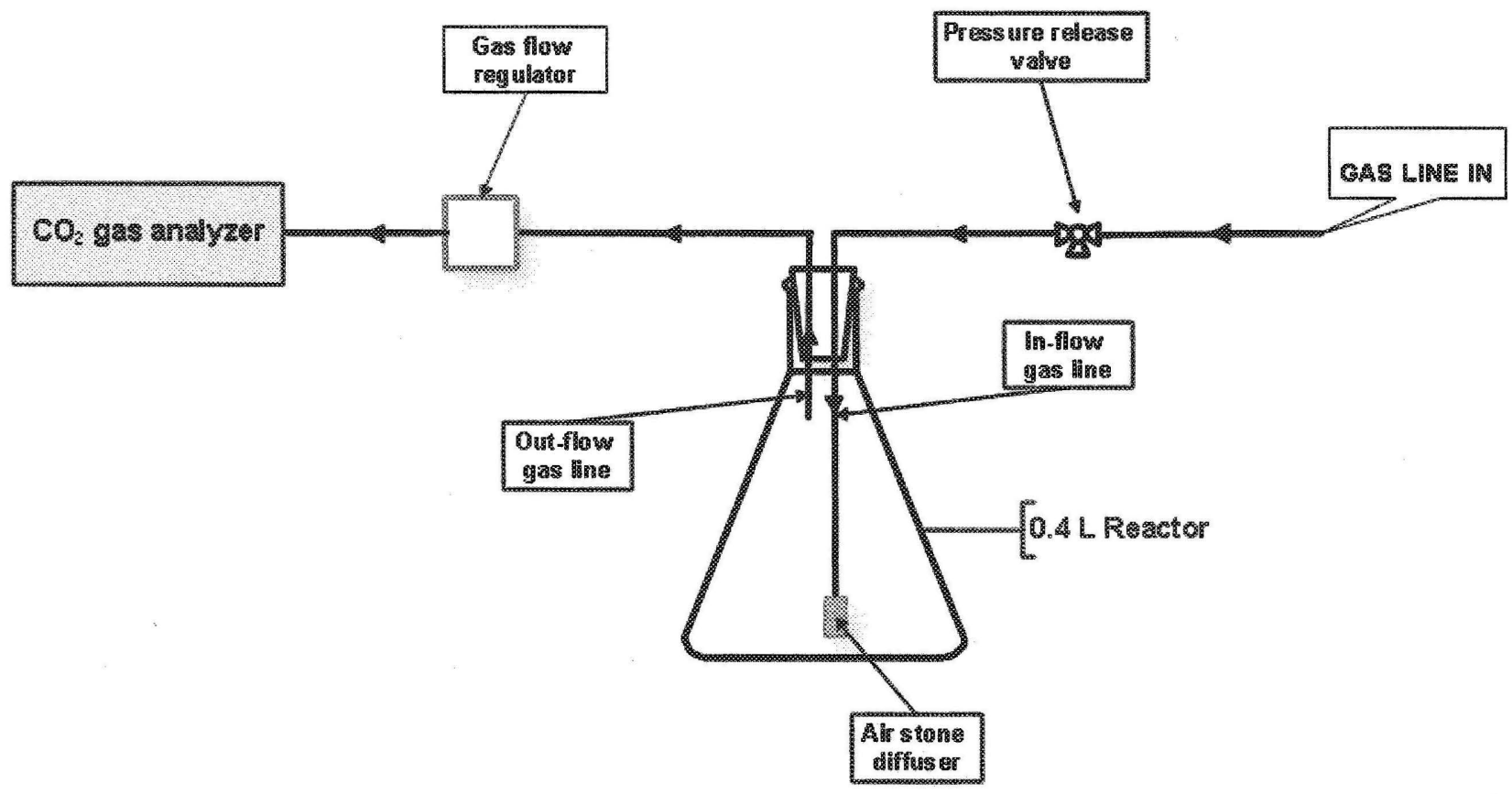

Figure 3.5 Diagram of the CO2 gas analyzer setup. 


\subsubsection{Experimental conditions:}

Biomass samples consisting of mixed liquor samples or biofilm growing on carriers were transferred from the hybrid sequencing batch reactors from enperimental Run 3 into the $0.4 \mathrm{LCO}_{2}$ reactors. The samples were collected from the hybrid reactors at different times during the reaction stag: at the beginning of the reaction stage (30 min samples), half way through the reaction stage ( 3 hour samples) and at the end of the reaction stage (6 hour samples). Mixed liquor samples of $0.4 \mathrm{~L}$ in volume were taken from the SBRs and allowed to settle for 15 minutes and after discarding the clear top section of synthetic wastewater the sedimented microbial flocs were transferred to the $\mathrm{CO}_{2}$ reactors and the volume was corrected to the $0.4 \mathrm{~L}$ mark with fresh synthetic wastewater feed. The biofilm samples taken from the SBRs were first washed of any non-attached biomass by submerging the carriers into a beaker with fresh synthetic feed and transferred to the $\mathrm{CO}_{2}$ reactors followed by the addition of synthetic feed to the $0.4 \mathrm{~L}$ mark.

The $\mathrm{CO}_{2}$ reactors were operated for the duration of a reaction stage (6 hours) and the carbon dioxide gas production from the metabolic activity of the biomass was recorded by the $\mathrm{CO}_{2}$ gas analyzer connected to a computer. 


\subsection{Standard Wastewater Analysis}

\subsubsection{Mixed Liquor Suspended Solids}

The mixed liquor suspended solids (MLSS) were measured in accordance with Standard Methods (APHA, 1998). MLSS which are composed of active microbial biomass, non-active microbial biomass, non-biodegradable organics as well as inorganic mass was used in this study along with COD in order to provide information about the operating conditions of the reactors.

A known volume of mixed liquor (between $10-20 \mathrm{~mL}$ ) was filtered through a 0.45 $\mu \mathrm{m}$ pore size filter paper (Glass Microfiber Filters, Whatman, $47 \mathrm{~mm}$ ) and the samples were then dried to constant weight at $105{ }^{\circ} \mathrm{C}$. The MLSS represented the increase in weight of the filter paper.

\subsubsection{Chemical Oxygen Demand}

The chemical oxygen demand of each reactor was monitored on a routine basis for the synthetic feed and the treated effluent. The closed reflux, colorimetric method (section 5220D in APHA, 1998) was used to measure the oxygen equivalent of the organic and inorganic matter content of a sample that is susceptible to oxidation by a strong chemical oxidant. The synthetic feed or the treated effluent were filtered through a $0.45 \mu \mathrm{m}$ pore size filter paper (Glass Microfiber Filters, Whatman, $47 \mathrm{~mm}$ ) before being analyzed. A $2.5 \mathrm{~mL}$ sample volume was placed in a culture tube with Teflon lined 
caps (Hach Co., Loveland, CO, USA) to which another $1.5 \mathrm{~mL}$ of digestion solution $\left(\mathrm{K}_{2} \mathrm{Cr}_{2} \mathrm{O}_{7}, \mathrm{HgSO}_{4}\right.$ and $\left.\mathrm{H}_{2} \mathrm{SO}_{4}\right)$ and $3.5 \mathrm{~mL}$ of $\mathrm{H}_{2} \mathrm{SO}_{4}$ reagent $\left(\mathrm{AgSO}_{4}\right.$ and $\left.\mathrm{H}_{2} \mathrm{SO}_{4}\right)$ were added. The culture tubes were placed in a COD block heater (Hach COD Reactor, model 45600-00, Hach Co., Loveland, CO, USA) and refluxed at $150^{\circ} \mathrm{C}$ for 2 hours. The cooled samples were then measured spectrophotometrically (Spectronic 20D; Milton Roy, Rochester, NY, USA) at $600 \mathrm{n} \mathrm{nm}$ along with the potassium hydrogen phthalate (KHP) standards.

\subsubsection{Surface Charge Measurements of the Microbial Flocs}

The surface charge of microbial flocs was measured by colloidal titration (Morgan et al., 1990). The surface charge of a given biomass can be measured by mixing a known volume of the sample with a specified quantity of positively charge polymer, polybrene and titrating the solution with a negatively charged polymer, polyanetholsulfonic acid. The endpoint volume of the titration was compared to the endpoint volume of a blank solution titration.

A mixed sample was collected from each sequencing batch reactor and washed once with Millipore water (Milli-Q Advantage ultrapure water system, Millipore Corp., MA, USA) and then centrifuged at $3000 \mathrm{~g}$ for 5 to 6 minutes. The samples were washed again with $\mathrm{pH}$-balanced water (Millipore water brought to $\mathrm{pH}=7.0$ ), and centrifuged for 5$6 \mathrm{~min}$ at $3000 \mathrm{~g}$. The MLSS measurements of the washed samples were taken at this point. To $2.0 \mathrm{~mL}$ of washed sample $40.0 \mathrm{~mL}$ of pH-balanced Millipore water and $4.0 \mathrm{~mL}$ of excess polybrene were added. The mixture was titrated with a standard solution of 
polyanetholsulfonic acid and toluidine blue as indicator. A blank was also titrated by replacing the $2.0 \mathrm{~mL}$ of washed sample with $2.0 \mathrm{~mL}$ of $\mathrm{pH}$-balanced Millipore water.

The surface charge of each sample was calculated by using the formula:

$$
\text { Surface charge }=\frac{-\left(V_{0}-V\right) * N * 10^{3}}{2 * \text { MLSS }}
$$

where $N=0.001$ meq $/ \mathrm{L}, V=$ volume of polyanetholsulfonic acid $(\mathrm{mL})$ used to reach the endpoint in titration of sample and $V_{0}=$ volume of polyanetholsulfonic acid $(\mathrm{mL})$ used to reach the endpoint in titration of blank solution. MLSS was measured in $\mathrm{g} / \mathrm{L}$.

\subsubsection{Relative Hydrophobicity Determination}

In determining the relative percent hydrophobicity of the microbial floc the Microbial Adherence to Hydrocarbons (MATH) methods was employed (Rosenberg et al., 1980). The method is based on the concept that upon a brief period of mixing, hydrophobics in the microbial sludge suspension adhere at various degrees to the hydrocarbon at the hydrocarbon-aqueous interface. Then the absorbance of the aqueous phase was measured to estimate the relative hydrophobicity of the sample.

A mixed liquor sample was collected from each reactor and analyzed immediately. The samples were washed twice with Millipore water and centrifuged once at $3000 \mathrm{~g}$. The samples were then shaken to resuspend the pellet and then homogenized by sonication for 30 seconds. The initial absorbance $\left(1_{0}\right)$ of the 
homogenized samples was adjusted to $1.5 \pm 0.2$ at $400 \mathrm{~nm}$ wavelength using Millipore water for dilution. $10 \mathrm{~mL}$ of the adjusted solution was mixed with $1 \mathrm{~mL}$ of hexadecane using a vortex mixer for 2 minutes. The two phases, hydrophobic and aqueous phases were left to separate for 10 minutes in a separatory funnel. The aqueous phase was collected and the absorbance (I) was measured spectrophotometrically at $400 \mathrm{~nm}$ (Spectronic 20D; Milton Roy, Rochester, NY, USA). The relative hydrophobicity was calculated using the formula:

$$
\% \text { Hydrophobicity }=\underset{\left.I_{0}-1\right)}{\left(I_{0}-100\right.} * 1
$$

\subsubsection{Nitrogen (Ammonia, Nitrite, Nitrate)}

The total nitrogen in the bioreactors is composed of the following forms: organic nitrogen, ammonia, nitrite and nitrate.

Ammonia was measured according to the phenate method (Standard Methods 4500-NH3 F, APHA 1998), however due to the limited amount of sampling volume; the sample size was reduced from $25 \mathrm{~mL}$ to $5 \mathrm{~mL}$. Mixed liquor samples were collected from the reactors and filtered through a $45 \mu \mathrm{m}$ pore size filter paper (Glass Microfiber Filters, Whatman, $25 \mathrm{~mm}$ ). To a $5 \mathrm{~mL}$ sample there were added with mixing after each addition the following solutions: $0.2 \mathrm{~mL}$ phenol solution $(\geq 89 \%), 0.2 \mathrm{~mL}$ sodium nitroprusside solution and $0.5 \mathrm{ml}$ oxidizing solution. The sample vials were covered with paraffin wrapper film and allowed to develop the colour at room temperature in the dark 
for 1 hour. The absorbance of the developed samples was then measured at $640 \mathrm{~nm}$ (Spectronic 20D; Miton Roy, Rochester, NY, USA) along with the blank and the stock ammonia solution standards.

Nitrite was measured using the colorimetric method (Standard Methods 4500NO2 B, APHA 1998). The sample size was reduced from $50 \mathrm{~mL}$ to $5 \mathrm{~mL}$ due to the limited amount of sample available for analysis. Mixed liquor samples collected from the reactors were filtered through a $45 \mu \mathrm{m}$ pore size filter paper (Glass Microfiber Filters, Whatman, $25 \mathrm{~mm})$. To $5 \mathrm{~mL}$ of filtered sample $0.2 \mathrm{~mL}$ of colour reagent $(0.2 \%$ aqueous solution of $\mathrm{N}$-(1-naphthyl)-ethylenediamine dihydrochloride) was added and allowed to develop colour in the dark for 10 minutes. The same amount of colour reagent was added to the standards and after colour development the samples and standards absorbance was measured at $543 \mathrm{~nm}$ (Spectronic 20D; Milton Roy, Rochester, NY, USA).

Nitrate was measured using the Cadmium reduction method (Standard Methods 4500- $\mathrm{NO}_{3} \mathrm{E}, \mathrm{APHA}$ 1998). There were some changes to the method due to the limited amount of sample available and the lack of a reduction column. Because of practical reasons the standard method's sample size was reduced from $25 \mathrm{~mL}$ to $5 \mathrm{~mL}$ and instead of a cadmium reduction column, cadmium reduction packs from nitrate kit (Nitrate Chemetrics, CHEMetrics Inc., VA, USA) were used. Mixed liquor samples were collected and filtered though a $45 \mu \mathrm{m}$ pore size filter paper (Glass Microfiber Filters, Whatman, $25 \mathrm{~mm}$ ). A total volume of $15 \mathrm{~mL}$ of filtered sample was mixed with the contents of one cadmium powder pack and mixed vigorously for exactly 3 minutes. The sample was allowed to sit for 2 minutes and then 2 aliquots of $5 \mathrm{~mL}$ reduced sample 
were transferred to culture tubes, making sure not to transfer any cadmium particles. From this point the samples were analyzed the same as the nitrite samples described above.

\subsubsection{Settled Sludge Volume and Sludge Volume Index}

The settled sludge volume of a biological suspension is often used in routine monitoring of biological processes (Section $2710 \mathrm{C}$, APHA 1989). The method can be used in activated sludge plant control as means to determine the returned sludge flow rate and to determine the appropriate time to waste sludge. The 30 minutes settled sludge volume was measured by placing $1 \mathrm{~L}$ of mixed liquor sample in a $1000 \mathrm{~mL}$ graduated cylinder and after 30 minutes of quiescent settling the level of the settled sludge was determined.

The sludge volume index is useful as a routine process control to monitor settling characteristics of activated sludge and represents the volume in milliliters occupied by 1 $\mathrm{g}$ of a suspension after 30 minutes of settling (Section 2710 D, APHA 1998). After determining the 30 minutes settle sludge volume and the mixed liquor suspended solids concentrations (MLSS) of the sample, the sludge volume index was calculated using the formula:

$$
S V I=\frac{\text { Settled sludge volume }(\mathrm{mL} / \mathrm{L}) * 1000}{\text { Suspended solids }(\mathrm{mg} / \mathrm{L})}
$$




\subsection{Microscopic Analysis}

\subsubsection{Optical Microscopy}

For the observation of microbial flocs structure an inverted microscope Zeiss Axiovert 200M (Carl Zeiss Inc., Toronto, ON) equipped with a black and white CCD camera (Zeiss AxioCam) was used. The microscope was connected to a computer equipped with Northern Eclipse Version 6.0 software (Empix Imaging Inc., Mississauga, ON) used for image acquisition. The mixed liquor samples analyzed were typical wet mounts visualized at $100 \times$ magnification (Plan-Neofluar 10x/0.30objective, Zeiss) using phase contrast microscopy.

\subsubsection{Confocal Laser Scanning Microscopy}

Confocal laser microscopy was performed on a Zeiss Axioplan LSM 510 (Carl Zeiss Inc., Toronto, ON) microscope. The microscope was equipped with an argon laser (excitation wavelength $488 \mathrm{~nm}$ ) and helium-neon lasers (excitation wavelengths of $543 \mathrm{~nm}$ and $633 \mathrm{~nm})$. The fluorescent molecules used for the investigation of the microbial flocs and the biofilm structure on the carrier material were: nucleic acid stains (acridine orange, Syto 9, ethidium bromide), bacterial viability stains (BacLight: Syto9/propidium iodide), and sugar binding lectins conjugated to FITC (fluorescein) or TRITC (rhodamine). The microbial aggregate samples and the biofilm samples were also embedded in low melting point agarose for stabilization during staining (Droppo et al., 1996). 


\subsection{Fluorescence In Situ Hybridization (FISH)}

\subsubsection{Sample fixation}

Mixed liquor and biofilm samples from the hybrid reactors were fixated using the ethanol-fixation method (Beimfohr et al., 1993). To one volume of samples one volume of $100 \%$ ethanol (not denaturated) was added, mixed by inverting the tube a few times and stored at $-20^{\circ} \mathrm{C}$ until hybridization.

The positive control consisted of a pure bacterial culture of Pseudomonas aeruginosa to check hybridization efficiency. The culture was grown under ideal conditions to log phase and fixated using the same method as described above.

\subsubsection{Hybridization of samples}

The fluorescent in situ hybridization of wastewater samples was performed according to the method described by Amann (1995). The 16S rRNA-targeted oligonucleotide DNA probes used in this study were specific for ammonia-oxidizing bacteria and used in a combination with a probe specific for most bacteria (eubacteria probe). The probes used were Nso190 and Nsv443 for AOB (Mobarry et al., 1996) and EUB338 for eubacteria (Amann et al., 1990). The preparation and the concentration of the working probe solutions can be seen in Table 3.5 . 
Table 3.5 The dilution of working solution for the hybridization probes.

\begin{tabular}{|c|c|c|c|c|c|c|}
\hline $\begin{array}{l}\text { Probe } \\
\text { name }\end{array}$ & Label & 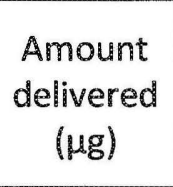 & $\begin{array}{c}\text { Stock } \\
\text { Concentration } \\
\mu \mathrm{g} / 1000 \mu \mathrm{L}\end{array}$ & $\begin{array}{c}\text { Concentration } \\
\text { of work } \\
\text { solution }\end{array}$ & $\begin{array}{c}\text { Amount of } \\
\text { Stock Used } \\
(\mu L)\end{array}$ & $\begin{array}{c}\text { Final Volume } \\
\text { of } \\
\text { Work Solutio } \\
(\mu \mathrm{L})\end{array}$ \\
\hline NSV 443 & Alexa 660 & 1081.56 & 1.08156 & 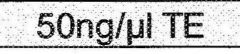 & 2.31 & 50 \\
\hline NSO 190 & Alexa 488 & 3129.51 & 3.12951 & 50ng/ul TE & 0.80 & 50 \\
\hline EUB 338 & Alexa 488 & 2629.42 & 2.62942 & 50ng/ul TE & 0.95 & 50 \\
\hline EUB 338 & Alexa 660 & 950.2 & 0.9502 & 50ng/ul TE & 2.63 & 50 \\
\hline
\end{tabular}

To clean hybridization slides (hydrophobically coated slides with uncoated wells -10 wells/slide) a volume of 5 to $8 \mu \mathrm{L}$ of fixed sample was applied to each well and was allowed to dry for 10 minutes in the hybridization oven set to $46{ }^{\circ} \mathrm{C}$. The same volume of sample was applied to each well for the second time to increase the amount of biomass.

The slides with dried samples were dehydrated in 3 steps by soaking the slides in beakers of $50 \%, 80 \%$ and $100 \%$ ethanol successively for 3 minutes each. The slides were air dried at this point and stored at room temperature until the hybridization.

One tube of hybridization buffer was prepared per slide to be hybridized. A $35 \%$ formamide concentration buffer was used for the Nso190 and EUB338 probe mixture and a $30 \%$ formamide concentration buffer was used for the Nsv443 and EUB338 probe mixture. The preparation of the hybridization buffer can be seen in Table 3.6. To each well containing the dried samples $8 \mu \mathrm{L}$ of hybridization buffer was added and $1 \mu \mathrm{L}$ of each probe from the mixture at a concentration of $50 \mathrm{ng} / \mu \mathrm{L}$ (see Table 3.5 for details). 
Table 3.6 Hybridization buffer (total volume $1.5 \mathrm{~mL}$ )

\begin{tabular}{|c|c|c|}
\cline { 2 - 3 } \multicolumn{1}{c|}{} & \multicolumn{2}{|c|}{$\begin{array}{c}\text { Hybridization buffer } \\
\text { concetration }\end{array}$} \\
$\begin{array}{c}\text { Volume Added } \\
(\mu \mathrm{L})\end{array}$ & $30 \% \mathrm{FA}$ & $35 \% \mathrm{FA}$ \\
\hline $\mathrm{NaCl}$ & 270 & 270 \\
\hline $\mathrm{Tris} / \mathrm{HCl}$ & 30 & 30 \\
\hline $\mathrm{ddH} 2 \mathrm{O}$ & 750 & 675 \\
\hline $\mathrm{FA}$ & 450 & 525 \\
\hline $10 \% \mathrm{SDS}$ & 1.5 & 1.5 \\
\hline Total & 1500 & 1500 \\
\hline
\end{tabular}

The hybridization oven was preheated at $46^{\circ} \mathrm{C}$ and the moisture chamber, consisting of a sterile $50 \mathrm{~mL}$ plastic tube containing a folded piece of tissue, was placed inside. The extra hybridization buffer that was not added to the wells on the slides was poured onto the tissue into the moisture chamber.

Once the moisture chamber reached the hybridization temperature the slide was placed inside the moisture chamber in a horizontal position to avoid the mixing of the solution from the different wells. The slides were kept in the horizontal position inside the oven and allowed to hybridize at $46^{\circ} \mathrm{C}$ for 1.5 hours.

Washing buffers were prepared in a $50 \mathrm{~mL}$ tube with concentrations varying according to the formamide concentration of the hybridization buffers (see Table 3.7) and were preheated to $48^{\circ} \mathrm{C}$ in a water bath. 
Table 3.7 Washing buffer (total volume $50 \mathrm{~mL}$ )

\begin{tabular}{|c|c|c|}
\cline { 3 - 3 } \multicolumn{1}{c|}{} & \multicolumn{2}{c|}{$\begin{array}{c}\text { Washing buffer } \\
\text { concentration }\end{array}$} \\
$\begin{array}{c}\text { Volume Added } \\
(\mu \mathrm{L})\end{array}$ & $30 \% \mathrm{FA}$ & $35 \% \mathrm{FA}$ \\
\hline $\mathrm{Tris} / \mathrm{HCl}$ & 1000 & 1000 \\
\hline $\mathrm{NaCl}$ & 1020 & 700 \\
\hline $\mathrm{EDTA}$ & 500 & 500 \\
\hline $10 \% \mathrm{SDS}$ & 50 & 50 \\
\hline $\mathrm{ddH} 2 \mathrm{O}(2)$ & 47430 & 47750 \\
\hline Total & 50000 & 50000 \\
\hline
\end{tabular}

After the hybridization was completed the slides were carefully removed from the chamber and washed with approximately $5 \mathrm{~mL}$ of washing buffer to remove any formamide from the slides. The slides were then placed in the remaining washing buffer in the washing buffer tube and placed in the water bath set at $48{ }^{\circ} \mathrm{C}$ for 20 minutes. At the end of the washing step the slides were removed from the washing buffer tube and gently washed with sterile $\mathrm{ddH}_{2} \mathrm{O}$ to avoid the removal of samples from the wells. The slide were air dried at room temperature and were ready for microscopic examination or they could be stored in a Petri dish covered with aluminum foil at $-20^{\circ} \mathrm{C}$ until microscopic examination.

\subsubsection{Microscopic examination}

The hybridization slides were embedded with a fixative (Citifluor) by using a small pipette tip to draw a line of citifluor in the middle of the slide between the wells and a cover slide was placed gently on top and pressed to spread the citifluor into each well. The confocal laser scanning microscope was used to inspect the slides and collect digital images. 


\section{Chapter 4. RESULTS AND DISCUSSION}

This study investigated the efficiency of a hybrid bioreactor containing suspended and attached biomass in treating wastewater. The results were recorded from running hybrid sequencing batch reactors operated under different conditions with regards to the support material load and nutrient load. There was a total of three experimental runs and in each run three bioreactors were operated in parallel and the conditions for each run are summarized in Table 3.2.4A and Table 3.2.4B. Each of the experimental runs consisted of an acclimatization period during which all the reactors received a standard synthetic wastewater feed and the biomass was able to accumulate in the reactor. The sequencing batch reactors were monitored to determine whether they reached system stability with respect to chemical oxygen demand (COD) removal and mixed liquor suspended solids (MLSS).

Floc particles were investigated with respect to their settling properties (settle sludge volume and sludge volume index) and their physicochemical properties (surface charge and hydrophobicity).

The nitrification capacity of the hybrid sequencing batch reactors was measured for each reactor as a whole as well as the suspended and attached phases. The nitrogen removal efficiency of the hybrid sequencing batch reactors was measured by monitoring the levels of ammonia, nitrite and nitrate in the bioreactors during the length of the reaction stage. The performance of the suspended phase (flocs) versus the attached phase (biofilms) was measured by separating the two components into two 
smaller bioreactors and measuring the nitrogen and chemical oxygen demand removal efficiency for each phase.

The suspended phase metabolic activity was compared to that of the attached phase by investigating the $\mathrm{CO}_{2}$ profile of the two separate phases over a full cycle run. The flocs and biofilms metabolic activity was monitored by measuring the carbon dioxide production over the length of the reaction stage.

Using optical and confocal laser scanning microscopy the biomass in the sequencing batch reactors was visualized. The flocs were characterized according to their appearance and size range and the biofilm colonization of the attachment surfaces was investigated using specific fluorescent probes visible under confocal laser scanning microscopy. The presence of nitrifying bacteria in the flocs or the biofilms was tested using fluorescence in situ hybridization by detecting the specific cells using phylogenetic markers (16S-rRNA-targeted oligonucleotide probes).

\subsection{Sequencing Batch Reactors System Performance}

\subsubsection{Chemical Oxygen Demand (COD) Removal Efficiency}

The performance of the hybrid system was evaluated based on the COD removal efficiency and the stability of the mixed liquor suspended solids (MLSS) concentration. Due to the small sample size with regards to the carrier load of each reactor during the three separate experimental runs the amount of attached biomass was only sampled at the end of each run. The COD removal efficiencies of the SBR system in all the runs when the systems reached operational stability were around the $90 \%$ COD removal 
(Figure 4.1, Figure 4.2, and Figure 4.3). The high COD removal efficiency was achieved in the hybrid reactors during all three experimental runs (once the systems have reached stable operating conditions) in less than 2 hours from the start of the reaction stage of each cycle. The COD removal was not influenced in any way by lowering the nutrient load with respect to phosphorus in Run 3. Also the carrier load in each reactor from all runs did not influence positively or negatively the COD removal. The difference in effective surface area for attachment from each hybrid reactor did not affect the stable operation of the systems.

$\because \mathrm{SBR} 1=\mathrm{SBR} 2=\mathrm{SBR} 3$

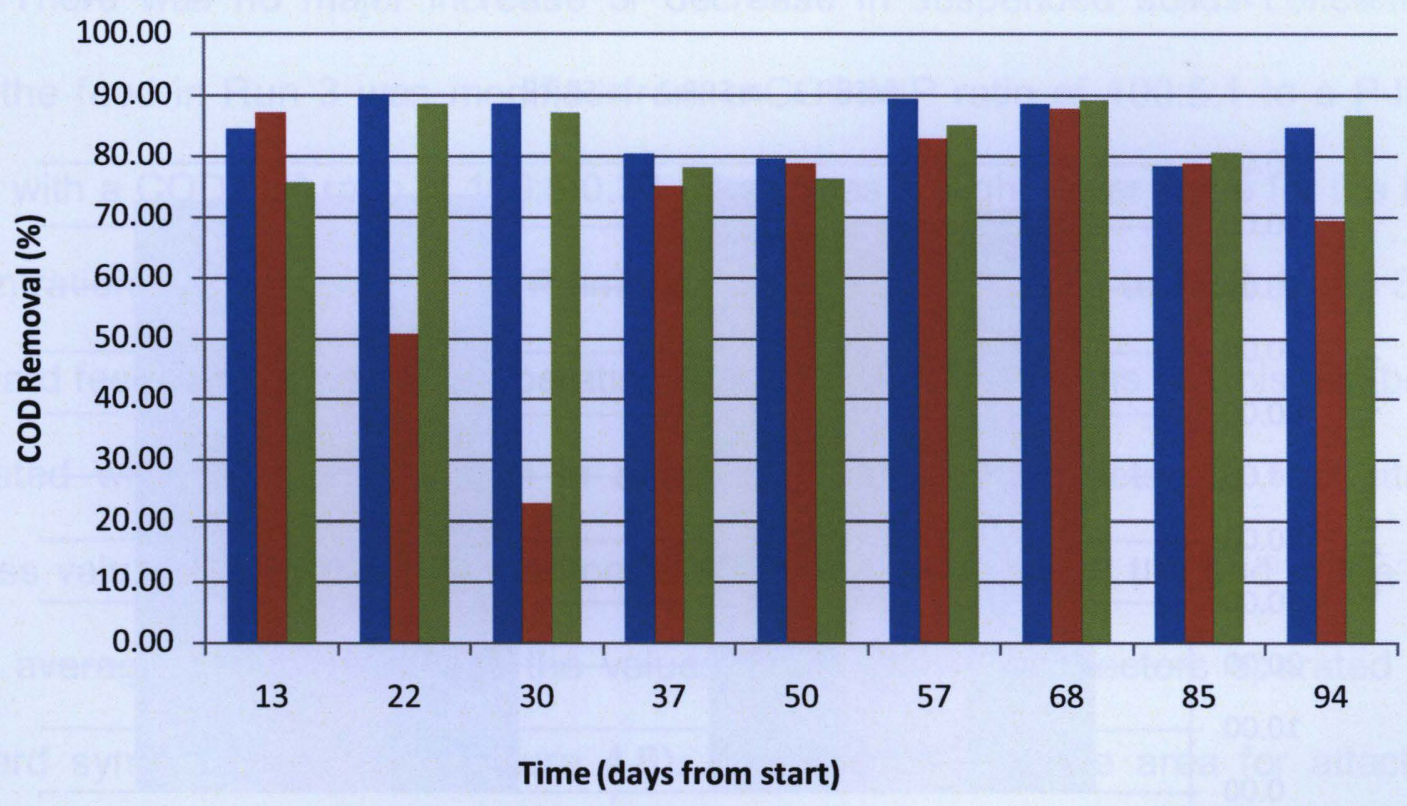

Figure 4.1 Percentage COD removal in the sequencing batch reactors from RUN 1. All three reactors were given a standard synthetic feed with COD:N:P ratio of 100:5:1 and a COD of approximately 500mg/L. 


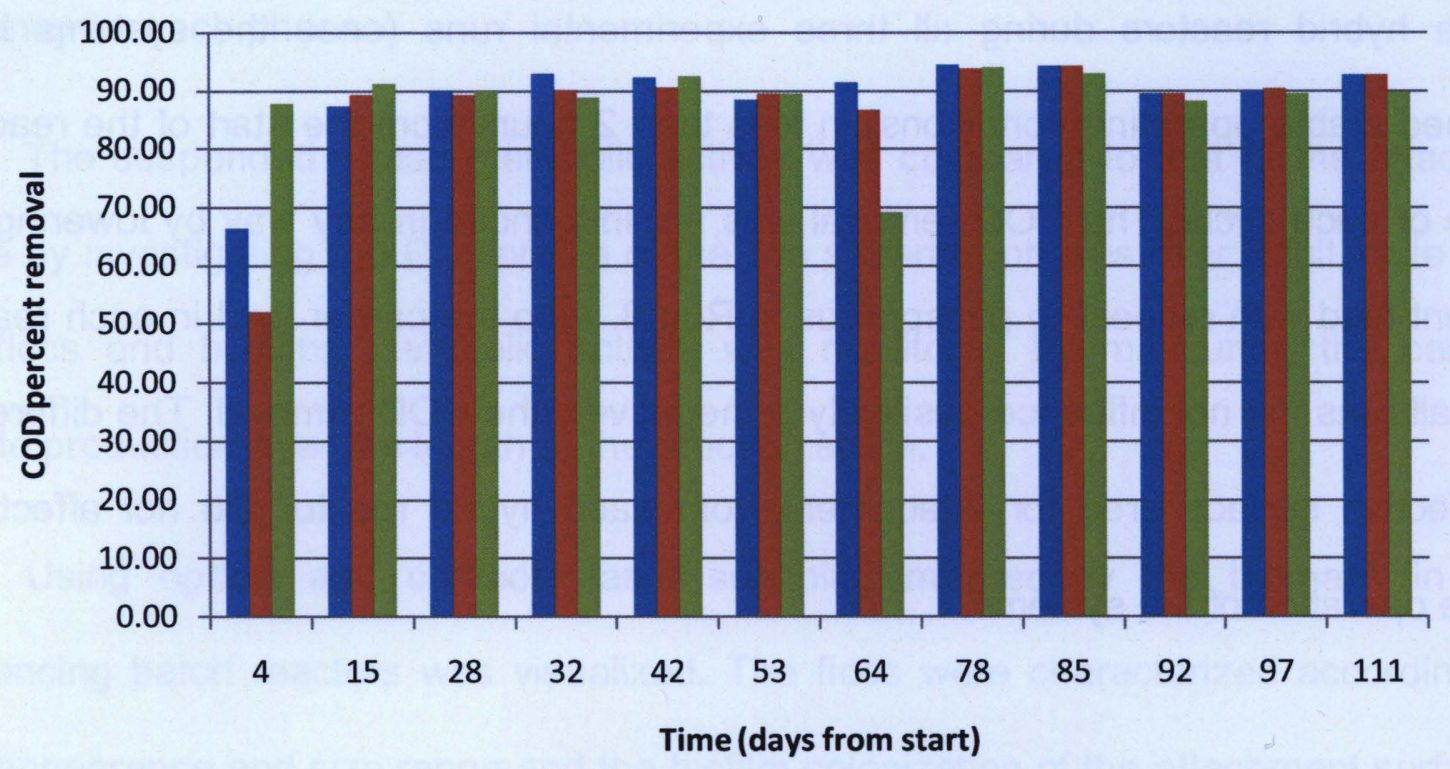

Figure 4.2 Percentage COD removal in the sequencing batch reactors from RUN 2. All three reactors were given a standard synthetic feed with COD:N:P ratio of 100:5:1 and a COD of approximately 500mg/L.

- $\mathrm{SBR} 1$ SBR 2 SBR 3

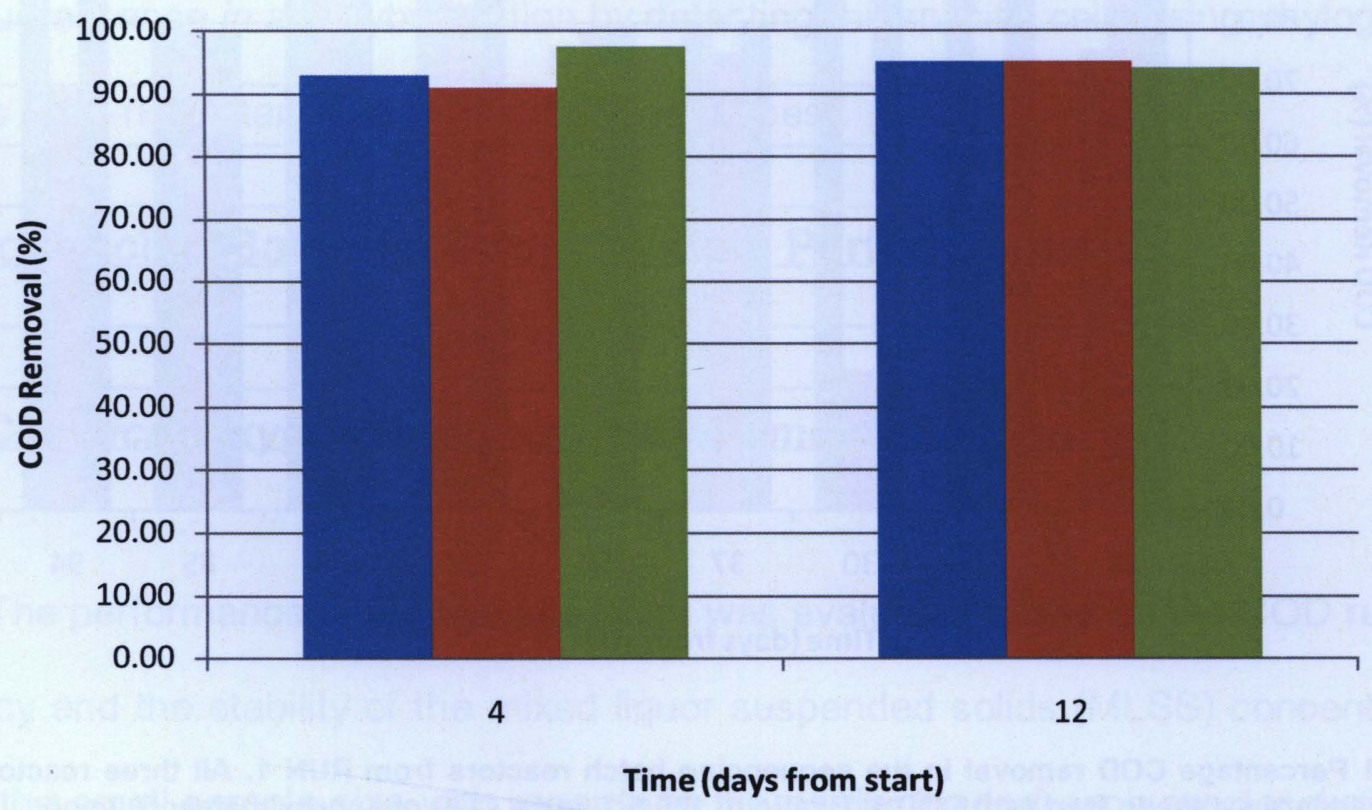

Figure 4.3 Percentage COD removal in the sequencing batch reactors from RUN 3. Reactor 1 and 2 were fed a synthetic wastewater with COD:N:P ratio of 100:5:1 and reactor 3 was given a P-limited feed of COD:N:P ratio of 100:5:0.33 


\subsubsection{Mixed Liquor Suspended Solids (MLSS) and Attached Biomass in the}

Reactors

The MLSS concentrations over time during all three experimental runs are shown in Figures $4.4,4.5$, and 4.6. The figures show an increase in the average MLSS values over time in the reactors in all the runs with the exception of the end period of Run 1 when most of the suspended biomass was accidentally discharged from the reactors. The MLSS concentrations in Run 1 and 2 started to increase after about 30 to 40 days of operation and reach same or even higher concentration of suspended solids to the concentration of the inoculum from the wastewater treatment plant.

There was no major increase or decrease in suspended solids concentration when the feed in Run 3 was modified from a COD:N:P ratio of 100:5:1 to a P-limited media with a COD:N:P ratio of 100:5:0.33. There was a slight lower value for the MLSS concentration recorded in SBR 3 (P-limited conditions) compared to SBR 1 and SBR 2 (standard feed) after 3 weeks of operating under the new conditions but this can be also correlated with the high increase in attached biomass for reactor 3 . The attached biomass values for SBR 3 (P-limited conditions) were recorded at the end of the run to be on average 3 times higher to the values in the other two reactors operated under standard synthetic feed (see Figure 4.8). The effective surface area for attachment provided by the free floating carriers was the same for all three sequencing batch reactors during Run 3 (see Table 3.4 ) and this can only be attributed to the different nutrient load since all the other operating parameters in the reactors were kept constant. 
The attached biomass in Run 1 when the effective surface area for attachment in each reactor varied according to the type and amount of carrier load in each reactor can be observed in Figure 4.7. In this case the sequencing batch reactors were all operated under identical synthetic feed concentrations and the only difference between them was the carrier load. SBR 1 which had a carrier fill ratio of $50 \%$, the same as SBR 2 , had a support surface area of $0.45 \mathrm{~m}^{2}$ and it recorded the highest value $(4.23 \mathrm{~g} / \mathrm{L})$ of attached biomass. The support surface area in SBR 2 was even higher at $0.55 \mathrm{~m}^{2}$ but the average attached biomass value recorded at the end of the run was three time lower $(1.33 \mathrm{~g} / \mathrm{L})$ than in SBR 1 . The difference in attached biomass can be explained by the difference in internal architecture of the carriers present in each reactor. The smaller carriers present in SBR 1 have less complicated design for the internal channels and this might explain the higher biomass accumulation on the inside channels compared to the bigger carriers present in SBR 2. The same trend was observed when the average values of attached biomass from SBR 2 and SBR 3 were compared at the end of Run 1 (see Figure 4.7). The smaller carriers in SBR 3 with an overall smaller support surface area of only $0.225 \mathrm{~m}^{2}$ presented a higher average attached biomass value $(1.61 \mathrm{~g} / \mathrm{L})$ when compared to the values from SBR 2. 


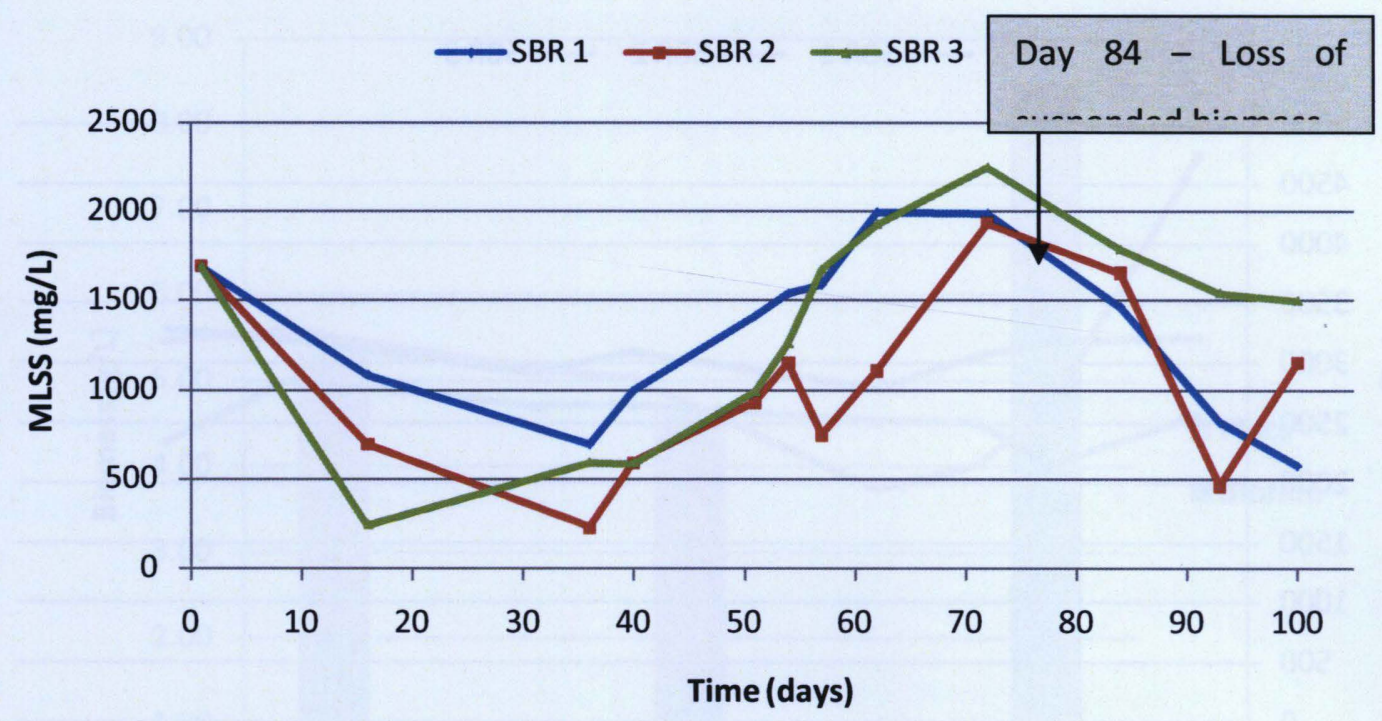

Figure 4.4 Mixed liquor suspended solids (MLSS) profile from the sequencing batch reactor setup in RUN 1.

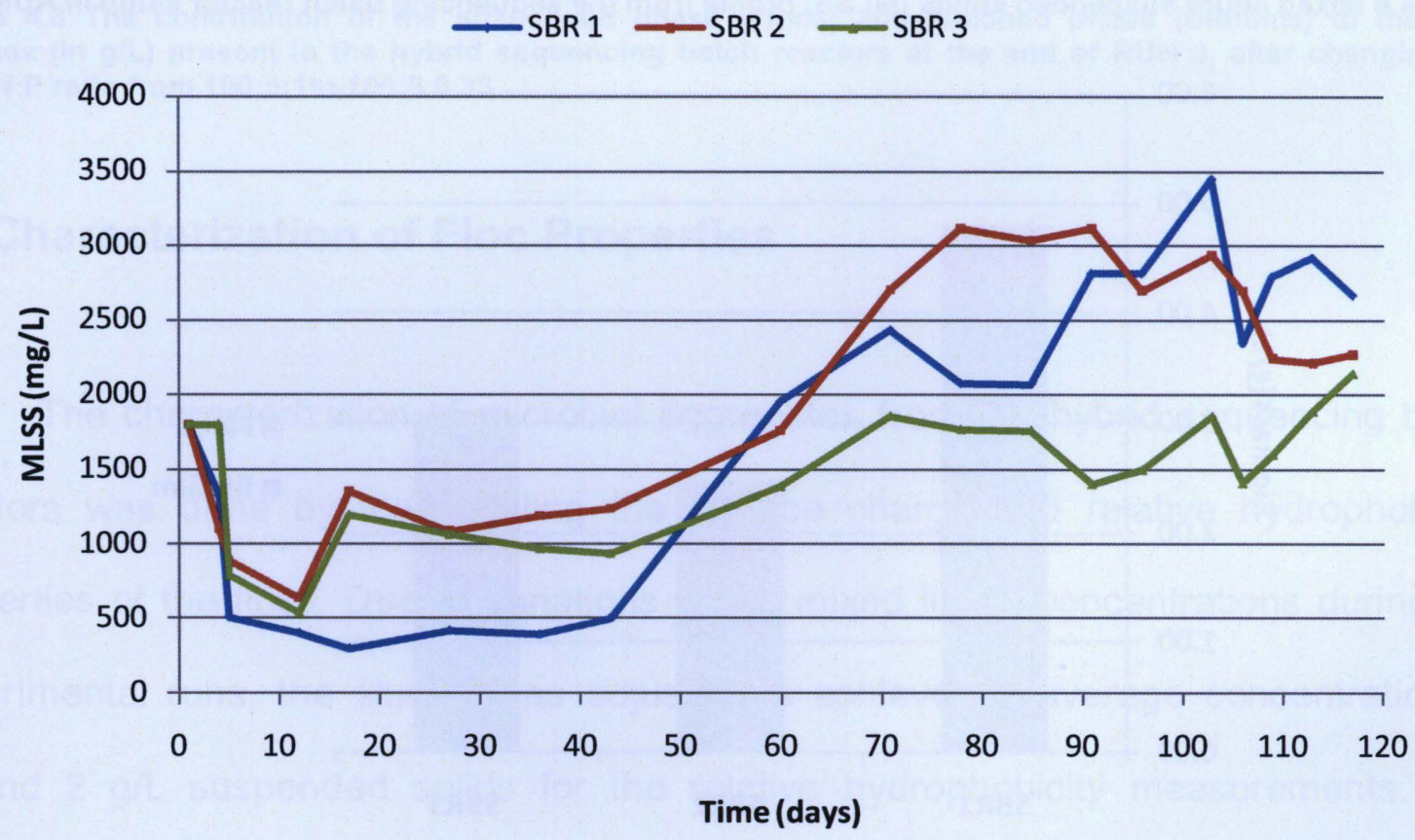

Figure 4.5 Mixed liquor suspended solids (MLSS) profile from the sequencing batch reactor setup in RUN 2. 


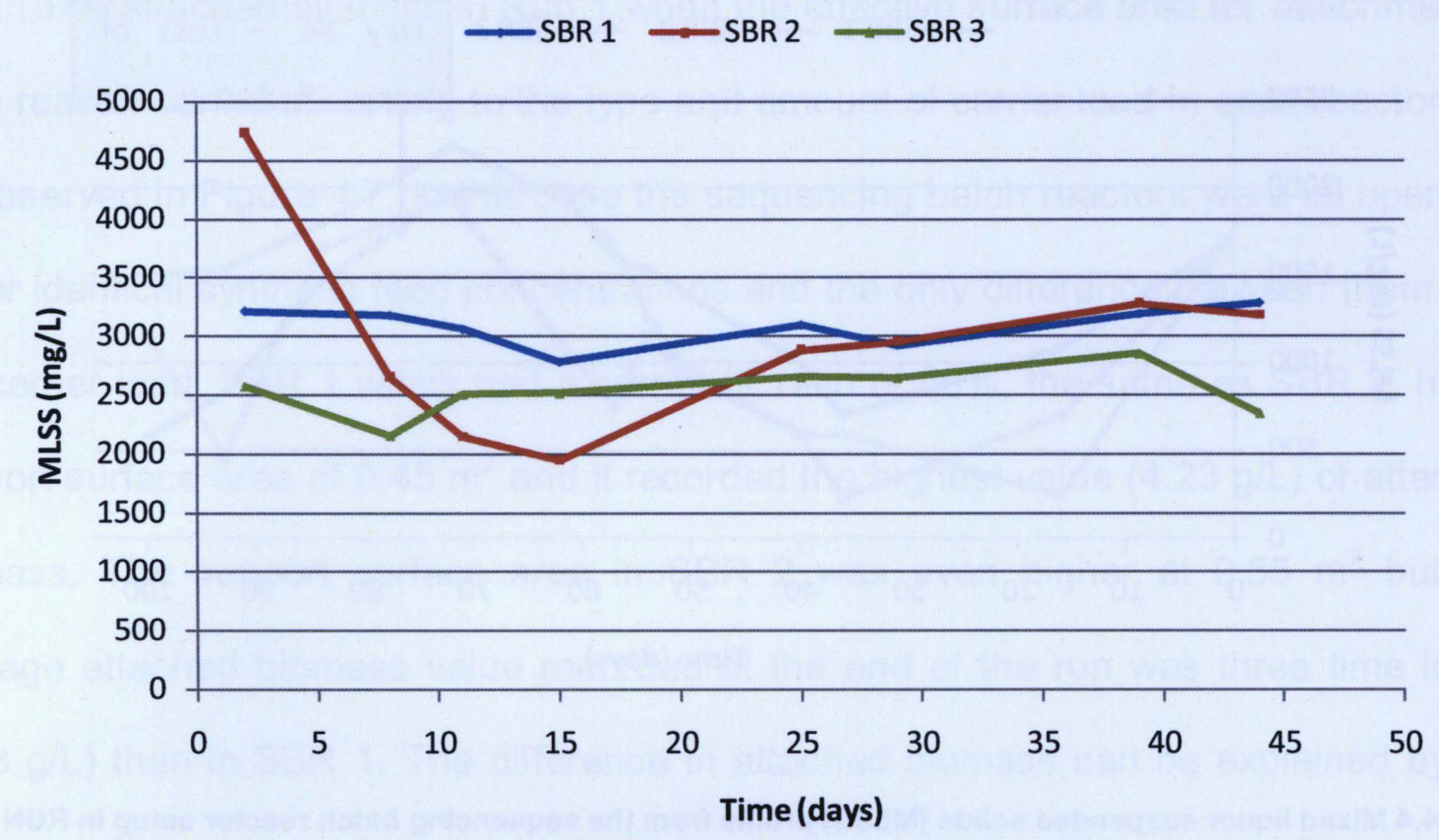

Figure 4.6 Mixed liquor suspended solids (MLSS) profile from the sequencing batch reactor setup in RUN 3.

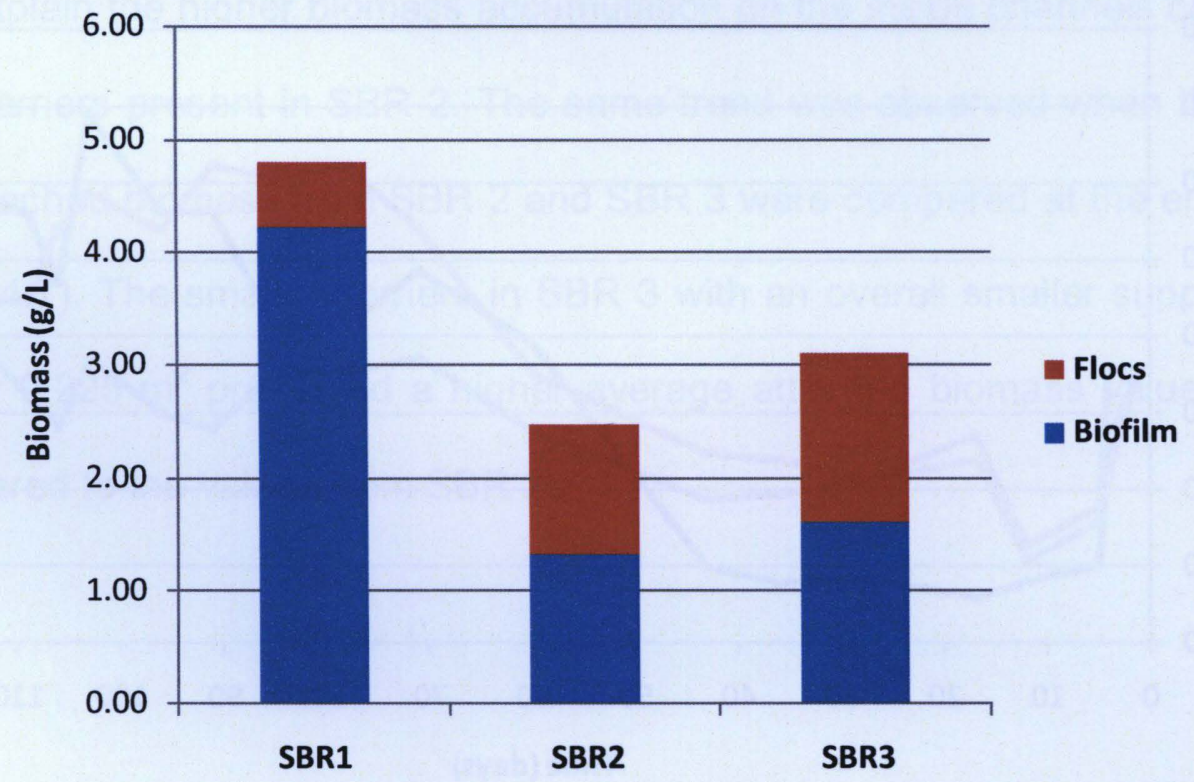

Figure 4.7 The contribution of the suspended phase (Flocs) and attached phase (Biofilms) to the total biomass (in $\mathrm{g} / \mathrm{L}$ ) present in the hybrid sequencing batch reactors at the end of RUN 1. 


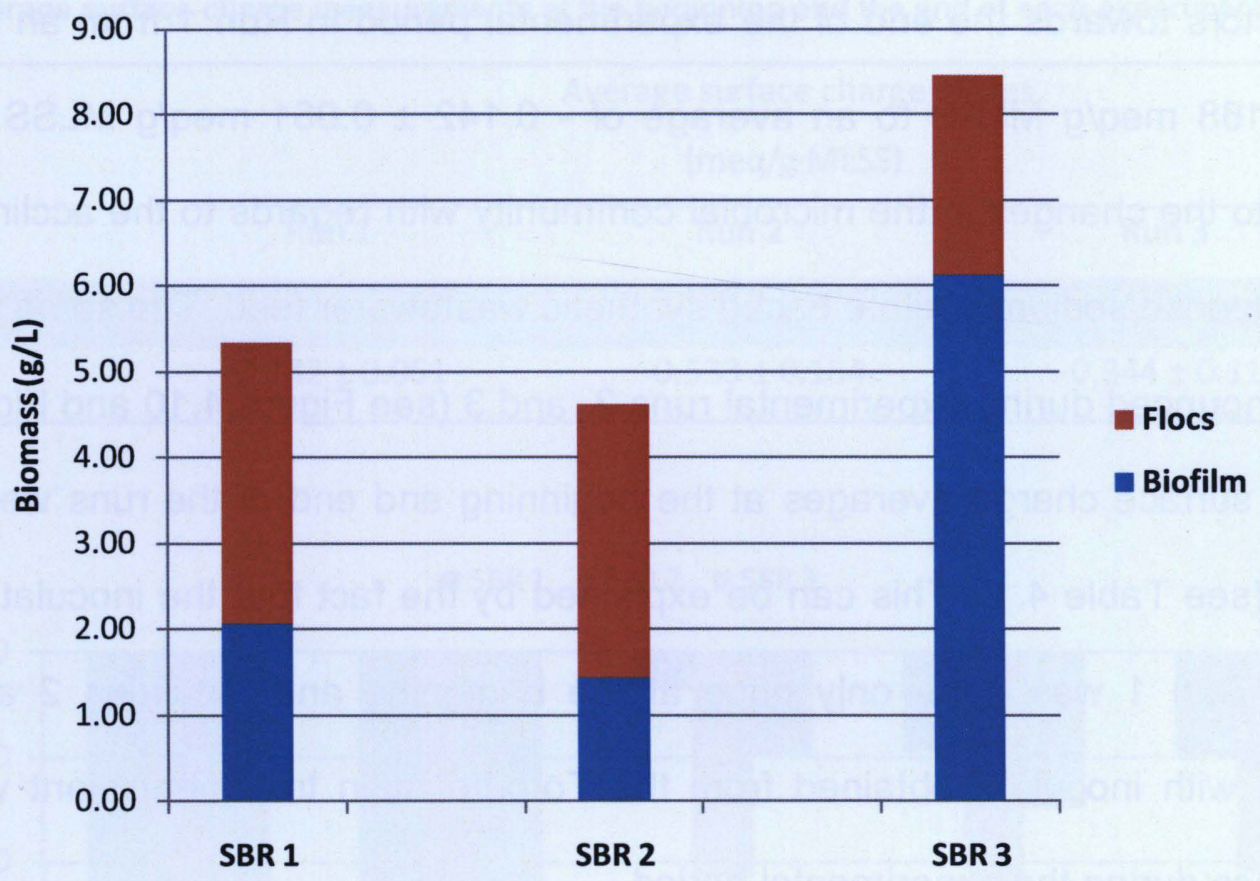

Figure 4.8 The contribution of the suspended phase (Flocs) and attached phase (Biofilms) to the total biomass (in $\mathrm{g} / \mathrm{L}$ ) present in the hybrid sequencing batch reactors at the end of RUN 3, after changing the COD:N:P ratio from 100:5:1 to 100:5:0.33.

\subsection{Characterization of Floc Properties}

The characterization of microbial aggregates from the hybrid sequencing batch reactors was done by investigating the surface charge and relative hydrophobicity properties of the flocs. Due to variations in the mixed liquor concentrations during the experimental runs, the sludge was adjusted to achieve an average concentration of around $2 \mathrm{~g} / \mathrm{L}$ suspended solids for the relative hydrophobicity measurements. The surface charge measurements were done at the original suspended solids concentration for all the reactors. As it can be seen from Figure 4.9 the surface charge was at higher negative values at the beginning of the experimental run and decreased by the end in all three reactors. This increase in net negative charge in the sequencing 
batch reactors towards the end of the experimental period in Run 1 from an average $0.424 \pm 0168 \mathrm{meq} / \mathrm{g}$ MLSS to an average of $-0.142 \pm 0.061 \mathrm{meq} / \mathrm{g}$ MLSS could be attributed to the changes in the microbial community with regards to the acclimatization to a new glucose/sodium acetate based synthetic wastewater feed. The same trend was not so pronounced during experimental runs 2 and 3 (see Figure 4.10 and Figure 4.11) where the surface charge averages at the beginning and end of the runs were almost the same (see Table 4.1). This can be explained by the fact that the inoculation of the system in Run 1 was done only once at the beginning and for Runs 2 and 3 the inoculation with inoculum obtained from the Toronto main treatment plant was done several times during the experimental period.

There was no significant difference in surface charge values when comparing the effect of phosphorus limited conditions in Run 3 during the first three weeks of operation. The surface charge of the microbial flocs in SBR 1 which was supplied with a standard feed having a COD:N:P ratio of 100:5:1 was around the same values to the flocs in SBR 3 which was fed a P-limited synthetic wastewater with a COD:N:P ratio of 100:5:0.33. Towards the end of the experimental Run 3 the surface charge of the flocs in the P-limited hybrid reactor was observed to have become more negative compared to the reactors fed with standard synthetic feed. These finding are contrary to the findings of Bura et al. (1998) where the microbial flocs from sequencing batch reactors treating synthetic wastewater using the activated sludge process presented a decrease under P-limited and P-depleted conditions. 
Table 4.1 Average surface charge measurements at the beginning and the end of each experimental run.

Average surface charge values

(meq/g MLSS)

Run 1 Run 2 Run 3

\begin{tabular}{llll} 
Beginning of Run & $-0.424 \pm 0.168$ & $-0.561 \pm 0.423$ & $-0.347 \pm 0.125$ \\
\hline End of Run & $-0.142 \pm 0.061$ & $-0.533 \pm 0.184$ & $-0.344 \pm 0.111$
\end{tabular}

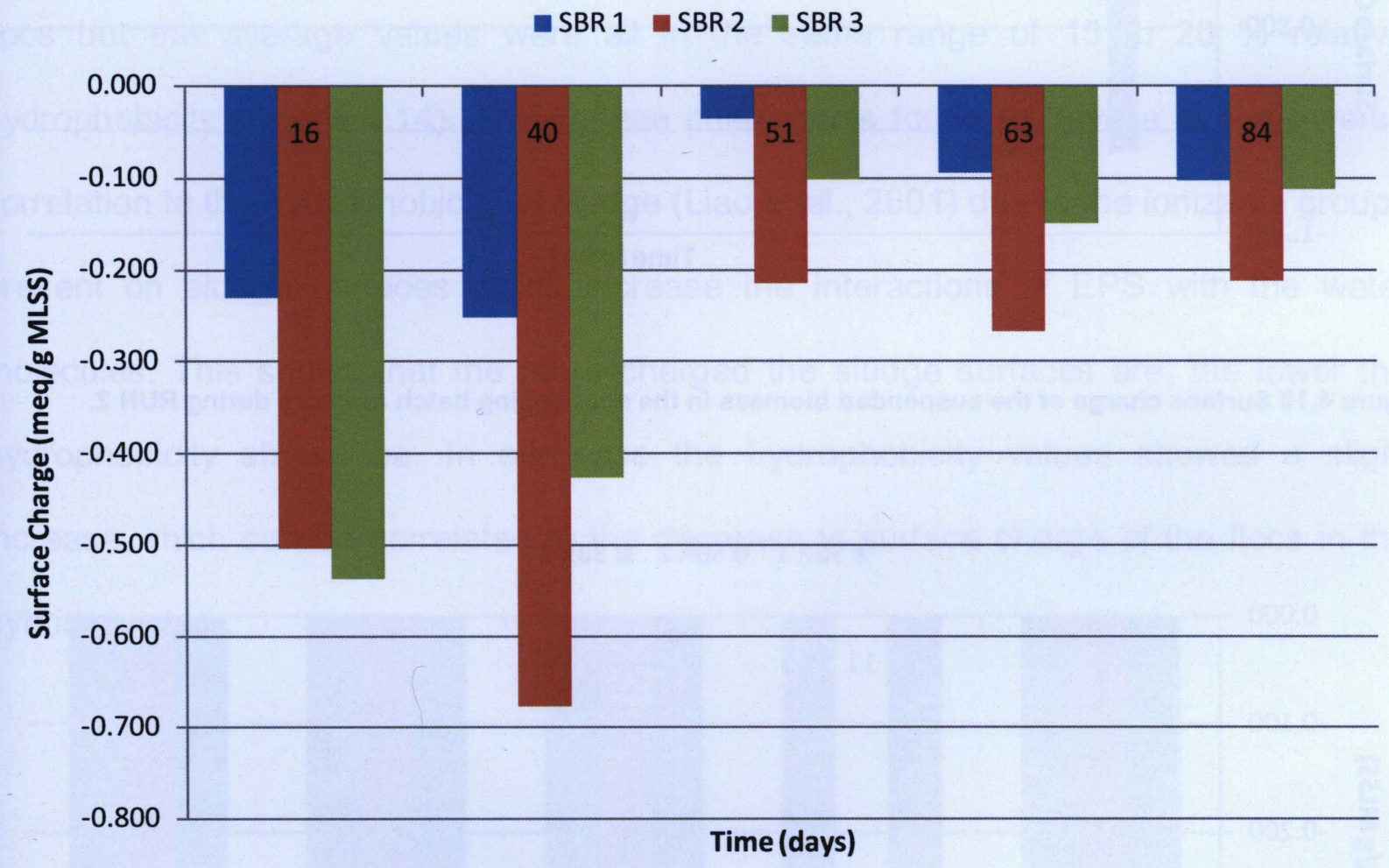

Figure 4.9 Surface charge of the suspended biomass in the sequencing batch reactors during RUN 1. 
$=\mathrm{SBR} 1=\mathrm{SBR} 2=\mathrm{SBR} 3$

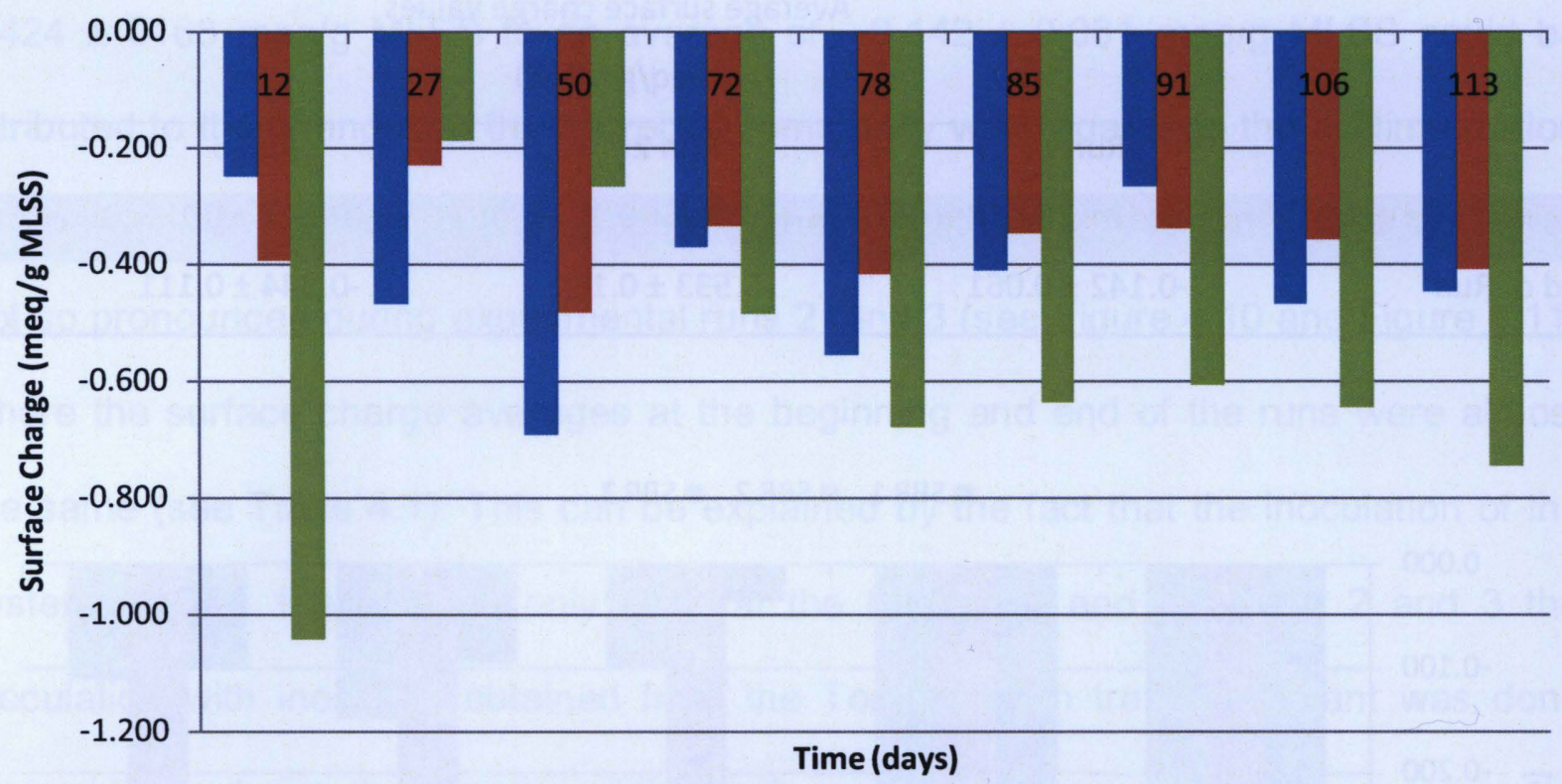

Figure 4.10 Surface charge of the suspended biomass in the sequencing batch reactors during RUN 2.

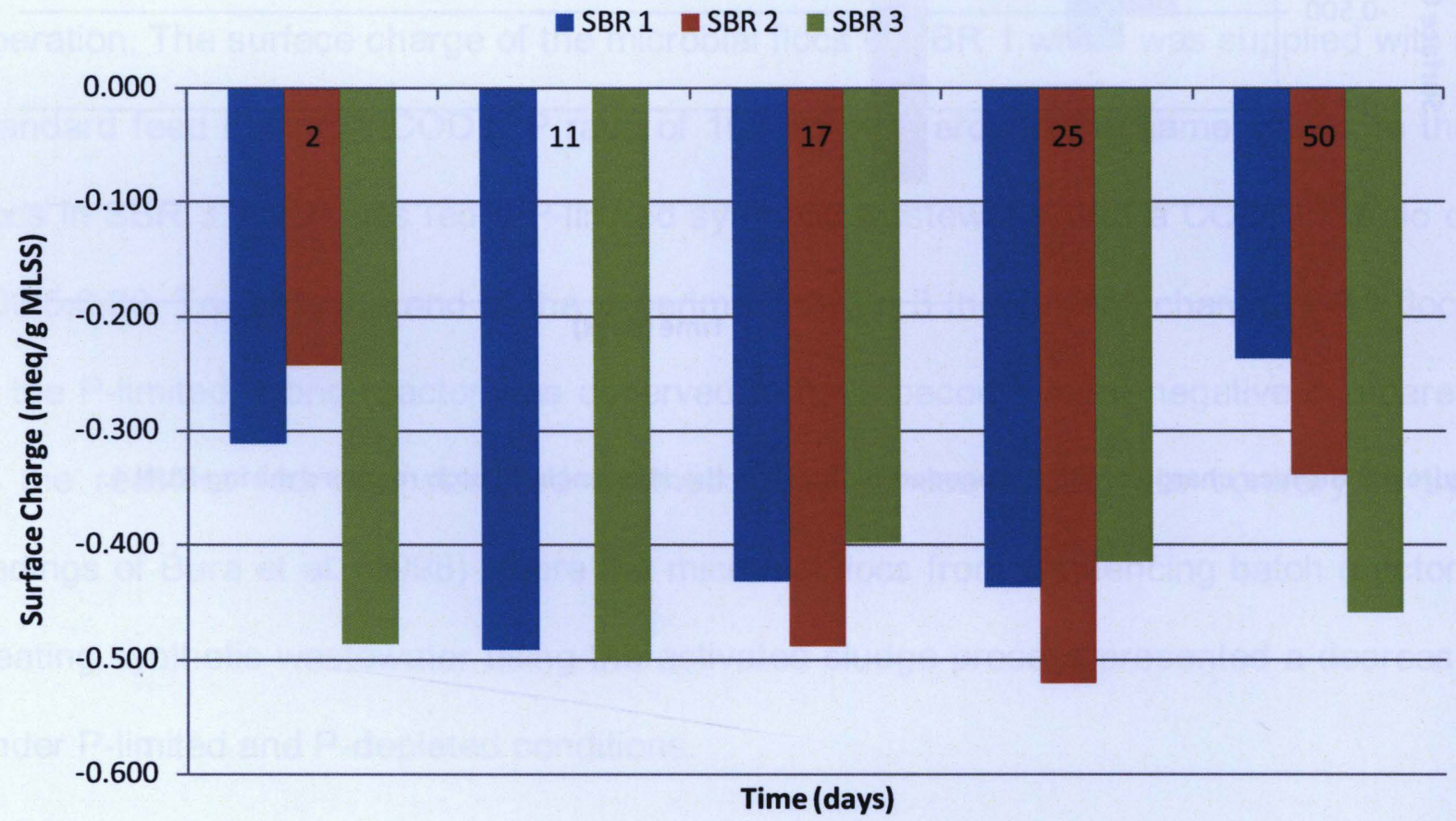

Figure 4.11 Surface charge of the suspended biomass in the sequencing batch reactors during RUN 3. 
The relative hydrophobicity values shown a general trend of increase during the experimental period of the first two runs in all the reactors with the exception of SBR 2 during Run 1 when the relative hydrophobicity decreased to about half the value when compared to the other two reactors (Figure 4.12 and Figure 4.13). The last experimental run when the nutrient conditions were changed between reactors all three sequencing batch reactors showed a slight decrease of the relative hydrophobicity of the microbial flocs but the average values were all in the same range of 15 to $20 \%$ relative hydrophobicity (Figure 4.14). The surface charge was found to have a strong inverse correlation to the hydrophobicity of sludge (Liao et al., 2001) due to the ionizable groups present on sludge surfaces which increase the interactions of EPS with the water molecules. This shows that the more charged the sludge surfaces are, the lower the hydrophobicity should be. In our case the hydrophobicity values showed a slight increase which can be correlated to the decrease in surface charge of the flocs in the hybrid reactors. 
-SBR $1=$ SBR $2=S B R 3$

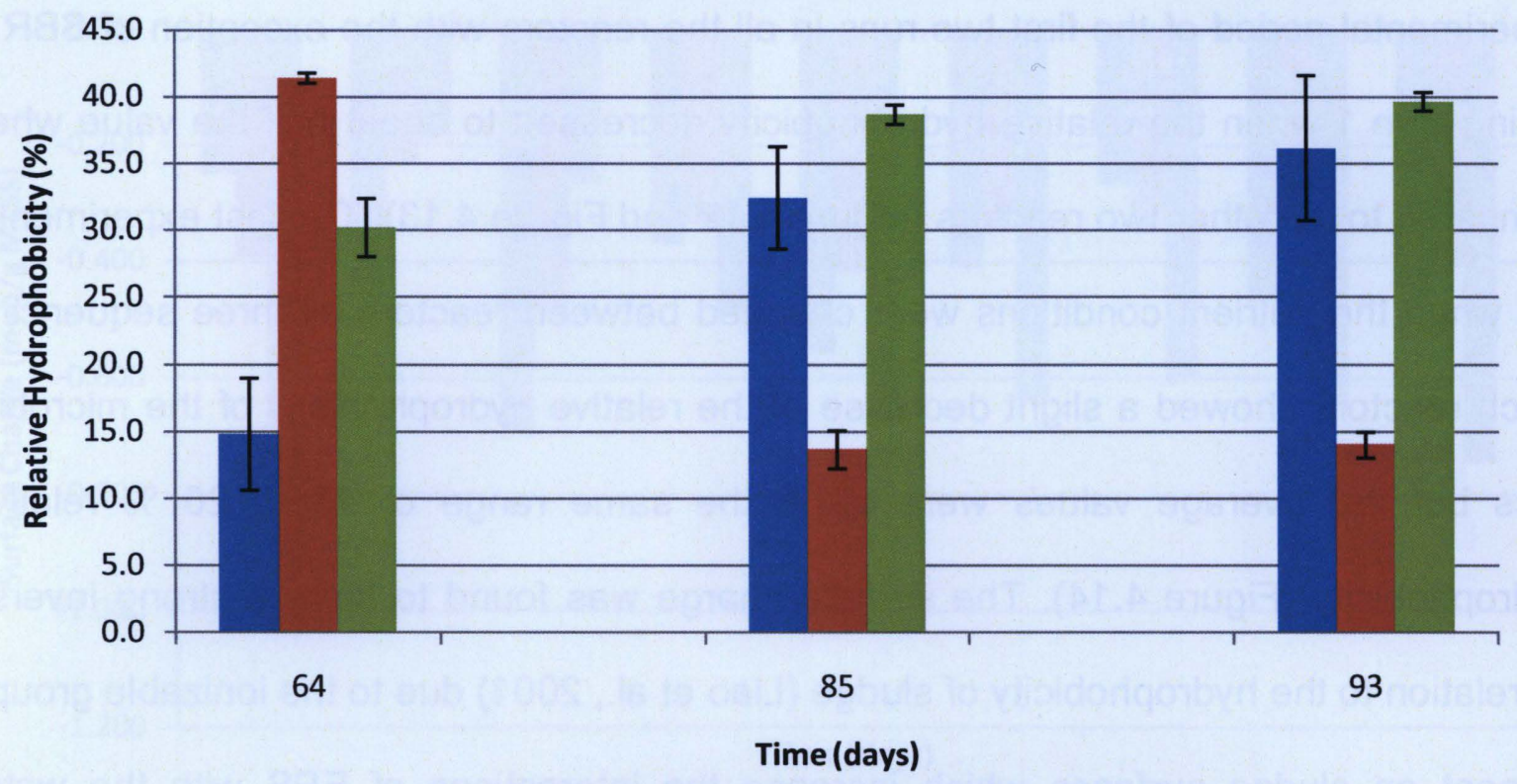

Figure 4.12 Relative hydrophobicity of the suspended biomass in the sequencing batch reactors during RUN 1.

\section{-SBR 1 SBR 2 SBR 3}

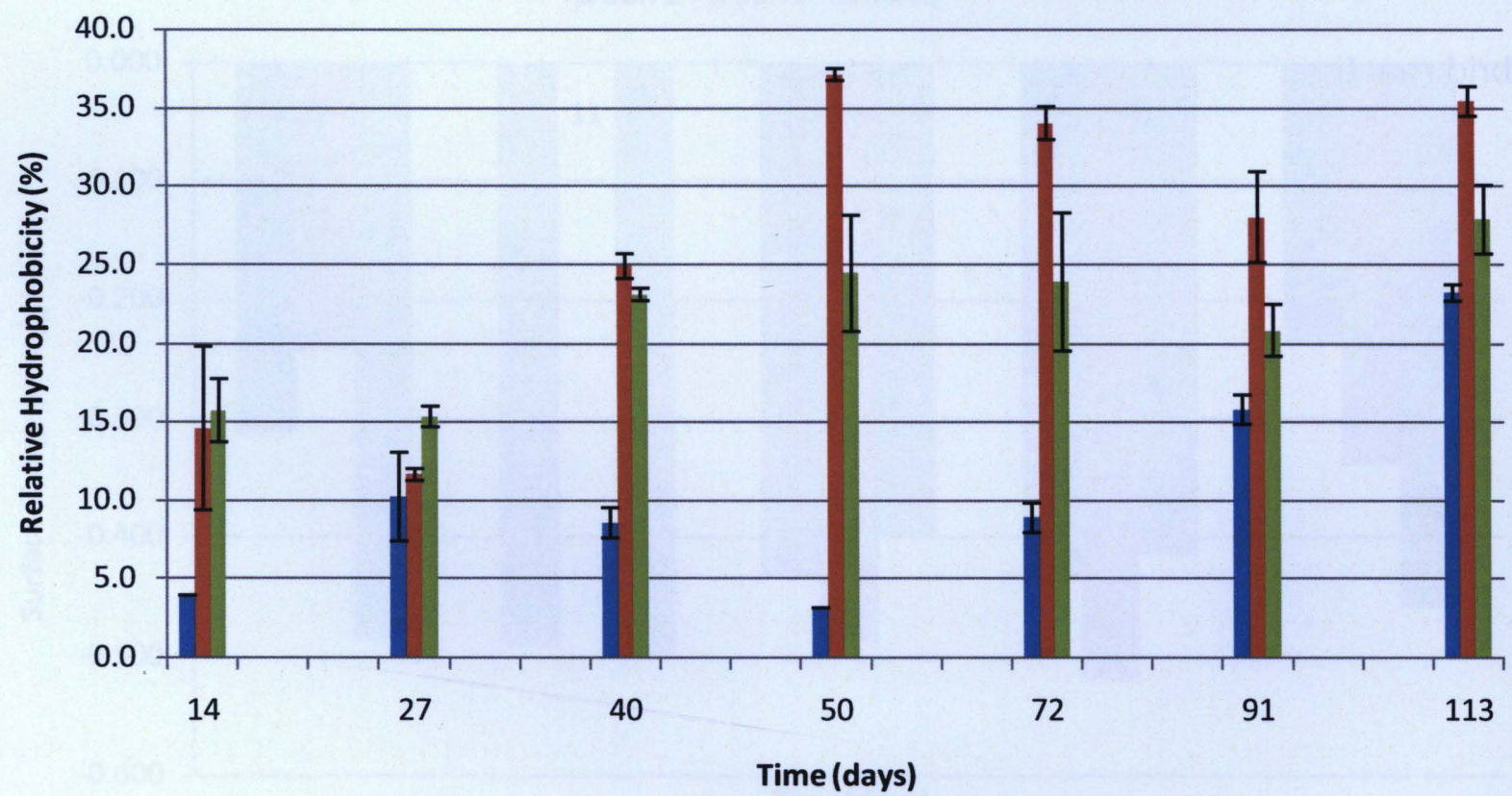

Figure 4.13 Relative hydrophobicity of the suspended biomass in the sequencing batch reactors during RUN 2. 


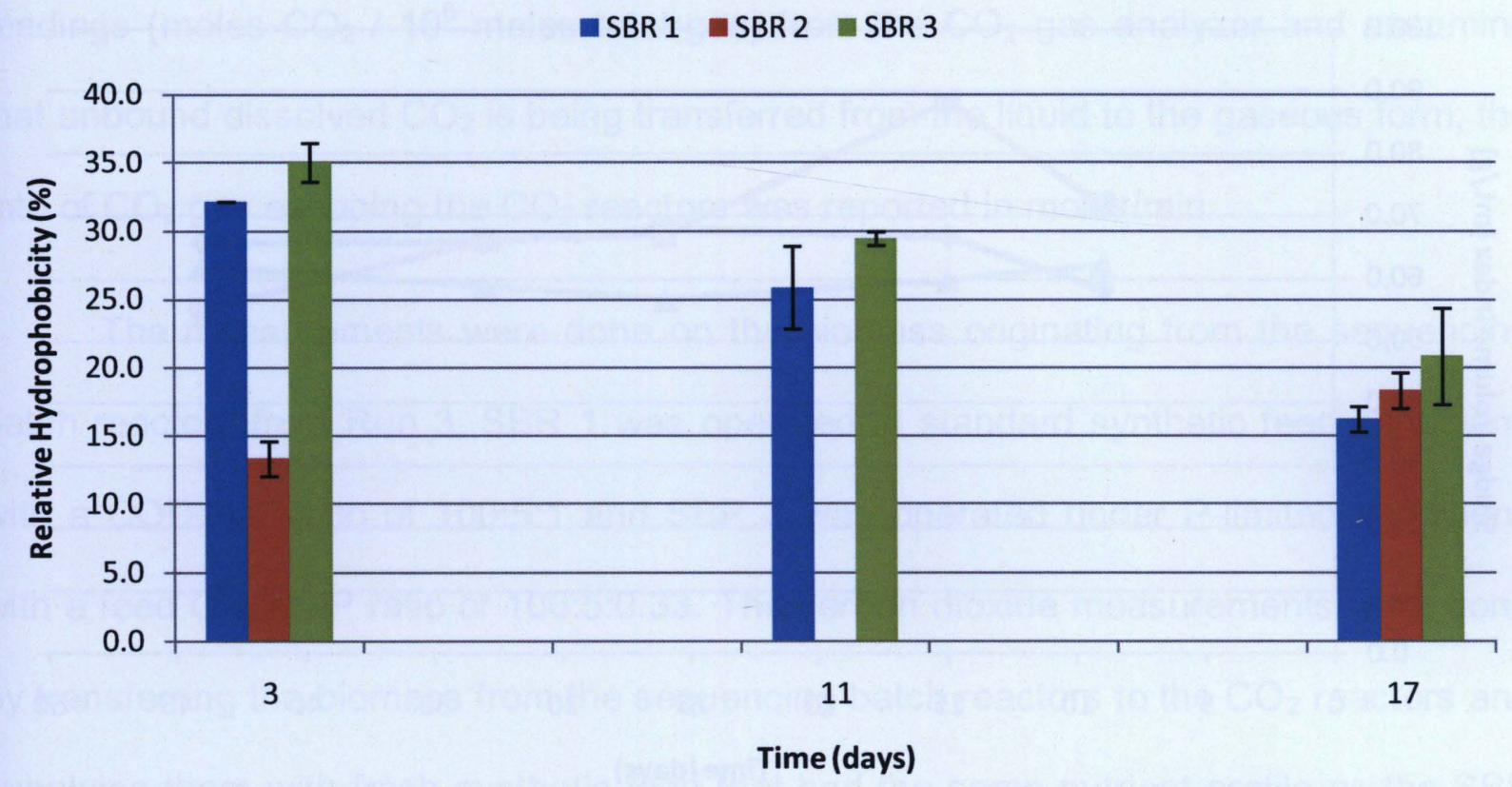

Figure 4.14 Relative hydrophobicity of the suspended biomass in the sequencing batch reactors during RUN 3.

The sludge volume index was measured to test the compressibility of sludge from the three sequencing batch reactors operated under different nutrient conditions but identical carrier load in Run 3. The sludge volume index showed constant values for all three reactors and could not be compared to the change recorded in the surface charge and hydrophobicity measurements of the flocs from any of the hybrid reactors in Run 3. The same finding were observed for activated sludge treated using sequencing batch reactors operated at different sludge retention times where there was no correlation between the SVI and the hydrophobicity or between the SVI and surface charge of flocs (Liao, 2000). 


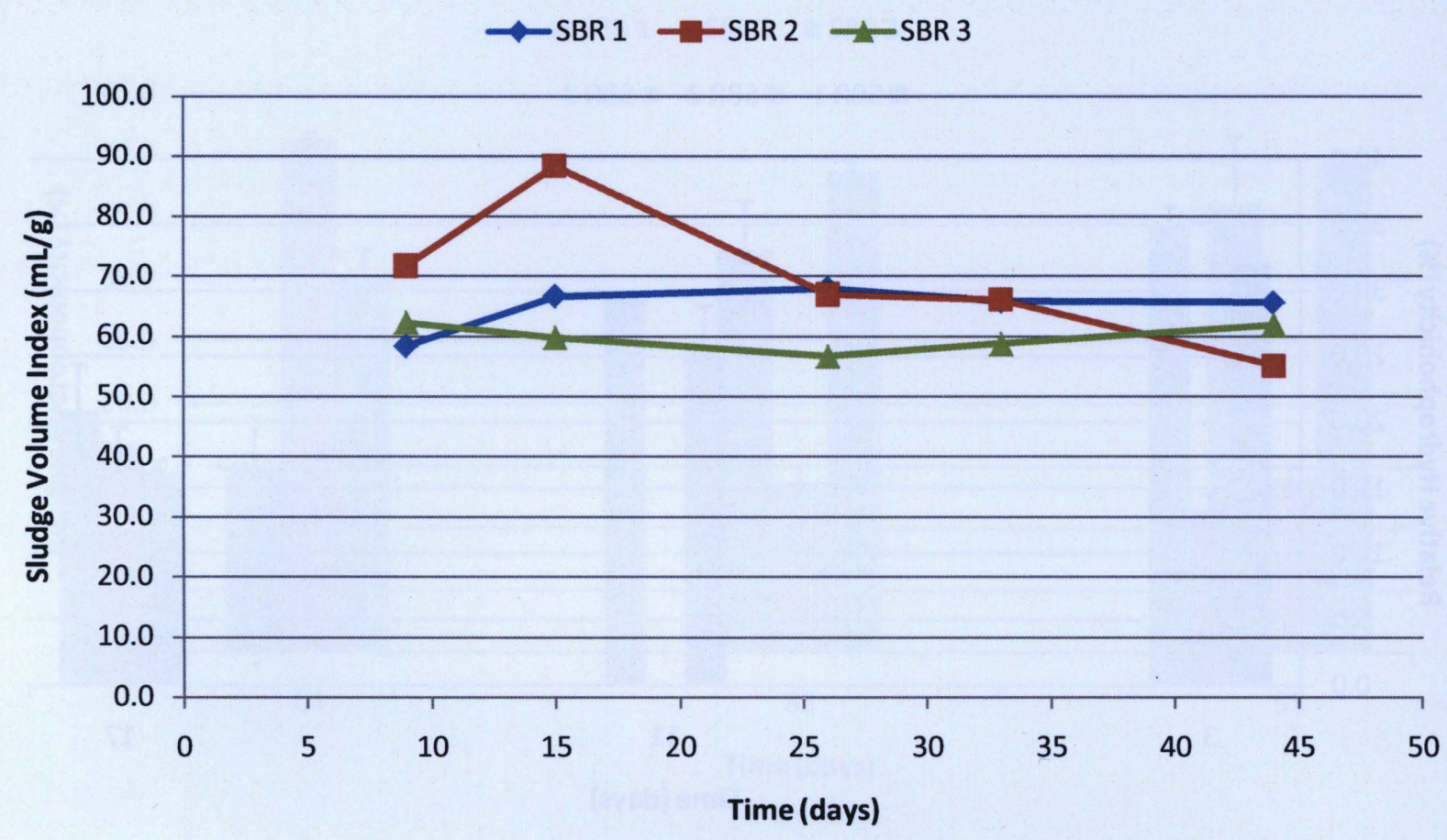

Figure 4.15 Sludge volume index of the sludge from the sequencing batch reactors in RUN 3. SBR 1 and SBR 2 were fed standard synthetic feed with COD:N:P ratio of 100:5:1 and SBR 3 was P-limited with a COD:N:P ratio of 100:5:0.33

\section{$4.3 \mathrm{CO}_{2}$ profile of the biomass from the SBR system}

Carbon dioxide measurements were used as a direct quantitative method to evaluate the metabolic activity of the biomass from the reactors, the attached phase (biofilms) and the suspended phase (microbial flocs), during the reaction stage.

Carbon dioxide was measured with an infrared gas analyzer as parts per million units from the total gas leaving the $\mathrm{CO}_{2}$ reactors (see Figure 3.5 ) at $1 \mathrm{~L} / \mathrm{min}$. The temperature $(T=324.60 \mathrm{~K})$, and pressure $\left(p=100.50 \times 10^{3} \mathrm{~N} / \mathrm{m}^{2}\right)$ are kept constant in the gas analyzer measuring unit and using the equation of state for ideal gases the total gas molar volume $\mathrm{V} / \mathrm{n}=\mathrm{RT} / \mathrm{p}=26.85 \times 10^{3} \mathrm{ml} / \mathrm{mol}$ (where gas constant $\mathrm{R}=8.314$ 
$\mathrm{Nm} / \mathrm{molK}$ ) was calculated. With a constant gas flow of $1 \mathrm{~L} / \mathrm{min}$ and factoring the ppm readings (moles $\mathrm{CO}_{2} / 10^{6}$ moles total gas) from the $\mathrm{CO}_{2}$ gas analyzer and assuming that unbound dissolved $\mathrm{CO}_{2}$ is being transferred from the liquid to the gaseous form, the rate of $\mathrm{CO}_{2}$ gas escaping the $\mathrm{CO}_{2}$ reactors was reported in moles/min.

The measurements were done on the biomass originating from the sequencing batch reactors from Run 3. SBR 1 was operated at standard synthetic feed conditions with a COD:N:P ratio of 100:5:1 and SBR 3 was operated under P-limited conditions with a feed COD:N:P ratio of 100:5:0.33. The carbon dioxide measurements were done by transferring the biomass from the sequencing batch reactors to the $\mathrm{CO}_{2}$ reactors and supplying them with fresh synthetic feed that had the same nutrient profile as the SBR that the biomass originated from. The $\mathrm{CO}_{2}$ reactors were operated in batch mode for the duration of the reaction phase and all the gas coming out of the system was passed through the $\mathrm{CO}_{2}$ gas analyzer. The $\mathrm{CO}_{2}$ reactors filled with the synthetic feed but not inoculated with biomass from the SBRs were first connected to the $\mathrm{CO}_{2}$ gas analyzer and the base line reading of the sweeper gas was recorded and later subtracted from the measurements of the biofilms and flocs. The sweeper gas flow rate was kept constant throughout all the measurements at $1 \mathrm{~L} / \mathrm{min}$.

The concentration of carbon dioxide gas from biofilms on the carriers from SBR 1 was reported in $\mu \mathrm{mol} / \mathrm{min}$ for the samples collected at different instances from the sequencing batch reactors (Figure 4.16). The carriers were sampled at the beginning ( 30 minutes) of the reaction stage and in the middle of the reaction stage ( 3 hours) from the sequencing batch reactors. The $\mathrm{CO}_{2}$ profile showed similar trends with an initial increase in carbon dioxide gas production $\left(7-8 \mu \mathrm{mol} / \mathrm{min} \mathrm{CO}_{2}\right.$ after only 15 minutes $)$ due 
to higher metabolic activity corresponding with the higher availability of nutrients. As the nutrients were depleting the $\mathrm{CO}_{2}$ production decreased and after approximately 2 hours the production was at only $2 \mu \mathrm{mol} / \mathrm{min}$ carbon dioxide. There was an increase in metabolic activity at 2 hours into the reaction stage which cannot be explained by the presence of nutrients in the feed because the organic compounds in the synthetic feed were below detection limit after 2 hours by measuring the chemical oxygen demand. One explanation for the increase in metabolic activity could be the presence of nutrient reserves trapped in the EPS matrix of the biofilms that the microorganisms could feed on after the organic matter in the feed was depleted.

The microbial flocs originating from SBR 1 were collected from the sequencing batch reactors at the beginning (30 minutes) of the reaction stage (Figure 4.17). The CO2 gas profile shows an increased metabolic activity at the beginning of the experiment followed by constant decrease in metabolic activity towards the end. In the case of flocs there is no significant increase in metabolic activity after the organic material from the synthetic feed is depleted at around 2 hours into the experiment. The high concentration of carbon dioxide gas recorded in the first $15-20$ minutes at the start of the experiment was attributed to the high amount of dissolved $\mathrm{CO}_{2}$ accumulating in the reactor while the flocs were settling for sampling. 


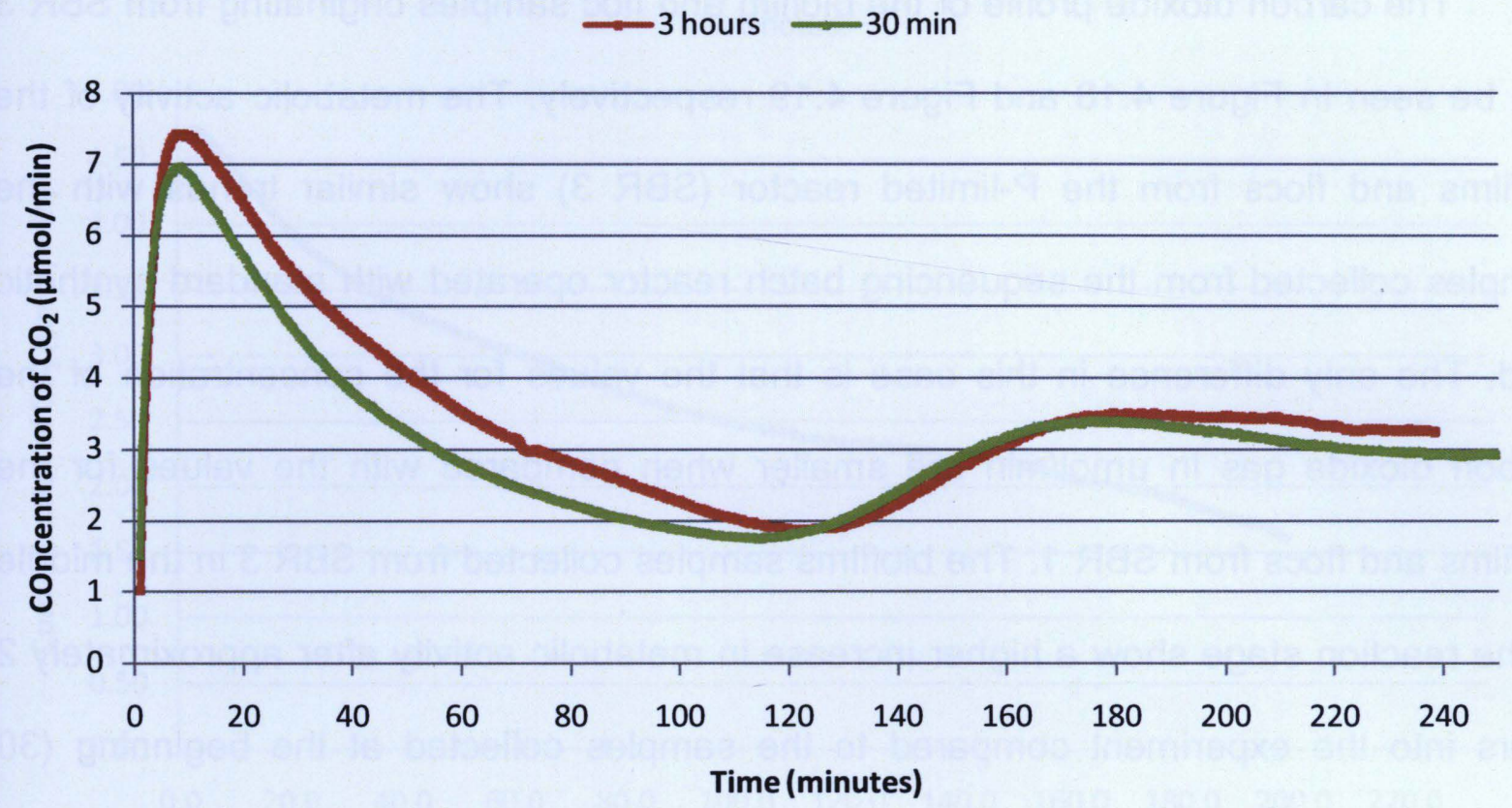

Figure 4.16 $\mathrm{CO}_{2}$ profile of biofilm on carriers from SBR1 during RUN 3. The carriers covered with biofilms were obtained from SBR 1 at 30 minutes and 3 hours respectively after the start of a new reaction cycle.

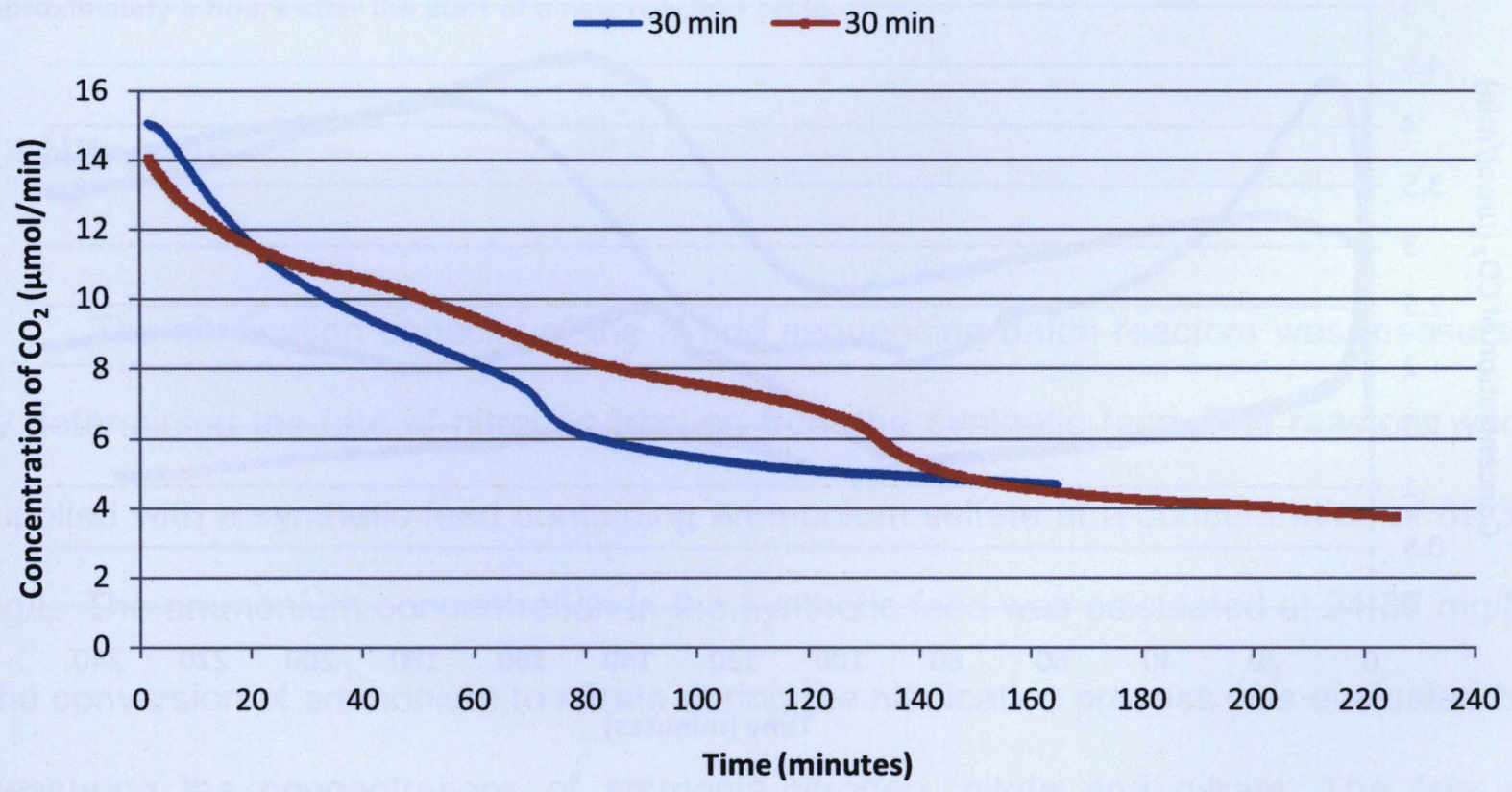

Figure 4.17 $\mathrm{CO}_{2}$ profile of flocs from SBR1 during RUN 3. The mixed liquor was obtained from SBR 1 approximately 30 minutes after the start of a new reaction cycle. 
The carbon dioxide profile of the biofilm and floc samples originating from SBR 3 can be seen in Figure 4.18 and Figure 4.19 respectively. The metabolic activity of the biofilms and flocs from the P-limited reactor (SBR 3) show similar trends with the samples collected from the sequencing batch reactor operated with standard synthetic feed. The only difference in this case is that the values for the concentration of the carbon dioxide gas in $\mu \mathrm{mol} / \mathrm{min}$ are smaller when compared with the values for the biofilms and flocs from SBR 1. The biofilms samples collected from SBR 3 in the middle of the reaction stage show a higher increase in metabolic activity after approximately 2 hours into the experiment compared to the samples collected at the beginning (30 minutes) or the end (6 hours) of the reaction stage.

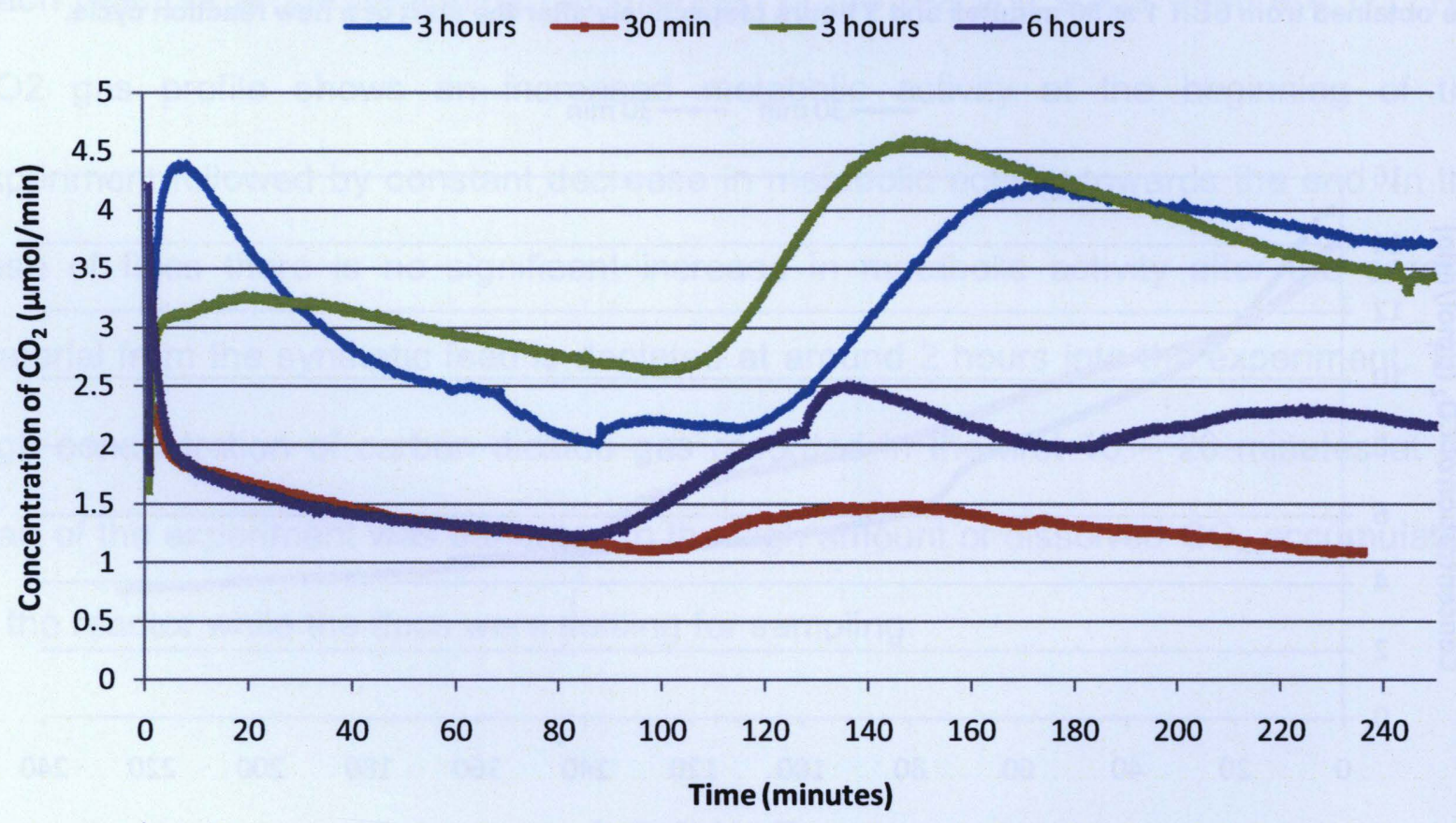

Figure $4.18 \mathrm{CO}_{2}$ profile of biofilm on carriers from SBR 3 during RUN 3. The carriers covered with biofilms were obtained from SBR 3 at $\mathbf{3 0}$ minutes, 3 hours and 6 hours respectively after the start of a new reaction cycle. 


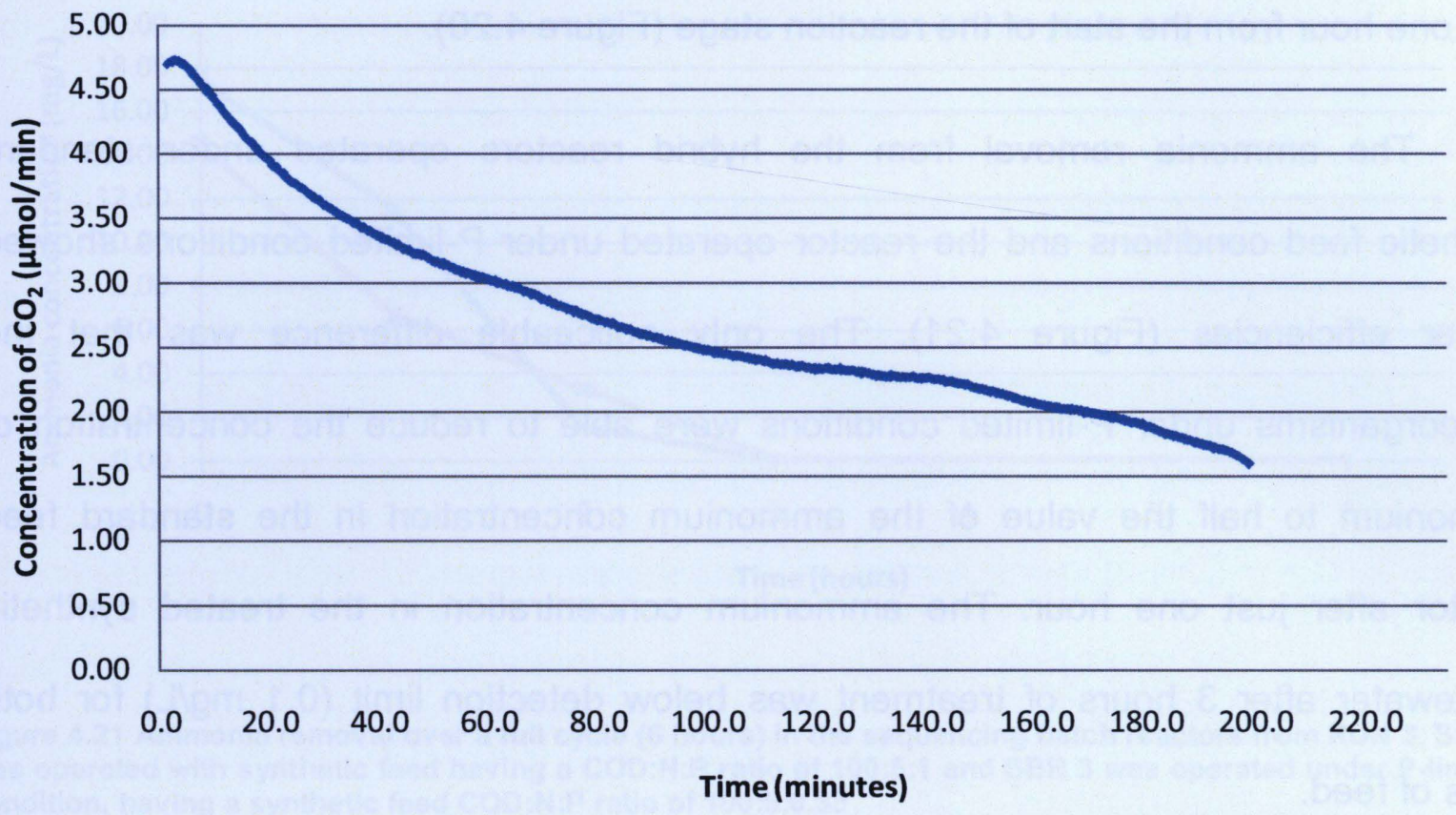

Figure $4.19 \mathrm{CO}_{2}$ profile of flocs from SBR 3 during RUN 3. The mixed liquor sample was obtained from SBR 3 approximately 6 hours after the start of a new reaction cycle.

\subsection{Nitrogen}

The nitrification capacity of the hybrid sequencing batch reactors was measured by determining the fate of nitrogen fraction from the synthetic feed. The reactors were supplied with a synthetic feed containing ammonium sulfate at a concentration of 89.33 $\mathrm{mg} / \mathrm{L}$. The ammonium concentration in the synthetic feed was calculated at $24.37 \mathrm{mg} / \mathrm{L}$. The conversion of ammonium to nitrate during the nitrification process was evaluated by measuring the concentrations of ammonia-nitrogen, nitrite and nitrate. The fate of ammonia-nitrogen during the nitrification depends on the rate in which the ammonia oxidizing bacteria $(\mathrm{AOB})$ convert the ammonia to nitrite through oxidation. The biomass consisting of both suspended and attached phase from the three sequencing batch 
reactors during Run 2 was capable of an average $90 \%$ removal rate of ammonia after only one hour from the start of the reaction stage (Figure 4.20).

The ammonia removal from the hybrid reactors operated under standard synthetic feed conditions and the reactor operated under P-limited conditions showed similar efficiencies (Figure 4.21). The only noticeable difference was that the microorganisms under P-limited conditions were able to reduce the concentration of ammonium to half the value of the ammonium concentration in the standard feed reactor after just one hour. The ammonium concentration in the treated synthetic wastewater after 3 hours of treatment was below detection limit $(0.1 \mathrm{mg} / \mathrm{L})$ for both types of feed.

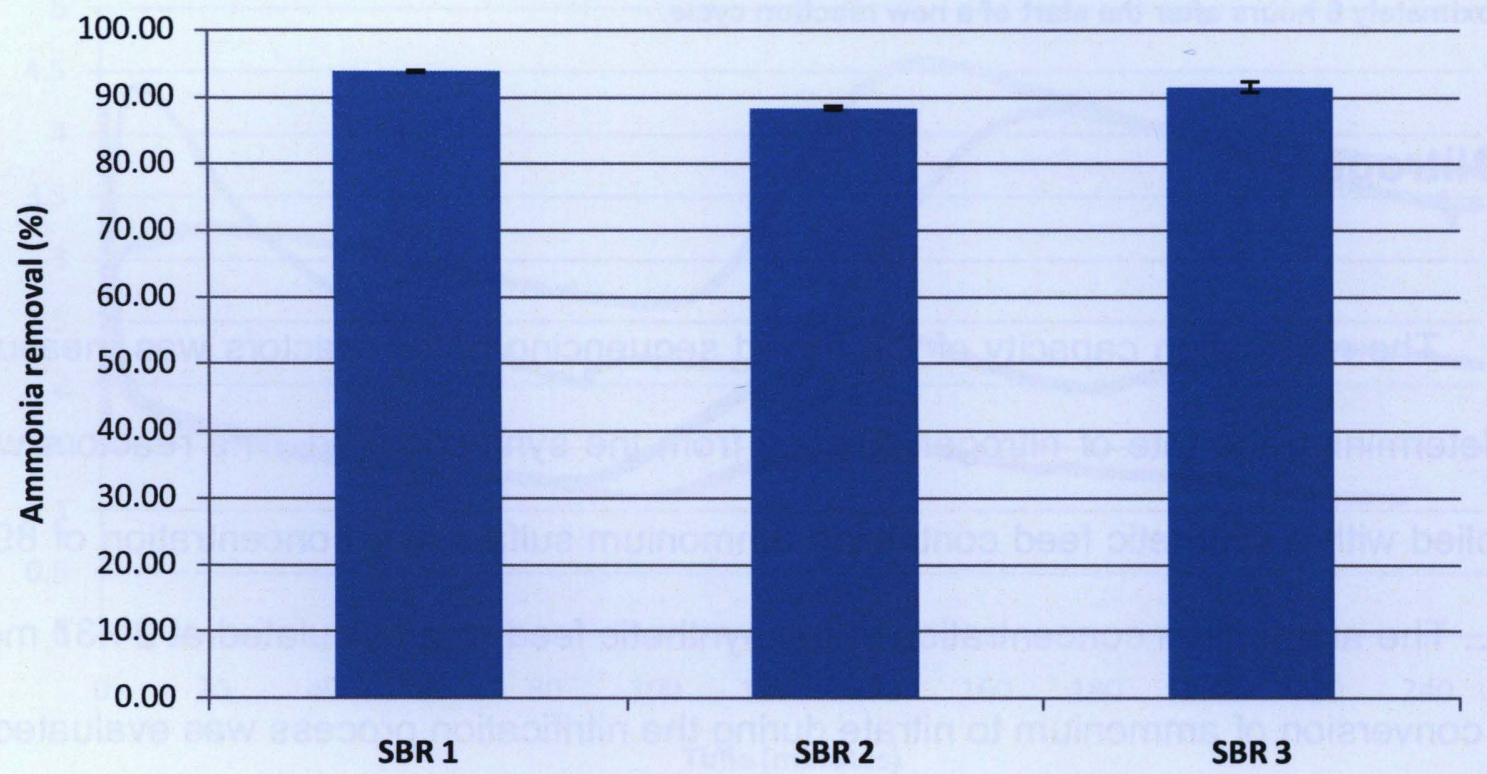

Figure 4.20 Average percent removal of ammonia from the sequencing batch reactors from RUN 2 measured from samples collected 1 hour into the reaction cycle. Measurements were taken on day 91 and 97 . All samples were measured in triplicate and the error bars represent the standard deviation from the mean. 


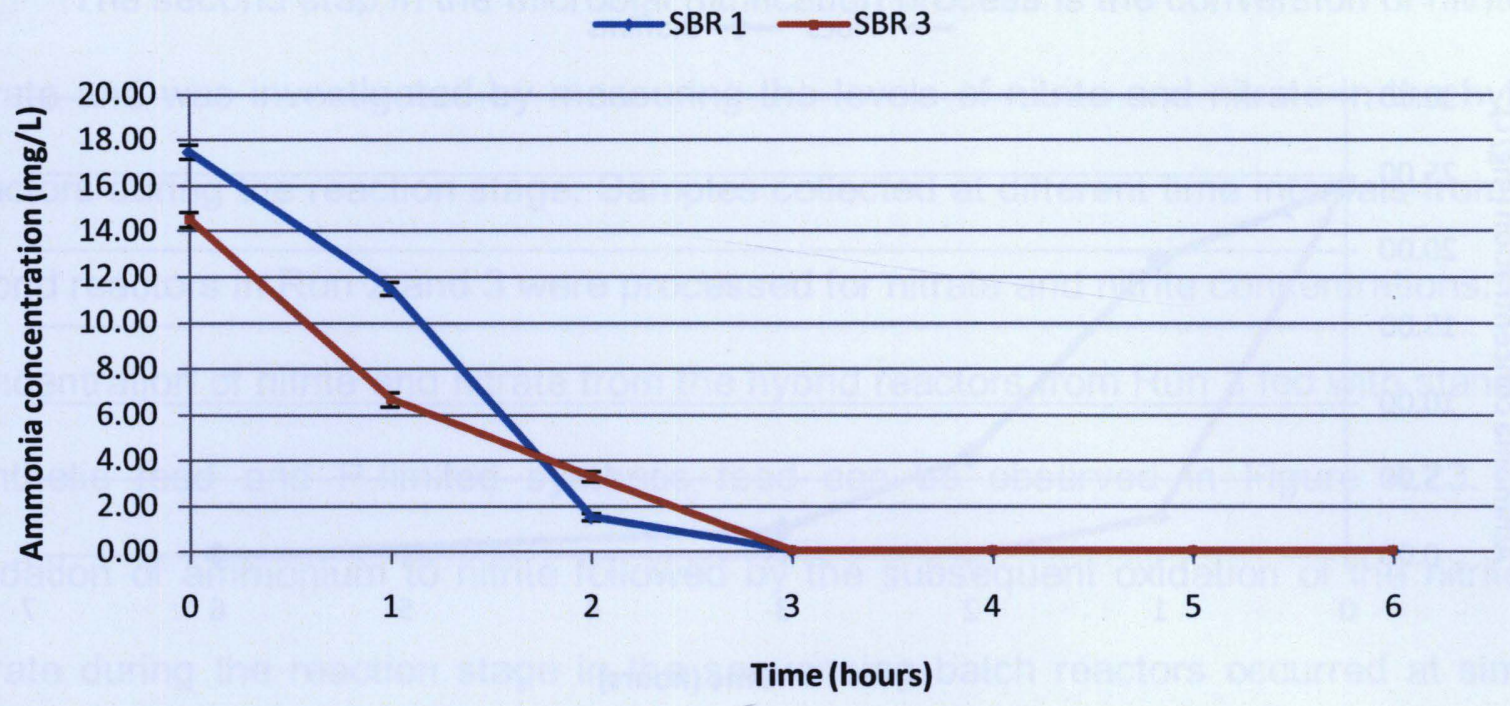

Figure 4.21 Ammonia removal over a full cycle ( 6 hours) in the sequencing batch reactors from RUN 3. SBR 1 was operated with synthetic feed having a COD:N:P ratio of 100:5:1 and SBR 3 was operated under P-limited condition, having a synthetic feed COD:N:P ratio of 100:5:0.33

The capacity of the attached biomass to remove the ammonium from the influent synthetic feed was compared to that of the suspended biomass (Figure 4.22). The two phases were separated into smaller reactors and operated in batch mode for the duration of a reaction stage ( 6 hours). The concentration of ammonium at the beginning of the experiment was $24.21 \mathrm{mg} / \mathrm{L}$ in each case. After one hour into the reaction stage the concentration of ammonium dropped to $2.55 \mathrm{mg} / \mathrm{L}$ in the flocs reactor and to 19.39 $\mathrm{mg} / \mathrm{L}$ in the biofilms reactor. The removal rate of ammonium increased for the biofilms reactor and by the middle of the reaction stage ( 3 hours) both reactors showed almost complete removal of ammonium from the synthetic feed. 


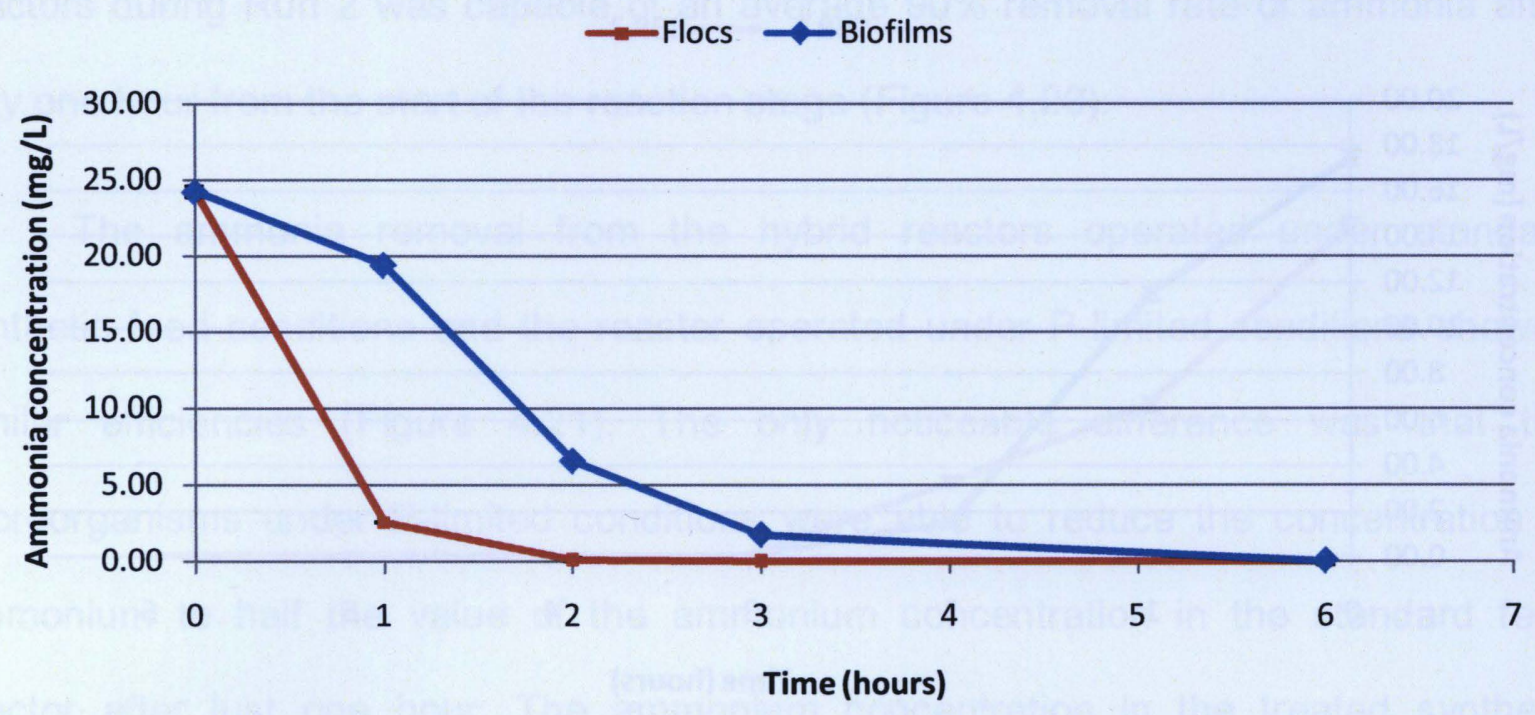

Figure 4.22 Comparison of ammonia removal by the suspended phase (flocs) and the attached phase (biofilms) from SBR 1 during a reaction phase in RUN 2.

In most systems treating domestic wastewater the nitrogen is found mostly in the form of ammonia and organic nitrogen. The discharge of effluents from wastewater treatment plants contain mostly nitrate and ammonia with some other forms of nitrogen (such as dissolved organic nitrogen) accounting for less than $10 \%$ of the nitrogen in wastewater effluent (Pehlivanoglu and Sedlak, 2004).

The nitrification process carried out by two groups of microorganisms takes place in two stages, first the conversion of ammonia to nitrite followed by the subsequent conversion of nitrite to nitrate. As previously shown the conversion of ammonia to nitrite carried out by the ammonia oxidizing bacteria took place in the hybrid systems with a high degree of removal efficiency. In less than half of the length (under 3 hours) of the reaction stages the hybrid reactors reached levels of 90 percent average ammonia removal. 
The second step in the microbial nitrification process is the conversion of nitrite to nitrate and was investigated by measuring the levels of nitrite and nitrate in the hybrid reactors during the reaction stage. Samples collected at different time intervals from the hybrid reactors in Run 2 and 3 were processed for nitrate and nitrite concentrations. The concentration of nitrite and nitrate from the hybrid reactors from Run 3 fed with standard synthetic feed and P-limited synthetic feed can be observed in Figure 4.23. The oxidation of ammonium to nitrite followed by the subsequent oxidation of the nitrite to nitrate during the reaction stage in the sequencing batch reactors occurred at similar rates regardless of the carrier load of the particular system or the nutrient conditions. The nitrite and nitrate levels during a reaction stage in SBR 1(P-normal) and SBR 3 (Plimited) show similar values with a steady increase in nitrate levels until 3 to 4 hours into the reaction stage. The nitrate concentration after 3 to 4 hours into the reaction stage remained constant (at around 7 to $9 \mathrm{mg} / \mathrm{L}$ ) or slowly decreased and this represents the major discharge of nitrogen in the treated effluent from the systems. The nitrite levels in the hybrid reactors during the reaction stage remained low due to the fact that the conversion of nitrite from ammonia by the ammonia oxidizing bacteria takes place at a slower rate than the conversion of nitrate from nitrite by the nitrite oxidizing bacteria, thus the levels of nitrite remained between 0.5 to $2 \mathrm{mg} / \mathrm{L}$ in the system.

There are several factors that control and influence the rate of nitrification in wastewater treatment plants. Such factors can include ammonia/nitrate concentration, oxygen concentration, $\mathrm{pH}$, temperature and the presence of toxic chemicals (Metcalf and Eddy, 1991; Bitton, 2005). The temperature and the $\mathrm{pH}$ in the system were not controlled from the outside but they remained almost constant throughout the 
experimental periods. The temperature in the reactors varied according to the outside temperature in the laboratory, which in fact represents lower variations of temperature than in full scale wastewater treatment plants were the variations of temperature are dependent on the seasonal values. The synthetic wastewater feed provided to all the reactors in all the runs contained $8.78 \mathrm{~g}$ of potassium phosphate monobasic and 11.24 $\mathrm{g}$ of potassium phosphate dibasic that increased the buffering capacity of the system. The optimal pH range for $95 \%$ nitrification is 7.2 to 8.4 and the optimal temperature range for $95 \%$ nitrification is 15 to $35{ }^{\circ} \mathrm{C}$ (U.S. EPA, 1977). The $\mathrm{pH}$ inside the sequencing batch reactors varied in the range of 7 to 8 , well within the limits for optimal nitrification and the temperature of the reactors varied around the room temperature value of $25^{\circ} \mathrm{C}$.

The dissolved oxygen (DO) concentration is considered to be one of the most important factors controlling nitrification (Metcalf and Eddy, 1991). According to that the aeration should take place in the entire reactor and the levels should never drop below $2 \mathrm{mg} / \mathrm{L}$ dissolved oxygen. The mixing and aeration in the hybrid system used for treating wastewater was provided by aquarium air pumps operated at maximum flow rate of 5 $\mathrm{L} / \mathrm{min}$. The dissolved oxygen concentrations were not measured for the reactors during the experimental period but it was assumed that the concentrations were well above the minimum DO level at peak flow of $1 \mathrm{mg} / \mathrm{L}$ according to U.S. EPA (1977). Mixing and aeration are important factors that prevent the accumulation of carbon dioxide from the nitrification process in the mixed liquor thus preventing acidification. The autotrophic nitrifying bacteria do not operate at optimal levels in acidic environments (Bitton, 2005). The nitrite oxidizing bacteria have lower affinity for dissolved oxygen than ammonia 
oxidizing bacteria (Jayamohan et al., 1988) and this means that at lower dissolved oxygen concentrations the nitrite accumulation in the system would be favoured. The results recorded from the hybrid reactors showed that the nitrate was the major nitrogen form discharged in the treated effluent which proves that there was enough aeration and mixing provided to the reactors. In a study by Bernet et al. (2005) the removal of ammonium by biological processes in an inverse turbulent bed flow reactor fed with synthetic mineral wastewater (with high ammonium content $250-500 \mathrm{mg} \mathrm{N}-\mathrm{NH}_{4}{ }^{+} / \mathrm{L}$ ) was investigated. The study found that with a DO level of $2 \mathrm{mg} / \mathrm{L}$ ammonia conversion was higher than $95 \%$ and nitrite accumulation was increased up to $60 \%$ and both biofilm covered and uncovered carrier particles were present in the system.

The MLSS concentrations in all the reactors during Run 2 and 3 were averaging between 1500 and $3500 \mathrm{mg} / \mathrm{L}$ which was just above the range of 1200 to $2500 \mathrm{mg} / \mathrm{L}$ MLVSS values considered as optimal values for nitrification in activated sludge systems (U.S. EPA, 1977). Heavy metals such as $\mathrm{Cu}, \mathrm{Zn}, \mathrm{Cd}, \mathrm{Ni}, \mathrm{Pb}$ and $\mathrm{Cr}$ were not present in the synthetic wastewater feed above the $5 \mathrm{mg} / \mathrm{L}$ level which is considered the maximum concentration above which the nitrification performance of the systems decrease. Organic compounds are not considered as direct toxic agents for the autotrophic nitrifying bacteria but higher organic loads in the system can lead to a depletion of the oxygen by the proliferation and excess metabolic functions of the heterotrophic microorganisms that lead to a depletion of dissolved oxygen and poor nitrification performance (Bitton, 2005). The organic load of $600 \mathrm{mg} / \mathrm{L}$ chemical oxygen demand of the synthetic wastewater feed supplied to the hybrid reactors did not present a high 
value that negatively influenced the nitrification performance since the ammonia removal during the experimental runs was averaging 90 percent in all the reactors.

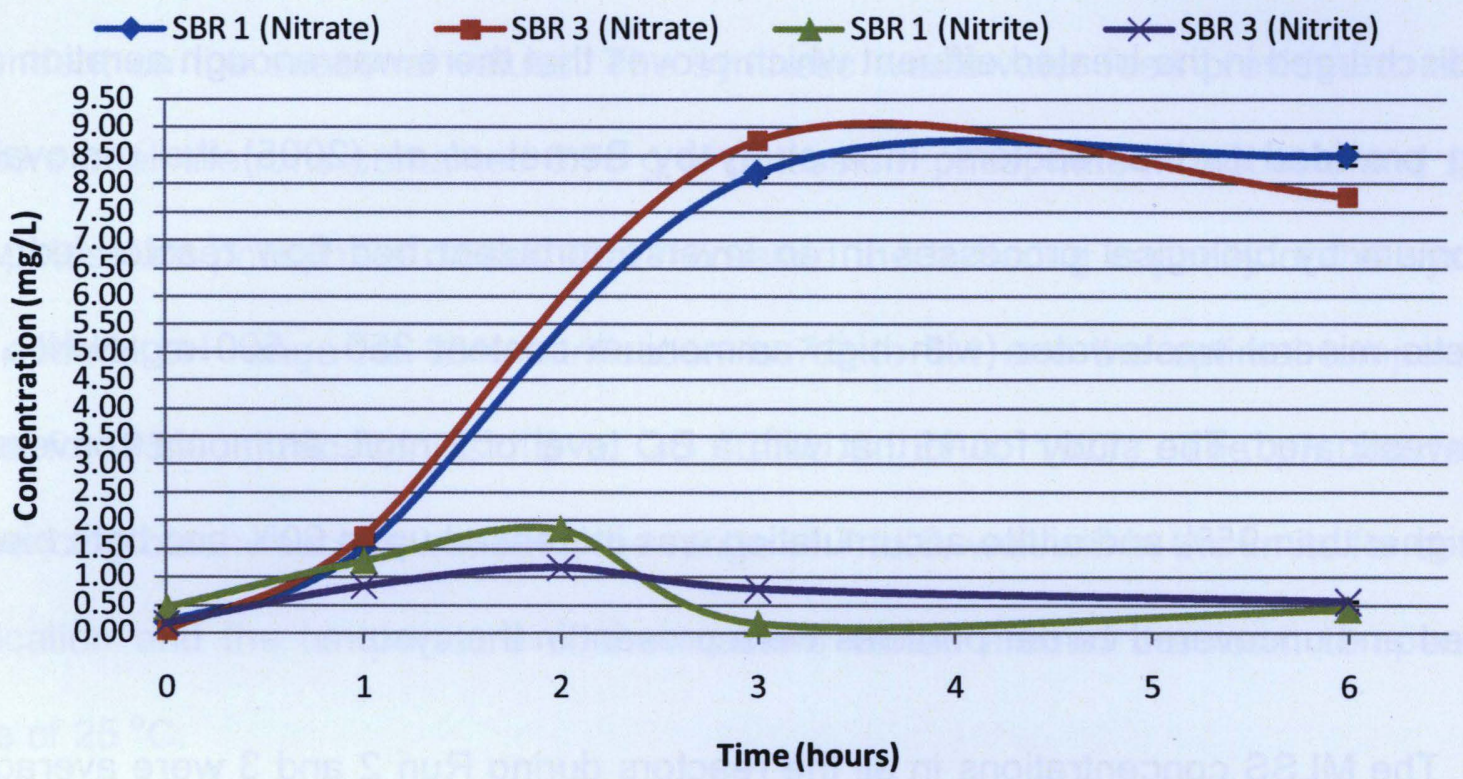

Figure 4.23 Nitrite and Nitrate concentrations of samples from SBR 1 (COD:N:P=100:5:1) and SBR 3 (COD:N:P=100:5:0.33) in Run 3. The samples were collected from the sequencing batch reactors during the period of one reaction stage.

When the suspended phase (flocs) and the attached phase (biofilms) were separated into smaller reactors and operated in batch mode for the duration of one reaction stage the nitrite and nitrate concentrations were observed to follow a similar trend as in the hybrid reactors (see Figure 4.24 and 4.25). The nitrite concentrations in the reactors containing only flocs or biofilms were recorded in a low concentration similar to the hybrid reactors with the levels of nitrite never increasing in the system past $1 \mathrm{mg} / \mathrm{L}$ with a slight decrease towards the end of the reaction stage. The samples collected from both the flocs and biofilms originating from the hybrid reactors operated under standard feed (P-normal) and P-limited feed showed similar trends for nitrite 
concentrations. The nitrate concentrations of the samples collected from SBR 1 (Pnormal, Figure 4.24) and SBR 3 (P-limited, Figure 4.25) were higher than the nitrite concentrations and the levels increased steadily for the duration of the reaction stage. The samples originating from the reactors with only biofilms treating the synthetic wastewater feed (both P-normal and P-limited) presented a similar trend with a linear increase in concentration from the beginning to the end of the reaction stage while in the samples originating from the reactors with only flocs treating wastewater the nitrate levels increased but to lower levels than for the biofilms. The reason for this difference could be attributed to a higher denitrification activity in the flocs compared to the biofilms or a slower rate of conversion from nitrite to nitrate in the smaller reactors operating with flocs only due to the lower dissolved oxygen concentration coupled with a simultaneous denitrification.

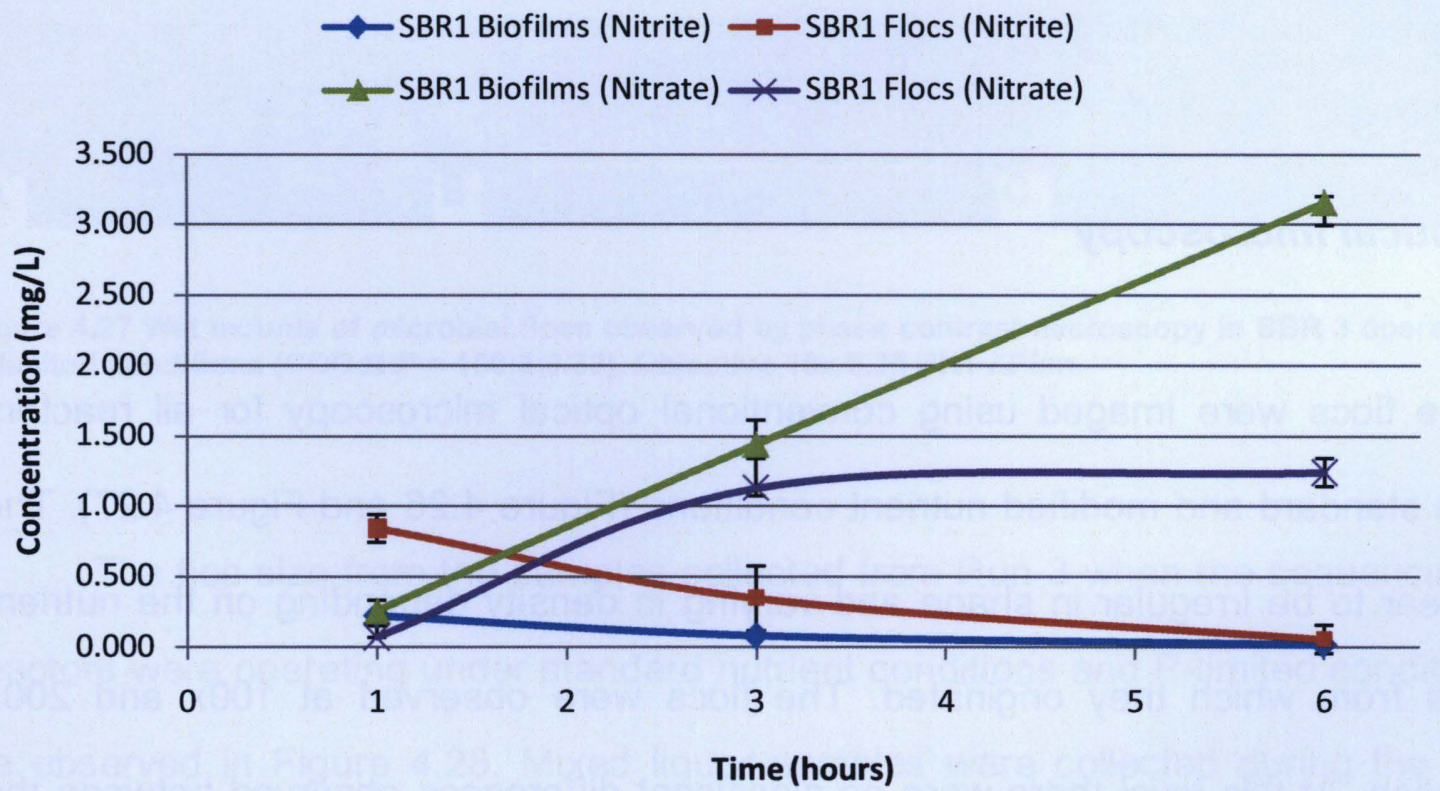

Figure 4.24 Nitrite and Nitrate concentrations from biofilm and floc samples collected from SBR 1 (COD:N:P = 100:5:1) during Run 3 . The biomass from the sequencing batch reactors was separated into the attached and suspended phase and the concentrations of nitrite and nitrate were measured for the duration of a reaction stage. 


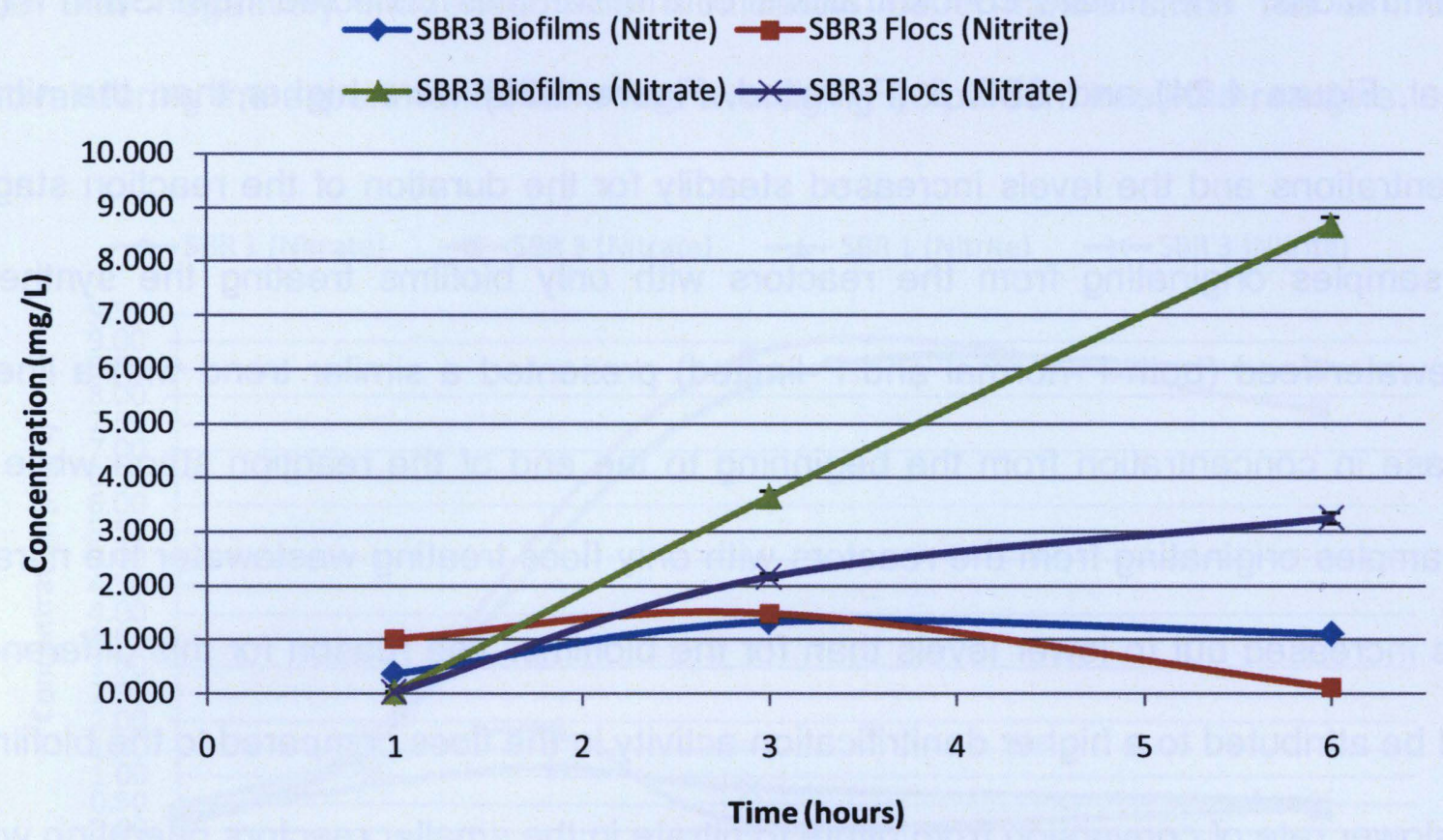

Figure 4.25 Nitrite and Nitrate concentrations from biofilm and floc samples collected from SBR 3 (COD:N:P = 100:5:0.33) during Run 3. The biomass from the sequencing batch reactors was separated into the attached and suspended phase and the concentrations of nitrite and nitrate were measured for the duration of a reaction stage.

\subsection{Imaging}

\subsubsection{Optical microscopy}

The flocs were imaged using conventional optical microscopy for all reactors under the standard and modified nutrient conditions (Figure 4.26 and Figure 4.27). The flocs appear to be irregular in shape and varying in density depending on the nutrient conditions from which they originated. The flocs were observed at $100 x$ and $200 x$ magnification. At this level there were no significant differences observed between the flocs in terms of shape. A slight increase in average floc size is observed for the flocs 
sampled from the P-limited reactor as well as darker areas due to the fact that the biomass appears more densely packed.

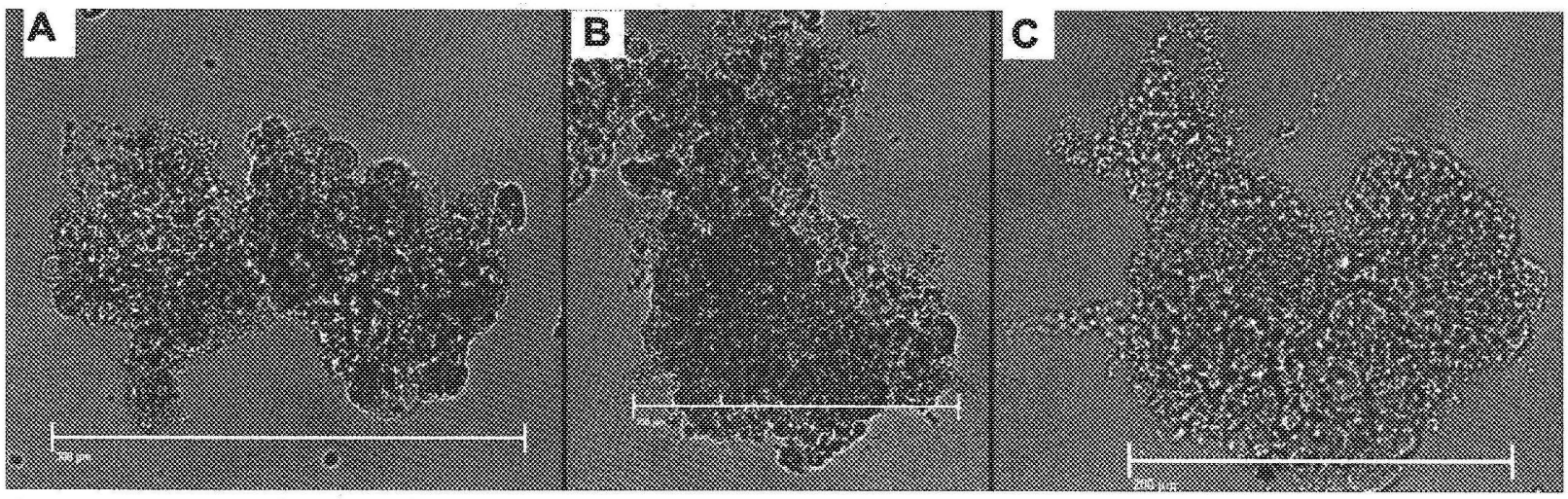

Figure 4.26 Wet mounts of microbial flocs observed by phase contrast microscopy in SBR 1 operating under standard nutrient load (COD:N:P = 100:5:1). Objective 20x/0.50 Plan-Neofluar.

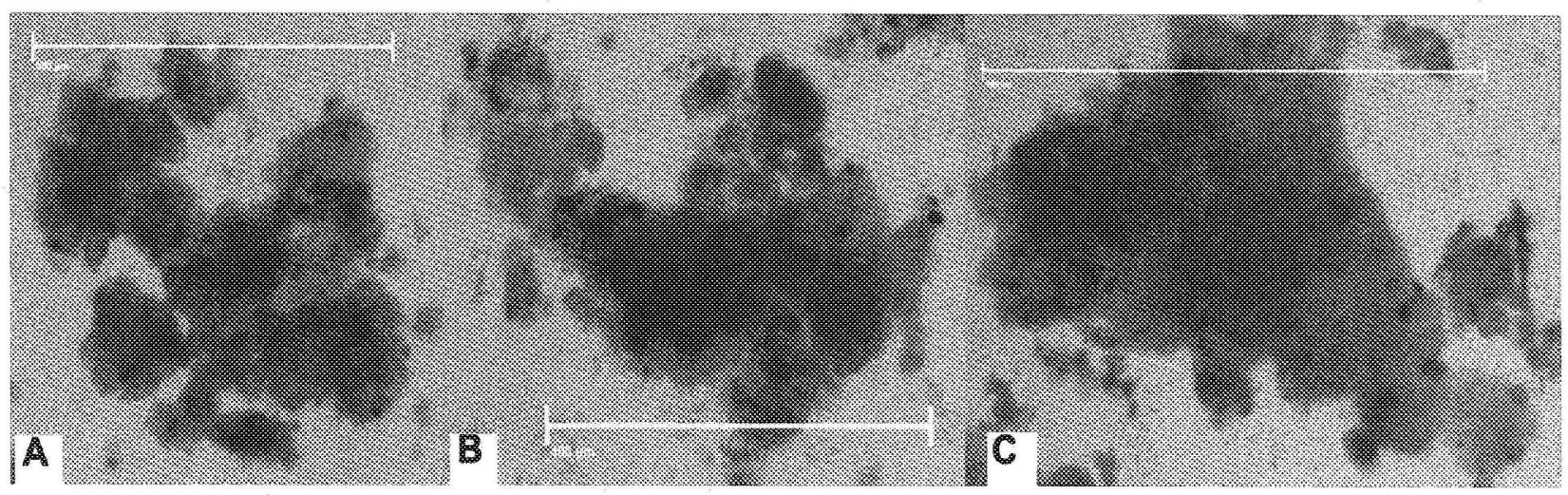

Figure 4.27 Wet mounts of microbial flocs observed by phase contrast microscopy in SBR 3 operating under P.limited conditions (COD:N:P = 100:5:0.33). Objective 10x/0.25 PHI APlan.

The floc size from the samples collected from Run 3 when the sequencing batch reactors were operating under standard nutrient conditions and P-limited conditions can be observed in Figure 4.28. Mixed liquor samples were collected during the reaction stage from the hybrid reactors and wet mounts were prepared from them for examination with the optical microscope. The microbial flocs from the reactor fed with 
standard synthetic wastewater with COD:N:P ratio of 100:5:1 presented smaller and less denser flocs than the flocs sampled from the reactor operating under P-limited conditions (COD:N:P = 100:5:0.33). The variations in overall floc sizes between the different sampling days could be attributed to the high variations in temperature from the laboratory where the sequencing batch reactors were operating. Even under these variations in operating conditions the floc size difference between the P-normal and Plimited reactors was maintained.

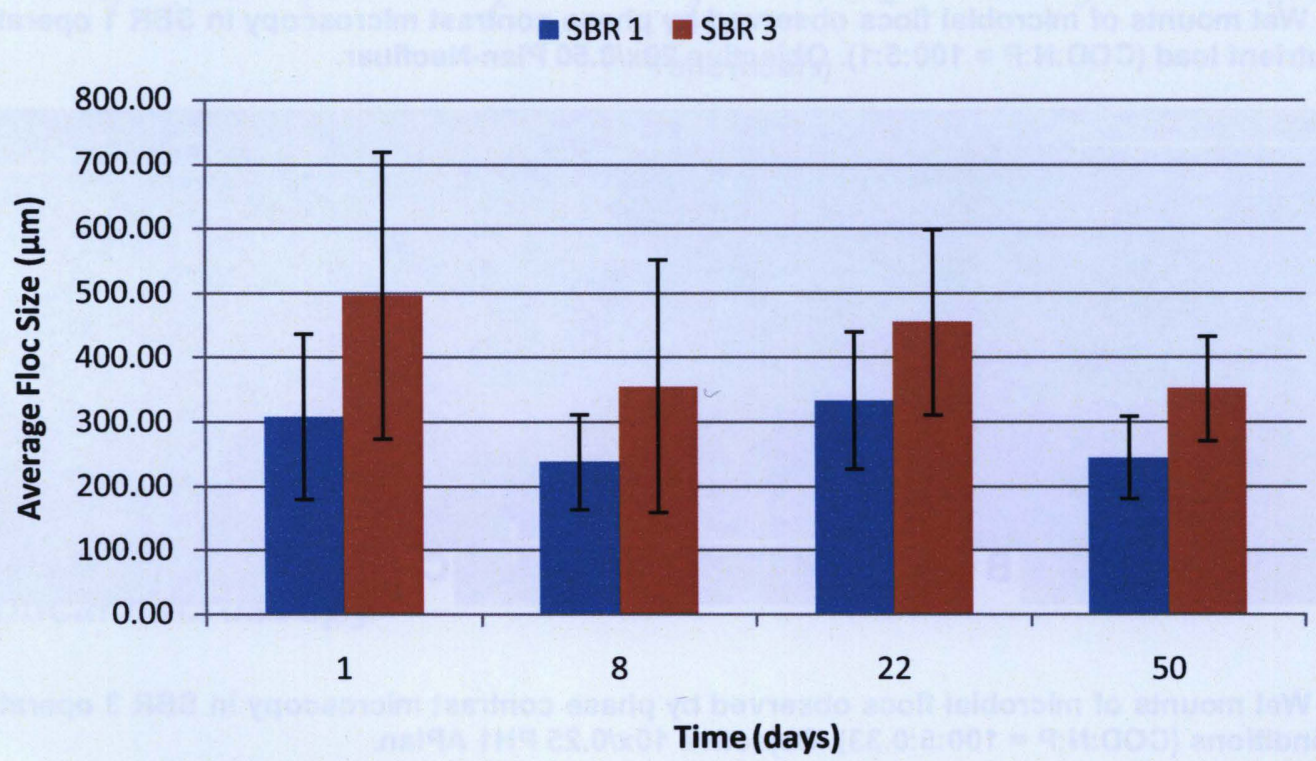

Figure 4.28 Average floc size from experimental Run 3 with samples taken from P-normal (SBR 1) and Plimited (SBR 3 ) conditions. Results are expressed as the mean \pm standard deviation.

\subsubsection{Images of biofilms on carrier material}

Notable biofilms formed on both types of carriers: Activecell $450^{\mathrm{TM}}$ and Activecell550 ${ }^{\mathrm{TM}}$ (Figure 4.29). From images taken at different days during the 
experimental period in all three runs the biomass covering the solid support material was present on the outside and the inside surface of the carriers. Throughout the entire experimental period of all the runs, after the systems reached constant operating parameters, the biofilms were visible covering most of the internal surface of the support material and the groves on the outer surface of the carrier material. The covering of the attachment surfaces was not uniform but varied in thickness on the inside and outside surfaces of the carriers. The thickness varied from a very thin biofilm layer (see Figure 4.29 $\mathrm{A}$ and $\mathrm{C}$ ) to very thick growth that was covering and almost blocking the internal channels through the carrier material (see Figure 4.29 B and D). Also not all the internal channel surfaces were covered with the same thickness of biofilms, due to overgrowth and sloughing events that were happening continuously throughout the carriers in the hybrid reactors. Not all the channels from one carrier suffered from loss of biofilm due to sloughing at the same time, this process was random and was present on most carriers in the reactors from all the runs. 


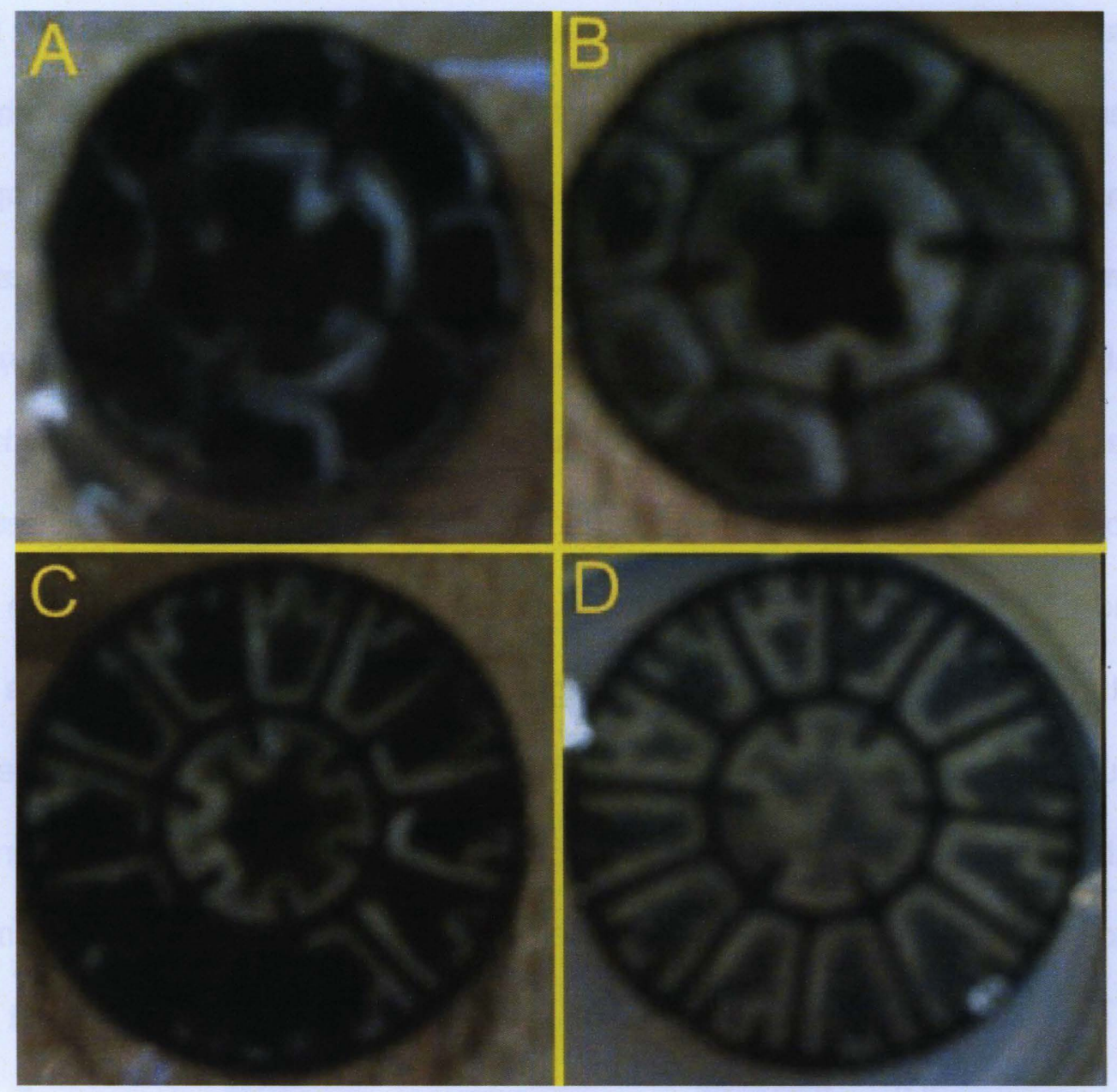

Figure 4.29 Image of biofilm growing on carrier material. A, B - biofilms on Activecell450TM; C, D - biofilms on Activecell550TM.

Biofilm growing on the outside surfaces of the support material were thinner than the biofilms growing on the inside channels and present mostly in the grooves of the outer surface (see Figure 4.30). A possible explanation why biofilms were growing mostly at the base of the groves and not the top is the continuous collisions between due to mixing and aeration. Also these surfaces were the most exposed to nutrient and oxygen compared to the internal channels which at some point were completely covered in biofilm and the flow through the channel blocked. 


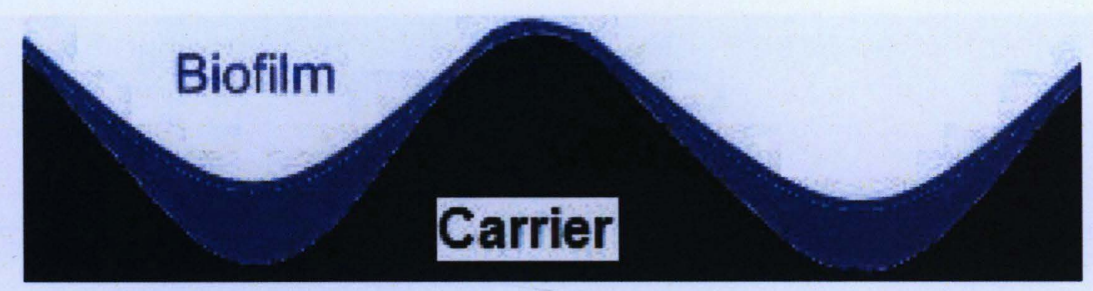

Figure 4.30 Diagram of biofilm growing in the grooves on the outer surface of the carrier material.

\subsubsection{CLSM of biofilms and flocs}

In order to visualize the microbial flocs morphology and characteristics and to examine the colonization of the attachment surfaces provided by the carriers with biofilms, images were captured with CLSM. The microbial floc samples were embedded in low melting point agarose to maintain the floc structural integrity during sample preparation and visualization. The biofilm samples were visualized in situ using water immersion lenses in order to preserve the biofilms in their fully hydrated form. The $63 \times 1.2$ or the $63 \times 0.9$ water immersion objectives with $0.24 \mathrm{~mm}$ and $2.2 \mathrm{~mm}$ working distances, respectively, dictated the range at which the biofilms could be visualized inside the grooves and channels of the carrier material. The stains used for visualization under confocal laser scanning microscopy were chosen based on previous studies. The stains were used alone or in combination in order to study the microbial flocs and also to investigate the colonization of solid support surfaces by biofilms. The nucleic acids specific stains were used to visualize the microbial cells by their ability to bind either DNA or RNA. This included Syto 9, propidium iodide, acridine orange, and ethidium bromide. The nucleic acids stains were also used as a counter stain when the visualization of the EPS was desired, to be able to observe the presence of cells in the 
matrix of EPS, stained with specific sugar binding lectins. The lectins used in this study were Canavalia ensiformis (Concanavalin A, Con A) with affinity for $\alpha$-glucose and $\alpha$ mannose, Pisum sativum (garden pea agglutinin, PSA) with affinity for $\alpha$-mannose, Dolichos biflorus (horse gram agglutinin, DBA) with affinity for $\mathrm{N}$-acetyl galactosamine, Arachis hypogaea (peanut agglutinin, PNA) with affinity for galactose, Ulex europaeus (furze agglutinin, UEA) with affinity for fucose, and Triticum vulgaris (Wheat germ agglutinin, WGA) with affinity for $\mathrm{N}$-acetyl glucosamine (see Table 2.1).

Carriers with biofilm covering all the surfaces were sampled from the hybrid reactors and placed in small beakers containing a mix of fluorescent molecules in the synthetic wastewater solution. In order to visualize the growth of biofilm on the internal surfaces smaller carrier sections were cut and observed under the microscope. The double staining of biofilms with a nucleic acid stain and a lectin cocktail for the visualization of EPS components revealed the complete covering of the smooth internal surfaces. The distribution of the EPS uniformly throughout the biofilms was observed by binding of the fluorescently tagged lectins to the specific sugar moieties (see Figure 4.31). The thickness of the biofilm on the inside or outside surfaces was impossible to determine because biofilm thickness exceeded the working distances of the objectives: for the $63 \times 1.2$ or the $63 \times 0.9$ water immersion objectives with a $0.24 \mathrm{~mm}$ and $2.2 \mathrm{~mm}$ working distance respectively it was impossible to precisely measure the thickness of the biofilm growing on the inside of the carrier due to the fact that the biofilm was in many case over $2 \mathrm{~mm}$ thick. 


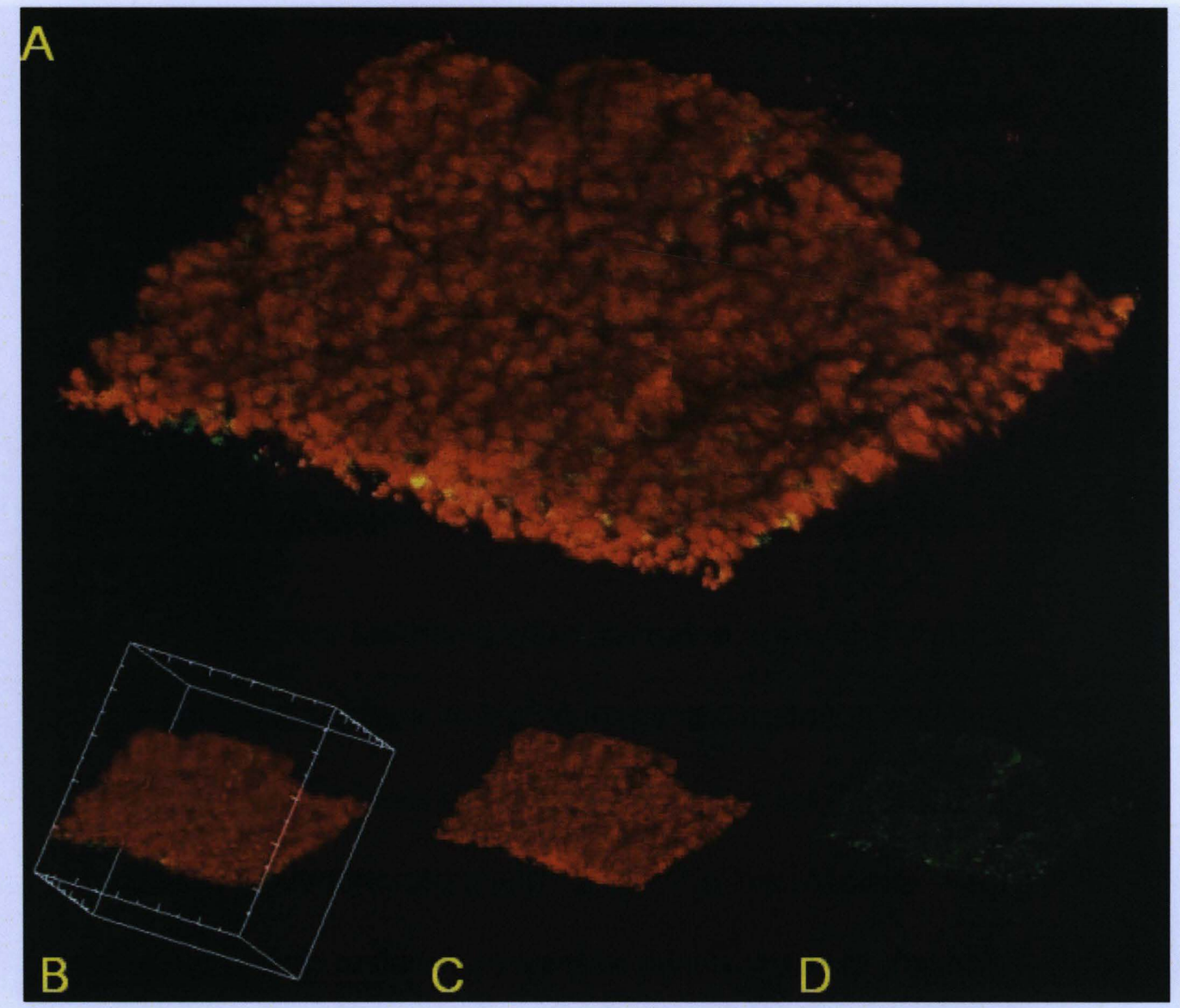

Figure 4.31 Confocal laser scanning micrographs of biofilm growing on the inside surface of one of the channels from the Activecell450 ${ }^{\mathrm{TM}}$ carriers (A, B). The image is a top view projection of biofilm attached to the support surface. Biomass stained (red) with Ethidium Bromide (C) and EPS stained (green) with a lectin cocktail tagged with FITC (D). The objective was $63 \times 0.9$ water immersion Achroplan.

The biofilms growing on the outside of the two types of carriers, the Activecell $450^{\mathrm{TM}}$ and Activecell $550^{\mathrm{TM}}$ was visualized after staining with nucleic acid stains and lectin cocktail. The biofilm on the smaller carrier (see Figure 4.32) covered completely covered the groove with a thin layer of biofilm. The cells were visualized after staining with a nucleic acid stain (Ethidium bromide) and the EPS distributed uniformly throughout the biofilm was visualized after staining with a fluorescently tagged lectin cocktail. The outer grooves on the bigger carrier (Activecell550 ${ }^{\mathrm{TM}}$ ) presented a more uniform and thicker biofilm (see Figure 4.33) than the smaller carrier. 


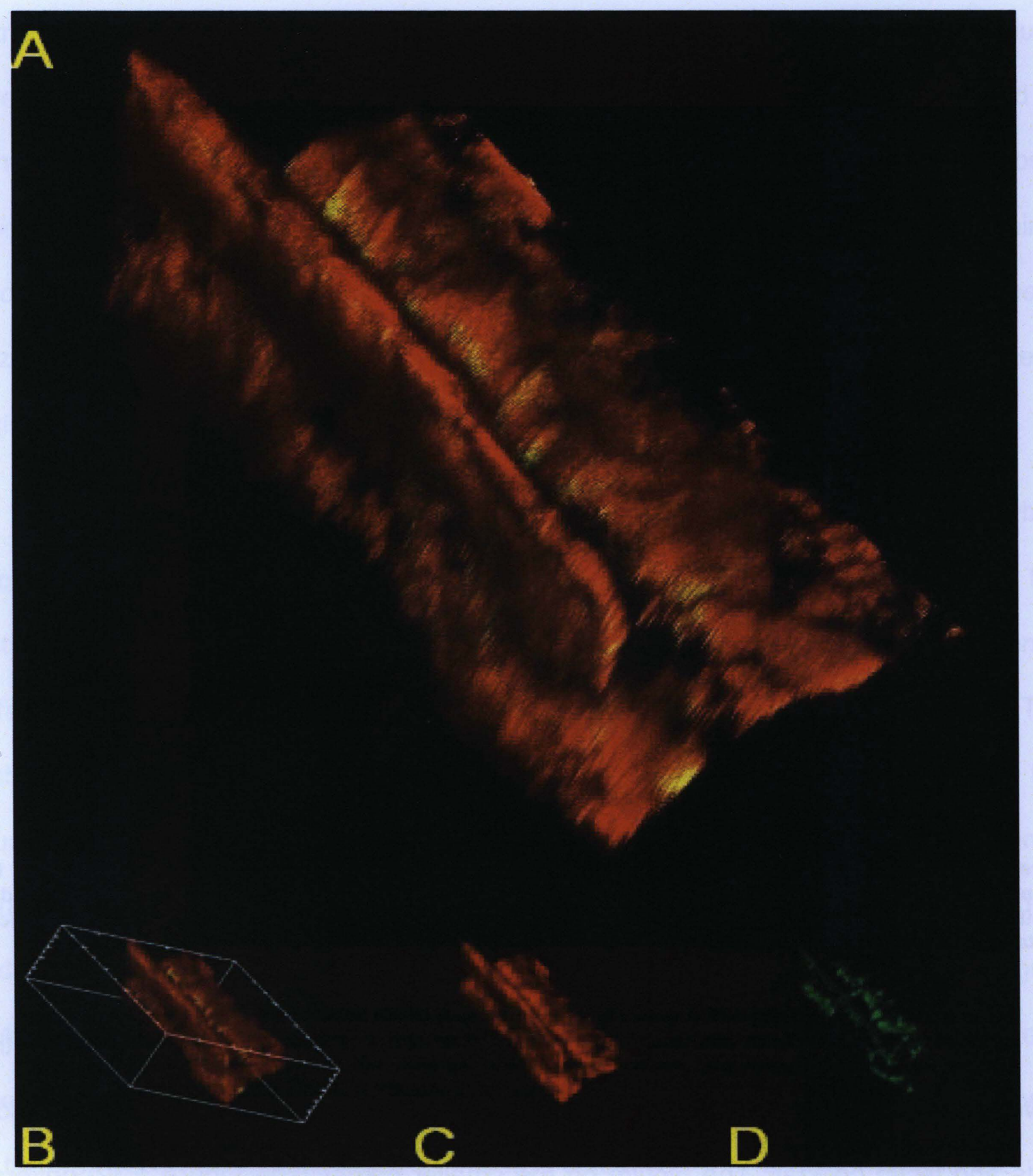

Figure 4.32 CLSM micrograph of biofilm growing in a groove on the outside surface of the Activecell450 ${ }^{\mathrm{TM}}$ carrier showing a top view of a three dimensional projection (A, B). The image shows the complete colonization of the groove surface with biofilm. Stains: cells (red) targeted with Ethidium Bromide (C) and EPS (green) targeted with FITC-conjugated lectin cocktail (D). The objective was $63 \times 0.9$ water immersion Achroplan. 


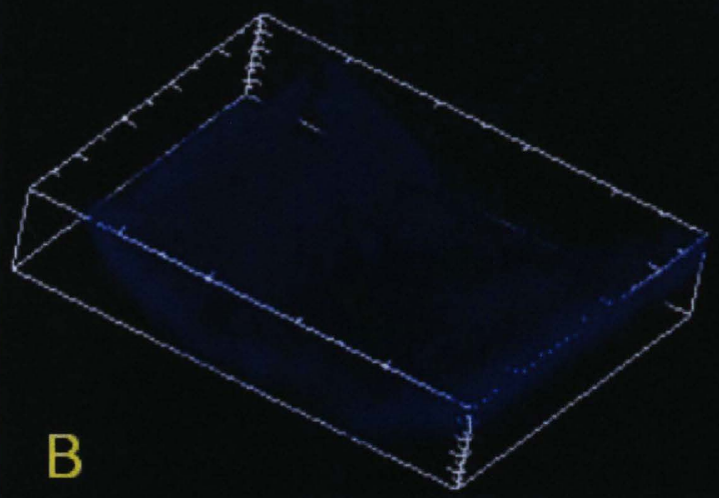

Figure 4.33 CLSM micrograph of biofilm growing in the groove on the outside surface of the Activecell550 ${ }^{\mathrm{TM}}$ carrier showing a top view of a three dimensional projection (A, B). The image shows the complete colonization of the outside groove with biofilm. The biomass was stained (blue) with Acridine Orange; objective 20x/0.75 Plan-Apochormat.

The flocs were visualized after fixation with low melting point agarose and staining with fluorescent molecules. The distribution of the EPS throughout the entire volume of the microbial floc was visualized by staining with Concanavelin A lectin conjugated to TRITC (see Figure 4.34). 


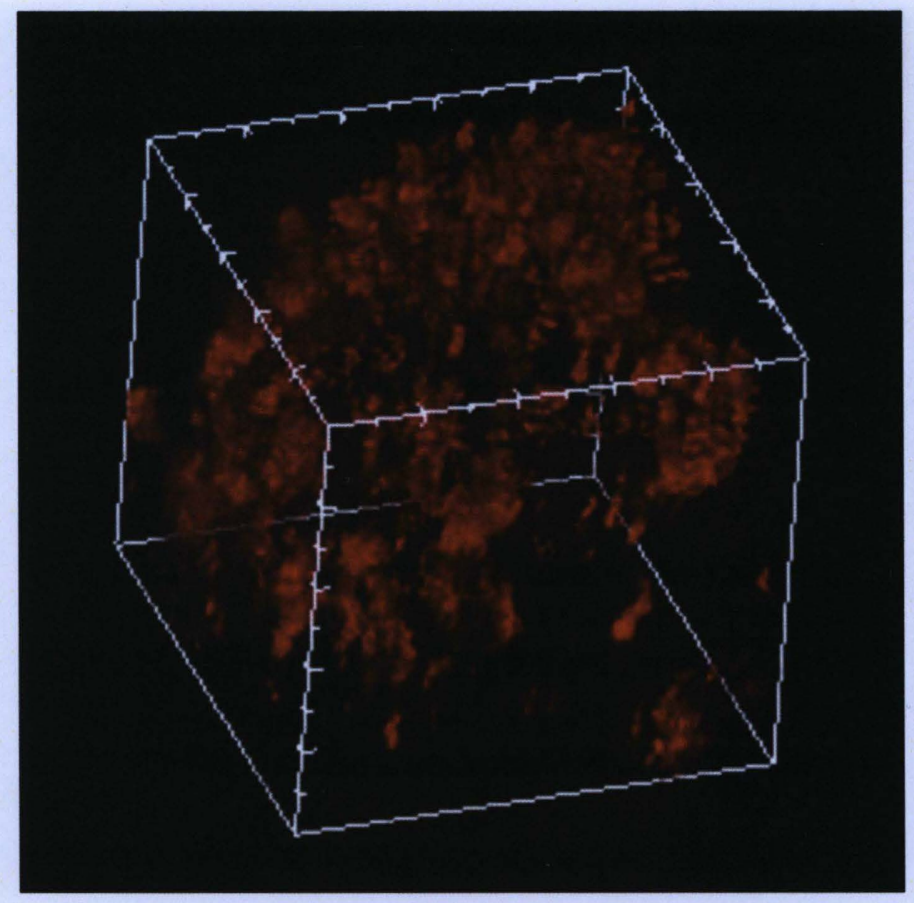

Figure 4.34 CLSM micrograph of floc structure showing TRITC-conjugated Concanavelin A, lectin with affinity for sugar moieties ( $\alpha$-glucose and $\alpha$-mannose) binding EPS of suspended biomass. This is a three dimensional projection of the scanned volume. Objective 63x/0.9 water immersion Achroplan.

All the samples collected from the reactors from all three experimental runs presented similar biofilm and floc characteristic when visualized under the confocal laser scanning microscope. There was no significant difference observed with CLSM in the aspect of the biofilms sampled from the hybrid reactors operated under different carrier load ( $\mathrm{v} / \mathrm{v})$ and under different nutrient conditions (P-normal and P-limited). Previous studies using lectin-conjugates have successfully studied the extracellular polymers present in the biofilm matrix (Lawrence et al, 1998; Wolfaardt et. al., 1998). Previous studies demonstrated that the lectins have affinity for common polysaccharides that can be present as intracellular polysaccharides, as capsular polysaccharides and as extracellular or soluble polysaccharides (Del Gallo et al., 1989). 
The fluorescence of lectin conjugates can thus be closely associated with the cells but most likely the lectins bound to the EPS represent the bulk of the signal.

\subsubsection{F.I.S.H. imaging of nitrifying bacteria}

The conversion of ammonia to nitrite is carried out by the ammonia oxidizing bacteria $(A O B)$ which belong to the $\beta$ - and $\gamma$-subdivisions of the Proteobacteria (Mobarry et al., 1996). In most wastewater environments the dominant $A O B$ belong to the genus Nitrosomonas, but others like Nitrospira, Nitrosovibrio and Nitrosolobus are also present (Bitton, 2005).

Samples of biofilm and flocs were collected from the reactors during experimental Run 3 and were hybridized with specific 165 rRNA-targeted oligonucleotide DNA probes with specificity for phylogenetically defined groups of autotrophic ammonia oxidizers. Floc and biofilm samples collected from the hybrid reactors were hybridized with a combination of 165 rRNA-targeted oligonucleotides consisting of a general eubacteria probe EUB338 with specificity for most bacteria and an ammonia-oxidizing bacteria probe Nsv443 with specificity for Nitrosolobus multiformis, Nitrosospira briensis, and Nitrosovibrio tenuis (Mobarry et al., 1996). The presence of the ammonia oxidizers was confirmed for both flocs and biofilms samples as clusters of cells inside the biomass samples (Figure 4.35). The slow rate of growth of autotrophic nitrifying microorganisms in comparison with heterotrophic bacteria present in the wastewater means they have fewer $16 S$ rRNA target sites and thus a reduced 
fluorescent signal. The use of a combination of oligonucleotide probes can lead to an additive increase in fluorescent signal intensity allowing for detection of even slow growing microorganisms (Amann et al., 1990).

Another 165 rRNA-targeted oligonucleotide DNA probe with specificity for ammonia oxidizers was used in combination with a general eubacteria probe (EUB 338) to investigate the presence of $A O B$ in flocs and biofilm samples (see Figure 4.36). The Nso190 probe has specificity for an even wider spectrum as it encompasses all sequenced ammonia oxidizers of the $\beta$ subclass of Proteobacteria (Mobarry et. al., 1996). The presence of $A O B$ was confirmed for both flocs and biofilms samples as clusters within the biomass samples collected from the hybrid reactors from Run 3 . The samples taken from biofilms growing on both the Activecell450TM and Activecell550TM carriers were positive for the presence of $\mathrm{AOB}$. The samples originating in the reactors operated under standard nutrient conditions (P-normal) and under P-limited conditions, both biofilm and floc samples, presented the ammonia oxidizers as clusters within the wastewater biomass. 


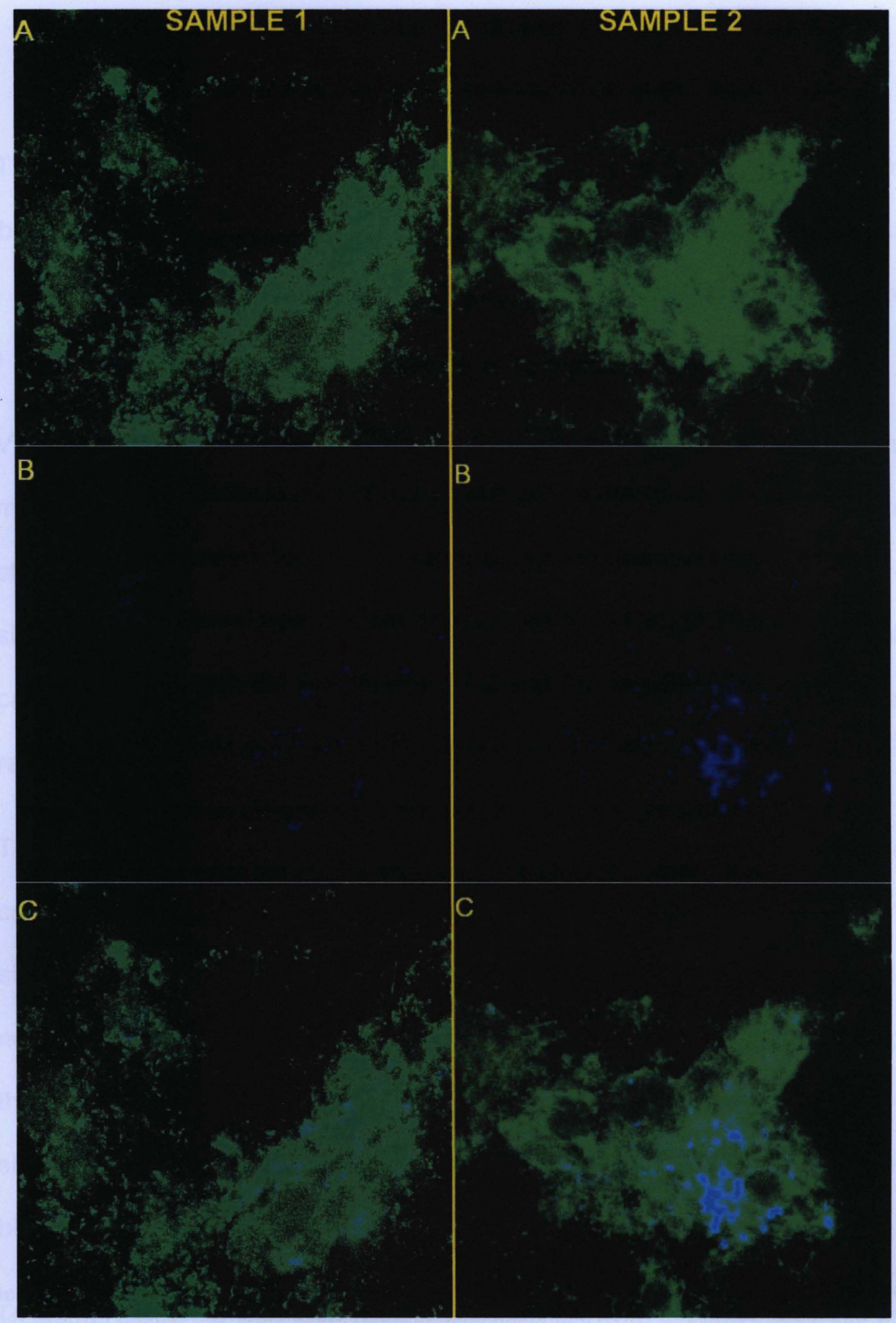

Figure 4.35 CLSM micrograph of ammonia-oxidizing bacteria from biofilms (Sample 1) and flocs (Sample 2). The biomass was tageted with 16S rRNA oligonucleotide probes: Alexa Fluor 488 tagged EUB338 (green) and Alexa Fluor 660 tagged Nsv443 (blue). Objective 63x/1.2 water immersion C-Apochromat. 


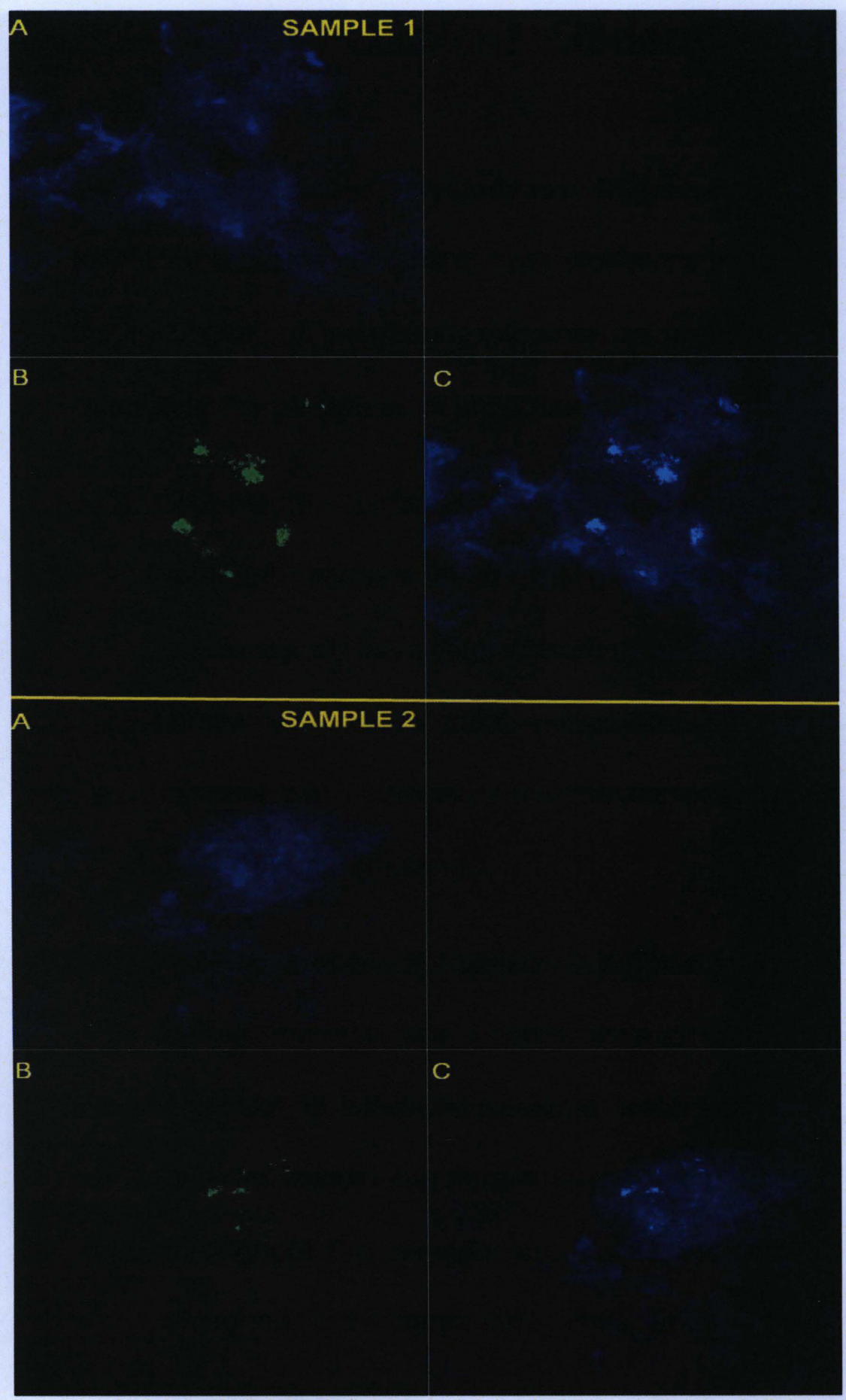

Figure 4.36 CLSM micrograph of ammonia-oxidizing bacteria from biofilms (Sample 1) and flocs (Sample 2). The biomass was tageted with $16 \mathrm{~S}$ rRNA oligonucleotide probes: Alexa Fluor 660 tagged EUB338 (blue) and Alexa Fluor 488 tagged Nso190 (green). Objective 63x/1.2 water immersion C-Apochromat. 


\section{Chapter 5. General Conclusions}

The purpose of this study was to gain a better understanding of the operation of hybrid bioreactors containing both biofilms and microbial flocs in treating wastewater. On the basis of the results obtained, a number of conclusions can be drawn with regards to the performance and characteristics of these kinds of systems:

1. Varying the surface area for attachment by loading the reactors with carrier material between 25 to $50 \%(\mathrm{v} / \mathrm{v})$ did not significantly influence the treatment efficiency of the system. Both COD removal rate and $N$ removal presented similar levels under these carrier loads. This suggests that the benefits of adding carriers can potentially be achieved in full scale systems over a relatively large range of carrier loading.

2. The accumulation of biofilm on the surface areas for attachment provided by the carrier material was uniform throughout the entire reactor and did not vary significantly when the reactors were operated under different carrier loads or nutrient conditions (P-normal and P-limited). Sloughing of biofilms occurred throughout the reactors but it was not a synchronized event, not all biofilms sloughed at the same time. Thus, at any given time there was sufficient biofilm biomass to perform the wastewater treatment function.

3. CLSM analysis of the microbial flocs and biofilms showed a heterogeneous distribution of EPS. 
4. The metabolic activity of the attached phase with regards to nitrogen removal was lower compared to the suspended phase and also the removal of organic compounds was performed faster by the suspended phase.

5. There was no correlation between total surface area for attachment and the ratio between the amount of suspended phase and attached phase present in the hybrid system but there was significantly more attached biomass than suspended phase when the system was under P-limiting conditions. Also, the average floc size was larger in the hybrid reactor operated under P-limited conditions.

6. Fluorescence in situ hybridization verified the presence of ammonia oxidizing bacteria in both flocs and biofilms in the reactors operated under the different nutrient conditions ( $P$-normal and P-limited). 


\section{References}

Alexander, M. (1985) Biodegradation of organic chemicals. Environ. Sci. Tech. 18, 106111.

Amann R.I. (1995) In situ identification of micro-organisms by whole cell hybridization with rRNA-targeted nucleic acid probes. Molecular microbial ecology manual, Vol 3.3.6. Kluwer Academic, Dordrecht, p. 1-15.

Amann, R.I., Binder, B.J., Olson, R.J., Chisholm, S.W., Devereux, R. and Stahl, D.A. (1990) Combination of $16 S$ rRNA-targeted oligonucleotide probes with flow cytometry for analyzing mixed microbial populations. Appl Environ Microbiol 56, 1919-1925.

Aoi, Y. (2002) In situ identification of microorganisms in biofilm communities. J.Biosci.Bioeng. 94, 552-556.

APHA (1998) Standard methods for the examination of water and wastewater, $20^{\text {th }}$ edition. American Public Health Association, American Water Works Association, and Water Pollution Control Federation, Washington, DC.

Barker, P.S. and Dold, P.L. (1995) COD and nitrogen mass balances in activated sludge systems. Water Research 29, 633-643.

Beimfohr, C., Krause, A., Amann, R., Ludwig, W. and Schleifer, K... (1993) In situ identification of lactococci, enterococci and streptococci. Syst App/ Microbiol 16, 450456.

Bernardes, R.S. and Klapwijk, A. (1996) Biological nutrient removal in a sequencing batch reactor treating domestic wastewater. Water Science and Technology 33, 29-38.

Bernet, N., Sanchez, O., Cesbron, D., Steyer, J.-. and Delgenès, J.-. (2005) Modeling and control of nitrite accumulation in a nitrifying biofilm reactor. Biochem Eng $J 24,173-$ 183.

Beveridge, T.J., Makin, S.A., Kadurugamuwa, J.L. and Li, Z. (1997) Interactions between biofilms and the environment. FEMS Microbiology Reviews 20, 291-303.

Bitton, G. (2005) Wastewater Microbiology. $3^{\text {rd }}$ ed. Wiley-Liss, New York, NY.

Broch-Due, A., Anderson, R. and Kristoffersen, O. (1994) Pilot plant experience with an aerobic moving bed biofilm reactor for treatment of NSSC wastewater. Water Sci Technol 29, 283-294. 
Bura, R., Cheung, M., Liao, B., Finlayson, J., Lee, B.C., Droppo, I.G., Leppard, G.G. and Liss, S.N. (1998) Composition of extracellular polymeric substances in the activated sludge floc matrix. Water Science and Technology 37, 325-333.

Caldwell, D.E., Korber, D.R. and Lawrence, J.R. (1992) Imaging of bacterial cells by fluorescence exclusion using scanning confocal laser microscopy. J Microbiol Methods $15,249-261$.

Chabaud, S., Andres, Y., Lakel, A. and Le Cloirec, P. (2006) Bacteria removal in septic effluent: Influence of biofilm and protozoa. Water Research 40, 3109-3114.

Chuichulcherm, S. (2004) An Integrated System for the Bioremediation of Wastewater Containing Xenobiotics and Toxcic Metals. Eng Life Sci 4, 354-357.

Del Gallo, M., Negi, M. and Neyra, C.A. (1989) Calcofluor- and lectin-binding exocellular polysaccharides of Azospirillum brasilense and Azospirilum lipoferum. J Bacterio/ 171, 3504-3510. .

Droppo, I.G., Flannigan, D.T., Leppard, G.G. and Liss, S.N. (1996) Microbial floc stabilization and preparation for structural analysis by correlative microscopy. Water Science and Technology 34, 155-162.

Droppo, I.G., Leppard, G.G., Flannigan, D.T. and Liss, S.N. (1997) The Freshwater Floc: A Functional Relationship of Water and Organic and Inorganic Floc Constituents Affecting Suspended Sediment Properties. Water, Air, and Soil Pollution 99, 43-54

Glasgow, L.A. and Hsu, J. (1984) FLOC CHARACTERISTICS IN WATER AND WASTEWATER TREATMENT. Part Sci Techno/ 2, 285-303.

Grau, P. (1991) Criteria for nutrient-balanced operation of activated sludge process. Water Sci Technol 24, 251-258.

Gulyas, H. (1997) Processes for the removal of recalcitrant organics from industrial wastewaters. Water Science and Technology 36, 9-16.

Hamoda, M.F. and Abd-El-Bary, M.F. (1987) Operating characteristics of the aerated submerged fixed-film (ASFF) bioreactor. Water Research 21, 939-947.

Hasar, H., Xia, S., Ahn, C.H. and Rittmann, B.E. (2008) Simultaneous removal of organic matter and nitrogen compounds by an aerobic/anoxic membrane biofilm reactor. Water Research 42, 4109-4116. 
Hem L. J. (1991) Nitrification in moving bed biofilm process. PhD thesis, Department of Hydraulic and Environment Engineering, The Norwegian Institute of Technology, The University of Trondheim.

Hem, L.J., Rusten, B. and $\varnothing$ degaard, H. (1994) Nitrification in a moving bed biofilm reactor. Water Res 28, 1425-1433.

Hems, L.J., Rusten, B., Broch-Due, A., Mattsson, E. and Westrum, T. (1994) Treatment of forest industry wastewaters in moving bed biofilm reactors. Proceedings of 49 th Purdue University Industrial Waste Conference, 509-518.

Jayamohan, S., Ohgaki, S. and Hanaki, K. (1988) Effect of DO on kinetics of nitrification. Water Supply 6, 141-150.

Jin, B., Wilén, B. and Lant, P. (2003) A comprehensive insight into floc characteristics and their impact on compressibility and settleability of activated sludge. Chem Eng J 95 , 221-234.

Jin, B., Wilén, B. and Lant, P. (2003) A comprehensive insight into floc characteristics and their impact on compressibility and settleability of activated sludge. Chemical Engineering Journal 95, 221-234.

Jorand, F., Boué-Bigne, F., Block, J.C. and Urbain, V. (1998) Hydrophobic/hydrophilic properties of activated sludge exopolymeric substances. Water Science and Technology 37, 307-315.

Kumar, P. and Dara, S.S. (1982) Utilisation of agricultural wastes for decontaminating industrial/domestic wastewaters from toxic metals. Agricultural Wastes 4, 213-223.

Lawrence, J.R. and Neu, T.R. (1999) Confocal laser scanning microscopy for analysis of microbial biofilms. Methods Enzymol 310, 131-144.

Lawrence, J.R., Neu, T.R. and Swerhone, G.D.W. (1998) Application of multiple parameter imaging for the quantification of algal, bacterial and exopolymer components of microbial biofilms. J Microbiol Methods 32, 253-261.

Lazarova, V., \& Manem, J. (2000) Innovative biofilm treatment technologies for water and wastewater treatment. In: Bryers JD (Ed) Biofilms II: Process Analysis and Applications (pp 159-206). Wiley-Liss, New York, NY. 
Lee, B. C., (1997) The Influence of nutrients on floc physicochemical properties and structure in activated sludge processes. MASc. Thesis, Graduate Department of Chemical Engineering and Applied Chemistry, University of Toronto.

Lessard, P., Tusseau-Vuillemin, M., Hélène, Héduit, A. and Lagarde, F. (2007) Assessing chemical oxygen demand and nitrogen conversions in a multi\&hyphen;stage activated sludge plant with alternating aeration. J Chem Technol Biotechnol 82, 367375.

$\mathrm{Li}, \mathrm{X}$. and Zhang, R. (2002) Aerobic treatment of dairy wastewater with sequencing batch reactor systems. Bioprocess Biosyst Eng 25, 103-109.

Liao, B.Q. (2000) Physicochemical Studies of Microbial Flocs. Ph.D. Thesis, Department of Chemical Engineering and Applied Chemistry, University of Toronto.

Liao, B.Q., Allen, D.G., Droppo, I.G., Leppard, G.G. and Liss, S.N. (2001) Surface properties of sludge and their role in bioflocculation and settleability. Water Research 35, 339-350.

Liss, S.N., Droppo, I.G., Flannigan, D.T. and Leppard, G.G. (1996) Floc Architecture in Wastewater and Natural Riverine Systems. Environmental Science \& Technology 30 , 680-686.

McLoughlin, A.J. (1994) Controlled release of immobilized cells as a strategy to regulate ecological competence of inocula. Adv. Biochem. Eng. Biotech. 51, 2-45.

Metcalf and Eddy, I. (1991) Wastewater Engineering: Treatment, Disposal, Reuse (Third Edition). Ed.: McGraw Hill, Inc.

Mino, T. (1995) Survey on filamentous micro-organisms in activated sludge processes in Bangkok, Thailand. Water Science and Technology 31, 193-202.

Mobarry, B.K., Wagner, M., Urbain, V., Rittmann, B.E. and Stahl, D.A. (1996) Phylogenetic probes for analyzing abundance and spatial organization of nitrifying bacteria. Appl Environ Microbiol 62, 2156-2162.

Morgan, J.W., Forster, C.F. and Evison, L. (1990) A comparative study of the nature of biopolymers extracted from anaerobic and activated sludges. Water Research 24, 743750 . 
Münch, E.V., Barr, K., Watts, S. and Keller, J. (2000) Suspended carrier technology allows upgrading high-rate activated sludge plants for nitrogen removal via process intensification. Water Sci Technol 41, 5-12.

Neu, T.R. and Lawrence, J.R. (1997) Development and structure of microbial biofilms in river water studied by confocal laser scanning microscopy. FEMS Microbiol Ecol 24, 1125.

Odegaard, H., Paulsrud, B., Bilstad, T. and Pettersen, J.E. (1991) Norwegian strategies in the treatment of municipal wastewater towards the reduction of nutrient discharges to the North Sea. Water Sci Technol 24, 179-186.

Parker, D.S., Jenkins, D., and Kaufman, W.J. (1971) Physical conditioning of activated sludge floc. J. Water Pollut. Control Fed. 43, 1897.

Pehlivanoglu, E. and Sedlak, D.L. (2004) Bioavailability of wastewater-derived organic nitrogen to the alga Selenastrum Capricornutum. Water Res 38, 3189-3196.

Plattes, M., Henry, E., Schosseler, P.M. and Weidenhaupt, A. (2006) Modelling and dynamic simulation of a moving bed bioreactor for the treatment of municipal wastewater. Biochemical Engineering Journal 32, 61-68.

Raszka, A., Chorvatova, M. and Wanner, J. (2006) The role and significance of extracellular polymers in activated sludge. Part I: Literature review. Acta hydrochim hydrobio/ 34, 411-424.

Reinoso, R., Torres, L.A. and Becares, E. (2008) Efficiency of natural systems for removal of bacteria and pathogenic parasites from wastewater. Science of the Total Environment 395, 80-86.

Rittmann, B.E., Jackson, D. and Storck, S.L. (1988) Potential for treatment of hazardous organic chemicals with biological processes. Biotreatment Systems 3, 15-64.

Rodgers, M., Zhan, X.\&. and M. (2003) Moving\&hyphen;Medium Biofilm Reactors. Reviews in Environmental Science and Biotechnology 2, 213-224.

Rodgers, M. and Zhan, X. (2004) Biological nitrogen removal using a vertically moving biofilm system. Bioresource Technology 93, 313-319.

Rosenberg, M., Gutnick, D., and E. Rosenberg. (1980). Adherence of bacteria to hydrocarbons: a simple method for measuring cell-surface hydrophobicity. FEM Microbiology Letters 9, 29-33. 
Rusten, B., Hem, L.J. and Odegaard, H. (1995) Nitrogen removal from dilute wastewater in cold climate using moving-bed biofim reactors. Water Environ Res 67 , 65-74.

Rusten, B., Mattsson, E., Broch-Due, A. and Westrum, T. (1994) Treatment of pulp and paper industry wastewaters in novel moving bed biofilm reactors. Water Sci Technol 30 , $161-171$.

Saunamäki, R. (1997) Activated sludge plants in Finland. Water Science and Technology 35, 235-243.

Saunamäki, R., (1994). Experimental study on the control of nutrient in activated sludge treatment. Water Sci. Technol. 29(56), 329-342.

Scragg, A.H. (2004) Environmental biotechnology. New York: Oxford University Press.

Shin, H.S., Kang, S.T., and Nam, S.Y. (2001). Effect of carbohydrate and protein in the EPS on sludge settling characteristics. Water. Sci. Technol. 43(6), 193-196.

Stewart, P.S., Murga, R., Srinivasan, R. and De Beer, D. (1995) Biofilm structural heterogeneity visualized by three microscopic methods. Water Res 29, 2006-2009.

Strehler, A. and Welander, T. (1994) A novel method for biological treatment of bleached kraft mill wastewaters. Water Sci Technol 29, 295-301.

Urbain, V., Block, J.C. and Manem, J. (1993) Bioflocculation in activated sludge: an analytic approach. Water Research 27, 829-838.

U.S. EPA. 1977. Wastewater Treatment Facilities for Sewered Small Communities. Report No. EPA-625/1-77-009, U.S. Environmental Protection Agency, Cincinnati, OH.

Wagner, M., Amann, R., Lemmer, H., and Schleifer, K.H. (1993). Probing activated sludge with oligonucleotides specific for Proteobacteria: inadequacy of culturedependent methods for describing microbial community structure. Appl. Environ. Microbiol. 59, 1520-1525.

Wanner, J., Kucman, K. and Grau, P. (1988) Activated sludge process combined with biofilm cultivation. Water Research 22, 207-215.

Weddle, C.L. and Jenkins, D. (1971) The viability and activity of activated sludge. Water Research 5, 621-640. 
Wilderer, P.A., Arnz, P. and Arnold, E. (2000) Application of Biofilms and Biofilm Support Materials As A Temporary Sink and Source. Water, Air, and Soll Pollution 123, 147-158.

Wolfaardt, G.M., Lawrence, J.R., Robarts, R.D. and Caldwell, D.E. (1998) In situ characterization of biofilm exopolymers involved in the accumulation of chlorinated organics. Microb Ecol 35, 213-223.

Wuertz, S., Bishop, P., and Wilderer, P., (2003) Biofilms in wastewater treatment: An interdisciplinary approach. TJ International Ltd., Padstow, Cornwall, UK.

Zeng, R.J., Yuan, Z and Keller, J. (2004) Improved understanding of the interactions and complexities of biological nitrogen and phosphorus removal processes. Rev Environ Sci Biotechnol 3, 265-272.

Ziglio, G., Andreottola, G., Barbesti, S., Boschetti, G., Bruni, L., Foladori, P. and Villa, R. (2002) Assessment of activated sludge viability with flow cytometry. Water Research 36 , $460-468$.

Zita, A. and Hermansson, M. (1994) Effects of lonic Strength on Bacterial Adhesion and Stability of Flocs in a Wastewater Activated Sludge System. App/ Environ Microbio/ 60, 3041-3048. 